\title{
IX Die Christianisierung und die ,Aristokratisierung des Christentums
}

Die Christianisierung der römischen Welt und insbesondere der gesellschaftlichen und politischen Elite ist bereits in unzähligen Forschungsbeiträgen behandelt worden. ${ }^{1}$ Untrennbar damit verbunden ist das Schicksal des Heidentums, welches von nicht wenigen Forschern ${ }^{2}$ schon zu Beginn des 5. Jhs. für tot erklärt wurde, um dann doch noch bis zur Mitte des Jahrhunderts ein beachtliches Nachleben zu entfalten, welches sich vor allem in der senatorischen Bildungs- und Kulturpflege ${ }^{3}$ manifestierte. Hier tat sich der sog. Symmachus-Kreis hervor, der im Folgenden genauer untersucht werden soll. Durch die bisherige Betrachtung wurde deutlich, dass die senatorische Repräsentation, sei es im Konsulat, in der Spielgebung oder in der domus, nicht vom paganen Kulturerbe $\mathrm{zu}$ trennen ist. ${ }^{4}$ Allerdings wurde hier offensichtlich ein Weg eingeschlagen, der die religiösen Elemente, vor allem den cultus, eliminierte. Dies war eine Konsenslösung vor allem für moderate Kreise, die sich an der Religionsfrage nicht radikalisierten. Wie sich hier die Korrespondenzpartner des Symmachus und christliche Häuser wie die gens Anicia einordnen lassen, wird eine wichtige Frage darstellen. Im Fokus steht hierbei aber nicht nur die Christianisierung der Senatsaristokratie, sondern auch die ,Aristokratisierung“ des Christentums. Die Genese einer christlichen Repräsentationskunst, die geeignet war, den gesellschaftlichen und politischen Führungsanspruch der Senatsaristokratie zu fundamentieren, stand noch aus und war, wie dies bereits Salzman ${ }^{5}$ feststellte, die wichtigste Grundbedingung, die das Christentum für die Aristokratie erfüllen musste. Hier wird vor allem auf die christliche Kunst und die Kirchenstiftungen zu blicken sein. ${ }^{6}$

1 In Auswahl: BROWN (2017) [2012]; ders. (2002); ders. (1992); ders. (1989) und ders (1991) [1981]. CAMERON (2011). Hier vgl. auch die Kritik und Gegenpositionen in RATTI (2012) 179-187, die jedoch größtenteils durch BRENDEL, Rez. Cameron. In: H-Soz-Kult, 14.01.2013 zurückgewiesen werden. Av. CAMERON (1993); dies. (1993) und dies. (1991) mit zahlreichen weiteren Spezialstudien. SALZMAN 2(2004).

2 So z. B. WYTZES (1977); nachfolgend KLEIN 2(1986) 12f.; zuvor bereits VON CAMPENHAUSEN (1929) 166: „Schwanengesang der stolzen römischen Religion“; SEECK (1913) 196: „Schwanengesang einer sterbenden Religion“. CAMERON (2011) behandelt zwar auch das 5. Jh. mit Rutilius Namatianus und Macrobius, legt aber seinen Schwerpunkt stärker auf Symmachus, den Streit um den Victoria-Altar und die Usurpation des Eugenius.

3 Vgl. STENGER (2009) für das 4. Jh. und GERTH (2013) 8-113 für das 5. Jh., i. B. zu Macrobius. Einen guten Überblick bietet FUHRMANN 2(1996) bes. 51-58, 142-149 u. 282-290.

4 Für das 4. Jh. vgl. CURRAN (2000) 116-259.

5 Vgl. SALZMAN 2(2004) 13-20.

6 Einen ähnlichen Zugang wählte bereits BRENK (2003) und ders. (1977).

○ OpenAccess. () 2021 Hendrik A. Wagner, publiziert von De Gruyter. (c) BY-NC-ND Dieses Werk ist lizenziert unter der Creative Commons Attribution-NonCommercial-NoDerivatives 4.0 International Lizenz. https://doi.org/10.1515/9783110727630-009 


\subsection{Das Erbe des ,Symmachus-Kreises‘ und die Bildwelt der

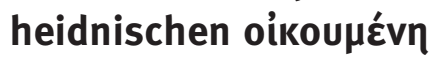

Die Bezeichnung ,Symmachus-Kreis ${ }^{67}$ ist etwas irreführend, suggeriert sie doch, dass Quintus Aurelius Symmachus signo Eusebius der Mittelpunkt dieses Kreises gewesen war. Tatsächlich dürften aber Vettius Agorius Praetextatus und Virius Nicomachus Flavianus einen noch deutlich aktiveren Beitrag zum heidnischen Kulturleben und Kult des ausgehenden 4. Jhs. geleistet haben. So engagierten sich beide in zahlreichen Priesterkollegien und waren in verschiedene Mysterienkulte eingeweiht. ${ }^{8}$ Symmachus stand diesen hierin sicherlich nicht nach, doch fehlen uns hierfür die entsprechenden Belege. ${ }^{9}$ Im persönlichen Engagement für die paganen Kulte, eben auch im politischen Auftreten, opferte Flavianus, der am Ende für seine Überzeugung sogar in den Tod ging, ${ }^{10}$ weit mehr. Symmachus vertrat dagegen wohl eher einen moderaten Kurs, ${ }^{11}$ womit er sich im Besonderen auch für die Senatsgesandtschaften am christlichen Kaiserhof empfahl.

Es sind vor allem aber die 902 Briefe des Symmachus, ${ }^{12}$ mit denen sich der Personenkreis der Gleichgesinnten und Weggefährten des sog. Symmachus-Kreises prosopographisch fassen lässt. Jüngst hat sich Siedow ${ }^{13}$ mit der minutiösen Erschließung

7 So benutzt u. a. bei CAMERON (2011) 353-398; DEMANDT (2008) 264; GEMEINHARDT (2007) 159 und MARKSCHIES (1994) 325 - 377, hier 357. Grundlegend ist hierfür der Beitrag CAMERON (1977) 1-30; ferner KLEIN 2(1986) und TÜRK (1961). Hier hat vor allem CAMERON nachweisen können, dass dieser Zirkel keineswegs so homogen war, wie es die ältere Forschung noch annahm; auch die Rolle des Symmachus wird von CAMERON eher relativiert.

8 Entsprechend CIL 6, 1777 (Praetextatus) und Ruf. hist. eccl. 11,33 und Macr. Sat. 1,24,17 (Flavianus augur); Symm. ep. 2,34 (Magna Mater), vgl. IAARA (2015) 172-174.

9 Eben dies stellte bereits CAMERON (2011) 154 fest: „Symmachus may not have shared Praetextatus's enthusiasm for mysteries"; für Symmachus ist lediglich ein Priesteramt belegt, das des pontifex maior (u. a. Symm. ep. 1,47; 1,49 u. 1,51; ferner vgl. CIL 6, 1699); hierzu vgl. auch IAARA (2015) 174f.; CAMERON (2011) 155f. und ausführlich MATTHEWS (1973) 175-195; vgl. auch die Stellungnahme WYTZES (1977) 120 - 124 in Erwiderung auf PASCHOUD (1967) 109f. und KLEIN ${ }^{2}(1986) 163 \mathrm{f}$.

10 Vgl. Symm. ep. 7,116 und CIL 6, 1783 (Kap. 8.1).

11 Zur Wertschätzung als Redner vgl. CIL 6, 1699: ORATORI DISERTISSIMO; ferner Socr. 5,14 und Prud. C. Symm. 2, praef. 56. Hierzu auch CAMERON (1999a) 109-121, hier 111f.; ihm folgt hierin GEMEINHARDT (2007) 159: „Er war nicht deshalb Wortführer der Delegation, weil er eine religiöse Autorität war, sondern weil er als moderat galt und zu Heiden und Christen gute Beziehungen pflegte." Von einer Zäsur in theodosianischer Zeit, die auch die Briefe des Symmachus betraf, geht RATTI (2012) 33-49 aus.

12 Die Briefsammlung und seine Reden werden erst von seinem Sohn veröffentlicht. Ein knapper Überblick findet sich bei MEURER (2019) 128-143 und jetzt auch dies. (2020) 429-450; CAMERON (2016b) 64-111 und SOGNO (2006) 59-63. Vgl. auch die Übersicht in SCHANZ (ND 1971) Bd. 4,1, 122129.

13 Hier SIEDOW (2014) 13-43; die Arbeit mit der Sozialen Netzwerkanalyse (SNA) ist überaus vielversprechend, jedoch handelt es sich hierbei nach Aussage des Autors um einen Werkstattbericht; die verwertbaren Ergebnisse sind daher begrenzt. Der Aufsatz entstand im Rahmen des Forschungsclusters der Universitäten Trier und Mainz „Gesellschaftliche Abhängigkeit und soziale Netzwerke“ (Teil- 
der spätantiken Beziehungsnetzwerke befasst. Auf die Ergebnisse dieser Arbeit, zu denen auch eine umfangreiche prosopographische Datenbank angelegt werden soll, ist noch zu warten. So wird auf eine Darstellungsweise zurückgegriffen werden müssen, die weder die Komplexität der sozialen Verbindungen komplett erfassen kann noch den Anspruch auf Vollständigkeit erheben darf. Im Unterschied zur Darstellung Whites handelt es sich bei der hier erstellten Übersicht (Grafik 4) nicht um ein erweitertes stemma. ${ }^{14}$ Verwandtschaftliche Beziehungen werden zwar zum Teil auch berücksichtigt, stellen aber nicht die Grundlage der Vernetzung dar. Diese wird in erster Linie von der Korrespondenz abgebildet und von verbindenden Handlungen. Der genaue Inhalt der herangezogenen Briefe ist hierbei erst einmal unerheblich. Ohnehin sind in den wenigsten Fällen, was zumindest die Briefe des Symmachus betrifft, religiöse Themen Gegenstand der Korrespondenz. Dabei fällt auf, dass es mindestens zwei regional getrennte Gravitationszentren gab, die zum einen in Rom selbst und zum anderen in der gallischen Provinz, insbesondere in der Region Bordeaux und Südgallien, lagen. Bis 394 wurde diese Verbindung maßgeblich durch die kontinuierliche und sehr umfangreiche Korrespondenz zwischen Symmachus und Ausonius ${ }^{15}$ aufrechterhalten. Der Tod des Ausonius und die Usurpationen der Folgejahre sowie der Einfall der ,Barbaren“ in Gallien störte diese Verbindung erheblich, zerstörte sie aber nicht, wie dies an dem freundschaftlich-vertrauten Umgang des Rutilius Namatianus mit Volusianus und Fl. Albinus ${ }^{16} \mathrm{zu}$ erkennen ist.

Die Briefe des Symmachus trugen außerdem dazu bei, die provinzialen und die hohen Amtsträger des Kaiserhofs mit Rom verbunden zu halten. So richten sich zahlreiche Briefe nicht nur an gallische Aristokraten, ${ }^{17}$ auch wandte sich Symmachus an die Spitzen des Hofes und der Reichsverwaltung. ${ }^{18}$ Von der Pflege politisch nützlicher Beziehungen und der informellen Einflussnahme waren diese Kontakte sicherlich stark motiviert. Die religiöse Haltung der Adressaten spielte hier jedenfalls keine Rolle. So gingen auch zahlreiche Briefe an die christliche gens Anicia. ${ }^{19}$ Eben diese Feststellung

projekt II.01). Der Aufsatz entstand im Rahmen des Forschungsclusters der Universitäten Trier und Mainz „Gesellschaftliche Abhängigkeiten und soziale Netzwerke“ (Teilprojekt II.01). Hier wurde vor allem die Zeit von 369 bis 373 berücksichtigt. Auch zum jetzigen Zeitpunkt (April 2020) ist noch keine Abschlusspublikation erfolgt.

14 WHITE (1992) 3-36, hier 11, Fig. 1; hierzu vgl. auch die Kritik SIEDOW (2014) 22 f.

15 Symm. ep. 1,13-43; zum Verhältnis vgl. jetzt auch MEURER (2019) 121-123.

16 Rut. Nam. 1,495ff.

17 Symm. ep. 4,17-34 (Protadius); 4,35-49 (Minervius) und 4,50-55 (Florentinus).

18 z. B. Fl. Eupraxius (Symm. ep. 4,64f.; PLRE 1, $299 \mathrm{f} .:$ QSP 367-371) und Fl. Claudius Antonius (Symm. ep. 1,89-94; PLRE 1, 77: QSP 371/373; PPO It, 377/8 und Cos. 382); hierzu vgl. auch SIEDOW (2014) 37-41 mit Abb. 2. Ferner auch Stilicho (Symm. ep.4,1-14); Mallius Theodorus (Symm. ep. 5,4-16); Marinianus (Symm. ep. 3,23-29) und Patroinus/Petronius (Symm. ep. 7,102-128 u. 8,18f.; PLRE 2, 843 f. u. 862: PPO Gall. 402/408). Zur Kommunikation mit den magistri militum vgl. jetzt auch MEURER (2020) 441-445 und dies. (2019) 140-143.

19 Symm. ep. 1,56-61: an Sextus Claudius Petronius Probus; Symm. ep. 5,67-71: an Olybrius und Probinus; Symm. ep. 9,20 u. 9,24: an Bassus (vermutlich Anicius Auchenius Bassus). 
hob so bereits auch Matthews hervor. ${ }^{20}$ Mehr als die Religion verband die Teilnehmer des brieflichen Austausches die Affinität zur klassischen Bildung und sprachlichen Eloquenz, die aristokratische Kultiviertheit sowie die Bereitschaft, politische Verantwortung $\mathrm{zu}$ übernehmen. Dementsprechend findet sich unter den Adressaten des Symmachus niemand, der diese Grundwerte ablehnte. An keinen Vertreter des christlich-asketischen Lebensideals erging ein Brief. Hier dominieren vor allem Hieronymus und Augustinus die Korrespondenz. ${ }^{21}$ In diesen Kreisen nahm des Weiteren Paulinus von $\mathrm{Nola}^{22}$ als aristokratischer ,Aussteiger ${ }^{6}$ und einstiger Schüler des Ausonius, selbst eine zentrale Position ein. ${ }^{23}$ Die Einflusssphären überschnitten sich hier offenbar nur sehr selten. Dies liegt zum einen daran, dass sich Hieronymus, Augustinus und Paulinus bevorzugt an die Damen der Aristokratie wandten, während Symmachus sich ausschließlich auf die männlichen Vertreter der senatorischen Häuser konzentrierte. Zum anderen standen sich hier zwei so konträr zueinander verlaufende Lebenskonzepte gegenüber, dass der kommunikative Austausch keine gemeinsame Basis finden konnte. ${ }^{24}$

Besonders interessant sind daher die wenigen Fälle, in denen die Einflusssphären sich überschneiden. Mallius Theodorus, der ausgiebig in Kontakt mit Symmachus stand $^{25}$ und zugleich von Augustinus das Werk De beata vita ${ }^{26}$ gewidmet bekam, ist hierfür ein besonders eindrucksvolles Beispiel. Hier trafen christliche Einflüsse auf eine Person, die im Grunde sehr stark durch die pagane (Bildungs-)Kultur sozialisiert war und dennoch wohl als Christ gelten muss. Theodorus war nicht nur aktiv in den höchsten Staatsämtern ${ }^{27}$ und kam damit dem alten Ideal der res publica nach, er ist darüber auch ein Musterbeispiel eines hochgebildeten Aristokraten, der auf dem Gebiet

20 Vgl. MATTHEWS (1974) 59-99, bes. 88-91.

21 Zum gesamten Briefkorpus des Augustinus vgl. knapp LÖHR (2007) 416-427; DIVJAK (2001) 8931057 und ausführlich MORGENSTERN (1993); zu Hieronymus vgl. CONRING (2001); FÜRST (1999) bes. 150 - 220 und REBENICH (1992); vgl. jetzt auch GHETTA (2014) 45-64, bes. 52-55, 60f. u. 63 f. Abb. 1 u. 2.

22 Zur Korrespondenz (insgesamt 50 Briefe) vgl. MRATSCHEK-HALFMANN (2002) 625-337 und in der Ausgabe SKEB (1998) 73-99; zum Personenkreis vgl. jetzt auch GHETTA (2014) 55-59 u. 63f. Abb. 1 u. 2.

23 Vgl. Paul. Nol. ep. 28f. u. 31f. sowie Paul. Nol. carm. 21.

24 Vgl. hierzu auch Rut. Nam. 1,440: lucifugi viri; hierzu Kap. 6.1.

25 Symm. ep. 5,4-16.

26 Aug. beat. vit. 1 vir humanissime atque magne Theodore; auch in De ordine wird Theodorus als Verfasser philosophischer Schriften gepriesen; in Aug. beat. vit. 1,5 bittet Augustinus sogar um (philosophische) Führung; Aug. ord. 1,11,31: vir et ingenio et eloquentia et ipsis insignibus muneribusque fortunae et [...] mente praestantissimus. Die persönliche Bekanntschaft rührt wohl aus der Zeit des Augustinus in Mailand (384-386); hierzu vgl. u. a. DOBELL (2009) 11f., 54 u. 143; LANCEL (2002) 65, 71, 83 f., 115 u. 221 und MORGENSTERN (1993) 8-12.

27 PLRE 2, 900 - 902: Cos. 399, PPO Gall. 382/383, PPO It. 397/399 und 408/409?; für die Ämterlaufbahn ist neben den entsprechenden Gesetzen, die an Theodorus adressiert waren, vor allem Claudians panegyricus heranzuziehen; i. B. Claud. Cos. Mall. 16-112 u. 161-162; zu seiner politischen Bedeutung vgl. auch Kap. 5.1. 
der Metrik ${ }^{28}$, Rhetorik, neo-platonischen Philosophie, Astronomie und Naturwissenschaft als versierte Kenner auftrat. ${ }^{29}$ Diesbezüglich war Mallius Theodorus von Männern wie Servius, dem Vergil-Exegeten, und Macrobius, der die Saturnalien für seinen Sohn als Lehrwerk verfasst hatte, ${ }^{30}$ nicht zu unterscheiden. Zugleich war Theodorus aber auch offen für den theologisch-christologischen Diskurs. Auch Rufius Antonius Agrypnius Volusianus, der ebenso hochgebildet war und als ,Heide“ im geistreichen Austausch mit Augustinus ${ }^{31}$ stand, beschritt diesen gesprächsoffenen Weg. An der Korrespondenz lässt sich allerdings auch erkennen, dass Augustinus, der Volusianus anhält, die biblischen Schriften zu studieren, ${ }^{32}$ durchaus versuchte, missionarisch $\mathrm{zu}$ wirken. Hierbei findet der Bischof von Hippo selbst zu einem sprachlichen Stil, der seinem gebildeten Gegenüber angemessen war. ${ }^{33}$ Augustinus ist sich dabei sogar völlig im Klaren, dass die Bibel diesem vornehmen Stil nicht gerecht werden kann und warnt daher Volusianus, nicht den sprachlichen Wohlklang einzufordern, sondern auf die Sache zu achten. ${ }^{34}$ Der intellektuelle Austausch war damit zwischen ,Heiden' und Christen sehr wohl möglich, sofern sich die Diskussionsteilnehmer noch auf eine gemeinsame Sprache einigen konnten und die Lebenswirklichkeit ihres Gegenübers respektierten.

Prinzipiell erwies sich auf dieser Basis selbst Symmachus als offen für den intellektuellen Disput mit den führenden Köpfen der Kirche, nur geschieht dies, wie in der Auseinandersetzung mit Ambrosius von Mailand, weit weniger freundschaftlich. ${ }^{35}$ Dennoch bleibt die Auseinandersetzung auf einem hohen rhetorischen und geistigen

28 Ein kleines Handbüchlein über Metrik, De metris, widmete er seinem Sohn; überliefert im Codex Parisinus lat. 7530; rezipiert von Beda Venerabilis in De arte metriea bzw. De re metrica und Julian von Toledo in Ars grammatica (Gramm. Lat. 6,593,6 und Gramm. Lat. 7,257,13); hierzu vgl. u. a. BISCHOFF (2007) 101f.; ferner MANITIUS (ND 2005) 74 und SCHANZ (ND 1971) Bd.4,1, 171. Ein weiterer Titel ist mit De natura rerum überliefert; vgl. Claud. Cos. Mall. $100 \mathrm{f}$.

29 Zum Bildungslob vgl. Claud. Cos. Mall. 80 - 115; hierzu auch HARICH-SCHWARZBAUER (2008) 347361, hier 351- 356 und GEMEINHARDT (2007) 139; speziell zum panegyricus vgl. DÖPP (1980) 150 - 157. 30 Vgl. hierzu die praeferatio des Werks, die den Zweck der Schrift als Lehrwerk für die Erziehung des Sohns formuliert; bes. Macr. Sat. praef. $1 \mathrm{f}$.

31 Vgl. Aug. ep. 132; 135; 136 (Antwort) und Aug. ep. 137; hierzu vgl. TOCZKO (2013) 449-459 und TORNAU (2006) 58-73 MORGENSTERN (1993) 124f. und BROWN (1982) 261-264 aus dem englischen ders. ${ }^{2}(2000)$; ferner MARROU (1995) 78-80 [1938].

32 In Aug. ep. 132.

33 In Aug. ep. 137,12 u. 14 werden Sallust und Vergil zitiert; hiervon löst sich Augustinus im Schluss seines Briefes, in dem er sich nicht auf die klassischen Vorbilder, sondern die der Bibel und patristischen Literatur beruft (ep. 137,18-20); vgl. hierzu TORNAU (2006) 65f. u.70 f. und RATTI (2012) 51-56, der aber hier einen latenten Konflikt bzw. Konkurrenzkampf mit den paganen Intellektuellen unterstellt.

34 Aug. ep. 132: verum etiam propter eorum inruentem praesentiam, qui plerumque non sunt apti tali negotio magisque linguae certaminibus quam scientiae luminibus delectantur. Hierzu TORNAU (2006) $59 \mathrm{f}$.

35 Ambr. ep. 17; 18 und 57 mit Symm. rel. 3; zum Streit um den Victoria-Altar, auf den hier nicht eingegangen werden soll, vgl. KLEIN (1972) mit Übersetzung; aktuell u. a. ROLLÉ DITZLER (2020) 308339 und CHENAULT (2008) 227-265; ferner zusammenfassend FUHRMANN ${ }^{2}(1996) 70$ - 80 und ausführlich WYTZES (1977) 200 - 320. 
Niveau und noch der Biograph des Mailänder Bischofs, Paulinus, behielt den Kontrahenten hochachtungsvoll als Symmachus vir eloquentissimus ${ }^{36}$ in Erinnerung. Mit radikalen Vertretern der christlich-asketischen Lebensideale ließ sich allerdings keine gemeinsame Kommunikationsbasis mehr finden. Bereits für die moderaten christlichen Kreise und die kirchlichen Amtsträger erwies sich der Umgang mit den Asketen als schwierig. Genau hier tun sich im 5. Jh. Spannungsfelder auf, die in der Tat den Charakter eines religiösen und kulturell motivierten Konflikts tragen. Hierbei verläuft die Trennlinie aber nicht zwischen ,Heiden' und Christen, sondern zwischen moderaten und extremen Positionen, die vor allem im senatorischen Familienverband unter den einzelnen Angehörigen ausverhandelt wurden. ${ }^{37}$

Symmachus scheint seinerseits auf diese Entwicklung noch in seiner letzten Lebensphase reagiert zu haben. Dies fällt besonders bei seinem Bemühen um den senatorischen Nachwuchs auf. An den noch jungen Fl. Pisidius Romulus richtete Symmachus mit der Anrede filius meus drei Briefe. ${ }^{38}$ Zum einen fordert Symmachus sein Gegenüber zur Aufrechterhaltung der Korrespondenz auf, die er mit schmeichlerischen Worten der Wertschätzung bedachte, zum anderen geht es um das persönliche Wohlbefinden und die Beteuerung der Zuneigung. Die Brisanz liegt demnach nicht im Inhalt der Briefe selbst, wobei im letzten gesammelten Brief Symmachus etwas konkreter wird, worauf diese Zuneigung beruht. Die Studien und die Liebe zum Guten, ${ }^{39}$ womit vor allem das pagane Bildungsgut und der mos maiorum angesprochen waren, sind hier essenziell. Zum wichtigen Appell wird dies, wenn Berücksichtigung findet, dass Romulus auch in Kontakt mit Ambrosius und Augustinus ${ }^{40}$ stand und somit christlichen Einflüssen ausgesetzt war. Letzterer dürfte maßgeblich an der Bekehrung des Romulus zum Christentum mitgewirkt haben. Jedenfalls schlägt Augustinus gegenüber diesem einen stark pastoral-mahnenden Ton $\mathrm{an}^{41}$ und erinnert an die Taufe, die er an ihm vollzogen habe. Wenngleich der Inhalt der Korrespondenz recht banal wirken mag, wird das Bemühen des Symmachus um Romulus damit noch einmal in ein anderes Licht gerückt. Es verankerte den jungen Mann fest im Kreis der stadtrömischen Aristokratie und verhinderte, dass aus dem christlichen Bekenntnis radikalere Lebensentscheidungen erwachsen konnten.

36 Paul. Vit. Abr. 26,2 (vgl. auch Prud. C. Symm. 1,648f.); zur Wertschätzung des Ambrosius gegenüber seinem Kontrahenten vgl. Ambr. obit. Val. 19; hierzu GNILKA (2001) 264f.; BRANDT (1999a) 131f. und REBENICH (1991) 53-75, hier 54.

37 So die „Melania-Affäre“; vgl. Kap. 3.2.

38 Symm. ep. 8,38; 8,62 u. 9,62 (vor 402); aus Symm. ep. 8,57 geht hervor, dass Romulus bedeutend jünger war als Symmachus; zur Identifizierung der Person mit Fl. Pisidius Romulus 6 (PLRE 1, 771f.; PVR 405/406?); vgl. VON HAEHLING (1978) 401 und HEINZBERGER (1976) 255.

39 Symm. ep. 9,62: efficacius studia et amorem bonorum probabilis vita conciliat. Habes iuvenam [...]. 40 Ambr. ep. 44 u. 48 und Aug. ep. 247; hierzu vgl. GEMEINHARDT (2007) 148, 196 u. 231 f.

41 Vgl. Aug. ep. 247,2; Augustinus tritt hier als Fürsprecher der Kolonen auf, die sich durch Romulus ausgebeutet fühlen; dementsprechend ermahnend sind die Worte des Bischofs. Zu den wirtschaftlichen Missständen vgl. z. B. DEMANDT (2013b) 199-202 [1993]. 
Noch deutlichere Konturen erhält dieses Bestreben des Symmachus hinsichtlich seiner Einflussnahme auf die Söhne des um 390 verstorbenen Sextus Claudius Petronius Probus. In dessen Haus war die Gefahr, sich von christlich-asketischen Idealen leiten zu lassen, noch weitaus virulenter. Wenngleich Anicia Faltonia Proba, ihre Tochter und ihre Enkelin ihre conversio zum asketischen Leben erst um 410 abschlossen, dürften die entsprechenden Impulse sicher schon wesentlich früher Eingang in das Haus des Probus gefunden haben. Insofern dürfen die Briefe des Symmachus an Olybrius und Probinus $^{42}$ vom Entscheidungskonflikt zwischen asketischen und senatorischen Lebensidealen, in welchem sich das Haus des Probus befand, her zu verstehen sein. So liegt das Hauptaugenmerk des Symmachus neben der Pflege der freundschaftlichen Beziehung insbesondere auf den förderlichen Aktivitäten der iuvenes. Die Jagd und das Studium der freien Künste (studia liberalia) werden hochschätzend erwähnt. Die jungen Männer sollen hier nur keine falsche Zurückhaltung üben. ${ }^{43}$ Überdies bleibt festzustellen, dass das Lob ihrer Leistungen immer auch ein Aufruf war, weiter daran festzuhalten. Auch präsentiert sich Symmachus in seinen Schreiben selbst als Vorbild für die jungen Männer. Hierbei verschweigt er nicht seine religiöse Pflichterfüllung ( $o b$ servantia in religionem). ${ }^{44}$ Damit werden von Symmachus beinahe beiläufig Prioritäten für das Leben aufgezeigt. ${ }^{45}$

Mit dieser Pflicht sind aber nicht nur religiös-kultische Leistungen angesprochen, auch die Verpflichtung gegenüber dem Gemeinwesen, sich aktiv in Dienste des römischen Staates und der Stadt Rom zu stellen und den politischen und sozialen Pflichten gegenüber den Klienten nachzukommen, sind damit gemeint. ${ }^{46}$ Dies ist letztlich nur konsequent, denn die geistige und körperliche Ertüchtigung sollte nicht primär zum eigenen Amüsement erfolgen, sondern zur Vervollkommnung der eigenen Person, die dann ihr Wissen und Können in den Dienst des Gemeinwesens zu stellen hatte. Obwohl die besprochenen Beispiele sehr selektiv wirken und es hier nicht möglich ist, sich tiefgreifender mit dem Gesamtkorpus der symmacheischen Briefe zu befassen, wird an den angeführten Beispielen bereits deutlich, dass es hier nicht um die Formierung einer

42 Symm. ep. 5,67-71 u. 9,60; hierzu knapp TAEGERT (1988) 28; GNILKA (1975) 45-90, hier 78; MACGEACHY (1942) 158 und ZARNCKE (1889) 19-22 u. 208f.; mit den beiden Briefen des Claud. carm. 40 u. 41.

43 Symm. ep. 5,70; zum Ärger des Symmachus über das Ausbleiben von Briefen vgl. auch SCHRÖDER (2007) 214f. u. 222f. Vgl. auch Claud. carm. 40 u. 41; hierzu ZARNCKE (1889) 208f.

44 Symm. ep. 5,70; observantia wird bei Cic. De inv. 2,22,65 u. 2,53,161 als eigenständiges Ideal genannt, welches zusammen mit vindicta, veritas, gratia, pietas und religio aufgeführt wird; das Wort meint „Ehrfurcht“ als Handlungsmotiv, welches die Rechtmäßigkeit bzw. Notwendigkeit einer Tat stützt; in diesem Fall der paganen Religionspraxis. Zur Vernachlässigung der Pflicht des Priesteramts (genus ambiendi) vgl. auch Symm. ep. 1,51 und zur Erfüllung Symm. ep. 1,47.

45 Zur Bewertung bei Symmachus vgl. RODA (1985) 95-108.

46 Ähnlich auch Symmachus, der gegenüber Ausonius die Pflichterfüllung (negotium laboris/officium) dem Schreiben von Briefen voranstellt; vgl. Symm. ep. 1,33,1. Hierzu vgl. RÜCKER (2012) 123f. und SCHRÖDER (2007) $222 \mathrm{f}$. 
„heidnischen Gegenreaktion“ oder gar des „heidnischen Widerstandes“47 ging, wie dies so oft für den ,Symmachus-Kreis“ postuliert wurde. Ebenso wenig ist zu erkennen, dass Symmachus hier als „Leiter der heidnischen Partei“48 fungierte.

Um sich zu vergegenwärtigen, wie stark sich der ,Symmachus-Kreis“ nach 394 verändert hatte, empfiehlt sich ein Blick auf das Bild, welches Macrobius von diesem zeichnete. Während Symmachus vor allem als Freund der Philosophie, Rhetor und Vergil-Kenner vorgestellt wird, ${ }^{49}$ bereichert Flavianus die Runde mit seinem auguralen Wissen, ${ }^{50}$ wie dies auch Praetextatus auf dem Gebiet des Pontifikalrechts ${ }^{51}$ vermochte. Als Priester wurden Flavianus und Praetextatus in Erinnerung gehalten, nicht aber Symmachus. Diese Unterscheidung lässt sich im Werk des Macrobius auch daran festmachen, welche Dinge an den drei Tagen zum Gegenstand der Erörterung gemacht wurden. So werden im Haus des Symmachus ${ }^{52}$ vor allem die Vergil-Exegese ${ }^{53}$ und naturwissenschaftliche Erörterungen ${ }^{54}$ gepflegt. Dagegen finden die umfangreichen Darlegungen zum paganen cultus und dem Wesen der Götter schon an den zwei Tagen davor statt, die im Haus des Praetextatus und Flavianus ausgerichtet wurden. Das Herzstück der theologischen Erörterung, die sog. Sonnentheologie ${ }^{55}$ im ersten Buch, wird von Praetextatus dargelegt. Die Kultpraxis, wie sie von Vergil dargestellt wurde, wird dann im Haus des Flavianus besprochen. ${ }^{56}$ Hierdurch wird der Gedanke nahegelegt, dass in erster Linie Praetextatus und Flavianus die großen Vorkämpfer und Verteidiger der paganen Kulte waren, während Symmachus sein Augenmerk doch eher auf die literarische Bildung und die Wissenschaften legte.

Dieser doch entscheidende Unterschied zwischen Symmachus und Flavianus, der ihr politisches und gesellschaftliches Auftreten stark beeinflusste, soll im Folgenden

47 Vgl. SEHLMEYER (2009) 250f.; MARKSCHIES (1997) 65f.; ders. (1994) 334f.; LATTE (ND 1992) Bd. 5,4, 368f. [1967] und HEINZBERGER (1976) 73; i. B. THRAMS (1992); WYTZES (1977) $98 \mathrm{ff.} \mathrm{und} \mathrm{BLOCH}$ (1963) 193-218; ferner schon SEECK (1913) 217-259: „Die letzte Erhebung des Heidentums“ und ROBINSON (1915) 87-101. Bezüglich des von Macrobius vermittelten Bilds vgl. TÜRK (1961).

48 So z. B. WYTZES (1977) 98.

49 Vgl. Macr. Sat. 1,24,10-13.

50 Vgl. Macr. Sat. 1,24,17.

51 Vgl. Macr. Sat. 1,24,16. Hierzu auch KAHLOS (1998) 231-235, i. B. 234: „symbolic pontifex maximus".

52 Dritter Tag ab Macr. Sat. 4,1-7,17.

53 Vgl. Macr. Sat. 5,1-6,9.

54 Vgl. Macr. Sat. 7,1-15; hier mit Fachbeiträgen des Arztes Disarius, zu welchem Symmachus selbst einige fachliche Ergänzungen beiträgt; in Macr. Sat. 7,5 (zur Ernährung) und Macr. Sat. 7,7 (zur Körperwärme); die Hauptredepassagen sind vermutlich verloren, so fehlt der Anfang des vierten Buches (Beginn im Haus des Symmachus); in Macr. Sat. 2,3,14f. trägt Symmachus auch einen Wortwitz des Cicero bei. Zur Rolle des Symmachus in den Saturnalien vgl. GERTH (2013) $70 \mathrm{f}$.

55 Vgl. Macr. Sat. 1,17-23; hierzu vgl. aktuell GERTH (2013) 18-38; grundlegend SYSKA (1993).

56 Vgl. Macr. Sat. 3,1-11 (Praetextatus, ab Macr. Sat. 3,10 die Kritik des Euangelus); die Einteilung ergibt sich aus Macr. Sat. 1,24,16f., jedoch bricht die Überlieferung nach Macr. Sat. 3,11 ab. 

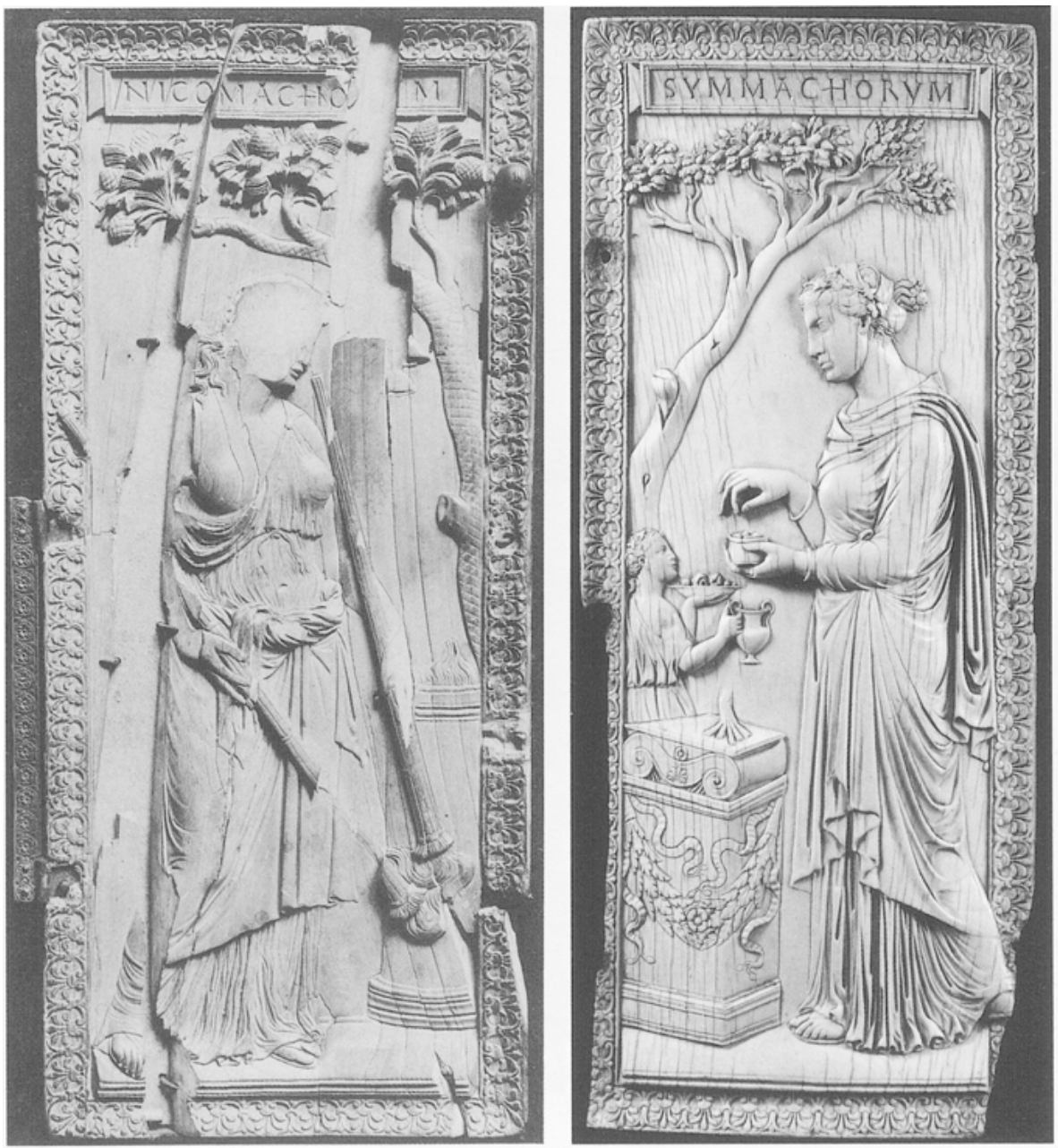

Abb. 25: Diptychon der Nicomachi und Symmachi.

anhand des berühmten „Symmachi-Nicomachi-Diptychons“ (Abb. 25) ${ }^{57}$ verdeutlicht werden. Zunächst muss hierbei auf den Irrtum in der Namensgebung hingewiesen werden, denn schon allein im Hinblick auf die ursprüngliche Anordnung und die Frage, welche der beiden Tafeln die Hauptseite darstellt, muss die korrekte Bezeichnung Ni-

57 Abbildung nach KINNEY (2008) Fig. 4a u. 4b. Vgl. auch VOLBACH ${ }^{2}(1952)$ Nr. 55, Taf. 14; Taf. A: NICOMACHORVM in Paris, Musée de Cluny, Inv.-Nr. 1036; die deutlich schlechter erhaltene Taf. A ist in einer Zeichnung DURANDs wiedergegeben; MARTÈNE/DURAND (1717) 98; vgl. DELBRUECK (1929) 211, Abb. 2; Taf. B: SYMMACHORVM in London, Victoria and Albert Museum. 


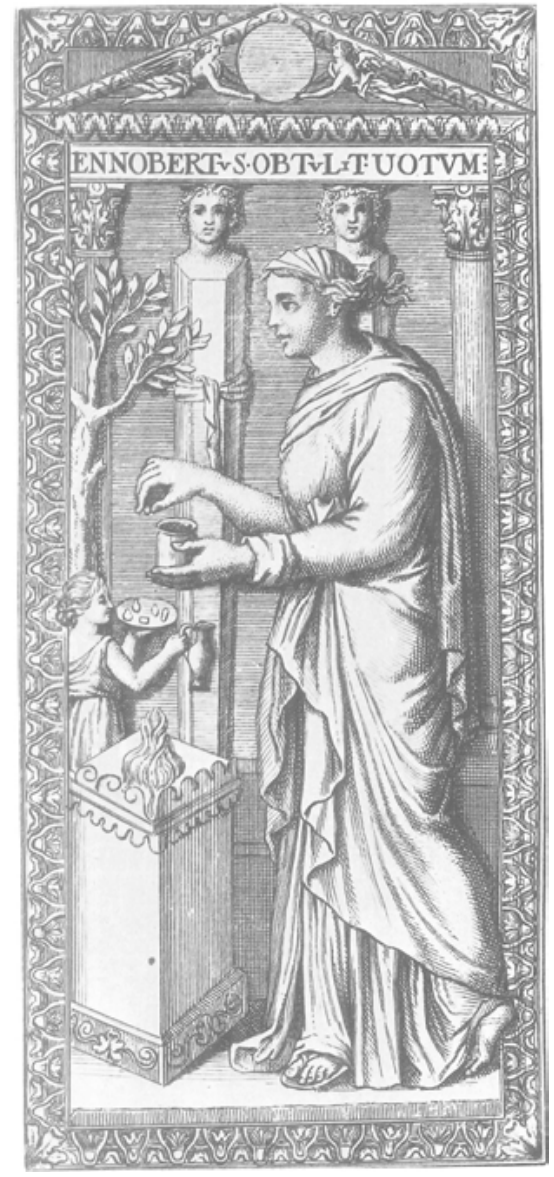

Abb. 26: Stich der Ennobertus-Tafel.

comachi-Symmachi-Diptychon lauten. ${ }^{58}$ Verbunden mit der Benennung ist die Entscheidung über die Urheberschaft, Datierung und den Anlass für die Herausgabe des Diptychons. Da die Seite mit der Aufschrift NICOMACH[or]VM, die links angebracht war, ${ }^{59}$ als Hauptseite zu identifizieren ist, ${ }^{60}$ lässt sich schlussfolgern, dass Anlass und

58 Dies wird immer wieder vertauscht, obwohl die Anordnung der Tafeln zumeist korrekt abgebildet wird; i. B. VOLBACH 2(1952) 39; CAMERON (1984a) und SIMON (1992); richtig u. a. MULRYAN (2013) 82; RAECK (1992) 163 und BECKWITH (1958) 29; bewusst bei KINNEY (1994) 64-96 und KIILERICH (1991) $115-128$.

59 Dies ergibt sich aus der konvexen Biegung der rechten Seite und der dort noch zu verifizierenden Bohrlöcher für die Aufhängung (mit vergoldeten Kugeln verfüllt); dementsprechend auf der SYMMACHORVM-Tafel auf der linken Seite. Hinzu kommt das ikonographische Argument, dass die dargestellten Figuren und Personen immer zur Innenseite ausgerichtet sind (aufgeklappter Zustand). 60 So schon richtig DELBRUECK (1929) 210; vgl. ebd. 16 zum Anordnungsprinzip westlicher Konsulardiptychons; nachfolgend auch ENGEMANN (1999) 159f.; ausführlich ders. (1998) 109-130. 
Auftrag zur Herstellung auf die Nicomachi zurückgehen muss. Naheliegend ist, hierin ein Konsulardiptychon oder das eines hohen Amtsträgers aus dem Haus der Nicomachi zu sehen. Weder die Klassifizierung als „Priesterdiptychon“61, wie sie Delbrueck vorschlug, noch die Spekulationen über eine Hochzeit oder einen Todesfall können überzeugen. Insbesondere die beiden letzten Vorschläge, die zum einen auf Shelton ${ }^{62}$ und zum anderen auf Cameron und Kiilerich ${ }^{63}$ zurückgehen, sind schon allein im Hinblick auf die ursprüngliche Funktion der Diptychen als Etui für die amtlichen Ernennungsurkunden $^{64}$ eher zurückzuweisen. Ohne sich übermäßig stark auf die Darstellung zu stützen, wird davon auszugehen sein, dass am ehesten das Konsulat des Virius Nicomachus Flavianus im Jahr 394 als Anlass für die Herausgabe des Diptychons infrage kommt. Wie zuletzt noch einmal Budesheim anführte, waren solcherlei Kostbarkeiten als Geschenkgabe nur dem Konsul gestattet, und zwar im Zusammenhang mit dessen Ernennung. ${ }^{65}$ Dies galt so auch für das Rufii-Lampadii-Diptychon ${ }^{66}$, welches trotz der Zuweisung an zwei senatorische Familien wohl nicht als „Hochzeitsdiptychon“ anzusprechen ist, sondern auf die senatorische Spielgebung verweist und damit im Kontext der senatorischen Amtsführung steht.

Die Argumente, die einst Delbrueck ${ }^{67}$ gegen die Datierung in das Jahr 394 und die Verbindung mit dem Konsulat des Flavianus anführte, sind nicht stichhaltig. Die Auffassung, dass mit der gewählten Form der Opferhandlung „eine gewisse Rücksicht auf die den heidnischen Kult einengende Gesetze ${ }^{\text {“68 }}$ genommen wurde, und damit eine Datierung zwischen 392 und 394 bzw. 409/410 ${ }^{69}$ unwahrscheinlich sei, kann so nicht

61 DELBRUECK (1929) 214; zu dieser Klassifizierung, die DELBRUECK von den „Amtsdiptychen“ absondert, ebd. $8 \mathrm{f}$.

62 Bereits SEECK (1883) 242; VOLBACH 2(1952) 39: „Hochzeitsdiptychon“ (a. 392 oder a. 401); besonders SHELTON (1979) 187 f.; SIMON (1992) 56- 65 wie dies. (1998) 240 f.: baut im Folgenden die gesamte Interpretation hinsichtlich eines „Eheschlusses“ auf; KINNEY (2008) 151: wobei hier zurückhaltender. Von DEMANDT (2008) 420 wird diese Interpretation übernommen.

63 KIILERICH (1991) 115-128: die Fackelträgerin (Taf. A) sei die Demeter suchende Kore (wie CAMERON (1986)); die Bäume seien im Zusammenhang mit der Sepulchralikonographie zu sehen, ebenso die Kulthandlungen; anlässlich des Todes des Praetextatus 384 herausgegeben. CAMERON (1986) 42-45: Demeter suchende Kore (gestützt auf Claud. rap. Pros. 3,375), deren Anwesenheit im Zusammenhang mit der gesenkten Fackel auf einen Todesfall hindeute, worauf die „Priesterin“ auf Tafel B ein Opfer für den Geist des Verstorbenen vollzieht; anlässlich des Todes des Symmachus 402 oder Flavianus 394; letzteres vorgeschlagen in CAMERON (1998) 385 f. und ders. (2011) $730-742$.

64 Hierzu DELBRUECK (1929) 3-6; wovon sich die von DELBRUECK als „Amtsdiptychen“ bezeichneten Stücke ableiten (Ebd. 6-8).

65 Vgl. BUDESHEIM (2007) 53-84, hier 58 f.; bereits DELBRUECK (1929) 214 gibt zu bedenken, dass es so etwas wie „Hochzeitsdiptychen“ wohl nicht gegeben habe, da in den Schriftquellen nicht die Rede davon ist; CTh. 15,9,1 (von 384) verbindet die Elfenbeindiptychen explizit mit dem Konsulat; ferner jüngst CAMERON (2013) 174-207, bes. 185-188; vgl. ders. (1998) 398-400.

66 Vgl. Kap. 8.2.

67 Vgl. DELBRUECK (1929) $212 \mathrm{f}$.

68 Ebd. 112.

69 DELBRUECK geht davon aus, dass sich sowohl unter der Usurpation des Eugenius als auch unter Attalus mehr Freiheiten in der Darstellung des cultus geboten hätten. 
geteilt werden. Für die Datierung ist dieses Argument ohnehin kaum zu verwenden. Der Einfluss der politischen Umstände und des Auftraggebers auf die Gestaltung des Diptychons wird hier deutlich überschätzt. Im Grunde ist seit langem schon bekannt, dass das Diptychon der Nicomachi und Symmachi keineswegs ein Unikat war. Durch einen Stich Montfaucons von 1719 ist das Aussehen der Ennobertus-Elfenbeintafel (Abb. 26) ${ }^{70}$ einsehbar, welche nahezu identisch mit der Symmachorum-Tafel war. Damit lässt sich belegen, dass das Diptychon der Nicomachi und Symmachi Bestandteil einer weitaus umfangreicheren Produktionsserie war und wohl auch auf einem von der Werkstatt standardisierten Bildmotiv fußte. Die Möglichkeit, ein individuelles, auf die Person des Auftraggebers zugeschnittenes Bildprogramm entwerfen $\mathrm{zu}$ lassen, relativiert sich hiermit stark. Offenbar wurde die Bildkomposition maßgeblich vom verfügbaren Produktionsrepertoire der Werkstatt bestimmt, aus welchem der Auftraggeber nur eine Auswahl traf, die andere Käufer prinzipiell so auch treffen konnten.

Wir müssen folglich berücksichtigen, dass das Nicomachi-Symmachi-Diptychon weitaus weniger individuelle Züge trägt, als zumeist angenommen wird. Die Folgen, die sich daraus zwangsläufig für die Interpretation und Bewertung des Stücks ergeben, sind sehr weitreichend. So kann im Grunde nicht davon ausgegangen werden, dass dem Stück eine konkrete Botschaft, die explizit auf die Häuser der Nicomachier und Symmachier zu beziehen ist, innewohnt. In dieses Stück schon fast ,kryptische‘ Botschaften hineinzudeuten, wie dies etwa Simon mit ihrem zwar eindrucksvollen, aber sehr komplexen ikonographischen Bezugssystem darlegte, ${ }^{71}$ verlangt dem Bildprogramm des Diptychons mehr ab, als die Werkstatt vermutlich leisten konnte. Die Bildkomposition ist wahrscheinlich um einiges beliebiger gewesen, so dass sich eine direktere Deutung, welche die ikonographischen Bezüge nicht unnötig verkompliziert, zu bevorzugen ist.

Unter den zahlreichen Interpretationsversuchen besticht insbesondere aufgrund seiner Evidenz der Lösungsansatz, welchen Budesheim 2007 vorschlug. Nach ihr zeigen die beiden Darstellungen weniger konkret zu identifizierende Gottheiten und Kulthandlungen als vielmehr ein allgemeines Abbild der pietas. ${ }^{72}$ Dabei repräsentieren die

70 Vgl. DE MONTFAUCON (1722) Vol. 2,1, 190, Pl. 83,1; erstmals besprochen bei CAMERON (1984a) 397402 und LASKO (1994) 131-138; zuvor ders. (1981) 89-93. Weder SHELTON und KIILERICH noch SIMON gehen hierauf ein.

71 Vgl. SIMON (1998) 242-245: Im Ergebnis sieht SIMON auf Taf. A (NICOMACHORVM) Kore mit Konnotation der Venus eine Mysterienfackel haltend (unter Verweis auf Eros-Cubido: ein Symbol für das „Mysterium Ehe“). Taf. B (SYMMACHORVM) soll sodann Kore mit der Konnotation der Libera/Iuventas (vereint im Fest der Libera/toga virilis) zeigen; der Widerspruch zwischen Efeu (Liber/Bacchus) und Eiche (Jupiter) hebt sich im „neuplatonischen Synkretismus“ auf. Kore-Venus wird hier als jungvermählte Braut und Kore-Iuventas als Braut vor der Eheschließung gedeutet, die Fackel und das Feuer an bzw. auf den Altären stellt hierbei den Übergang her (beginnend auf der Tafel der Symmachi, was aber die üblichen Anordnungsprinzipien missachtet).

72 BUDESHEIM (2007) 81f.; gleichzeitig macht sie darauf aufmerksam, dass die Ikonographie der weiblichen Gestalt auf Taf. B (Symmachorum) mit der Pietas-Darstellung der antoninischen Münzprägung verbunden ist (vgl. z. B. Antoninus Pius RIC 3, 356-357; RIC 3, 392-395; RIC 3, 617; RIC 3, 977; 
zwei Tafeln jeweils zwei übergeordnete Aspekte bzw. Ausprägungen der Kultpraxis. Auf der Tafel der Nicomachi wäre so der heiteren, lasziven und freudigen Aspekte der Kultausübung gedacht, während die Tafel der Symmachi mehr den Aspekt der Würde und Gewissenhaftigkeit der pietas betone. So zeigen sich dem Betrachter auf diesem Diptychon noch einmal „die alten, Status begründenden kultischen Verpflichtungen des Adels“73, die es zu verteidigen und erhalten galt, um nicht zuletzt hierdurch die eigenen Privilegien und den gesellschaftlichen wie auch den religiösen Führungsanspruch zu bewahren.

Diese beiden Aspekte der pietas sind im Einzelnen ikonographisch wie folgt $\mathrm{zu}$ fassen: Auf der Tafel mit der Aufschrift NICOMACH[or]VM sehen wir eine weibliche Gestalt im ärmellosem Chiton mit rechts entblößter Brust und offenem Haaren, die an einem Rundaltar mit Brandopfer stehend eine zu Boden gesenkte Fackel an einer zweiten entzündet. Die Szenerie spielt sich hierbei unter einer Pinie ab, in deren Geäst zwei Zimbeln hängen. Allein in dieser Darstellung wird die Sphäre von gleich mehreren Gottheiten und ihren Kulten berührt: Kybele und Attis, auf welche die Pinie und die Zimbeln hindeuten, treten dabei neben Ceres-Demeter und Kore-Persephone, deren Präsenz die Fackeln ${ }^{74}$ anzeigt. Hinzu kommt die lasziv entblößte Brust, welche vielleicht darüber hinaus noch eine Venus-Konnotation ${ }^{75}$ mitschwingen lässt. Die zweite Tafel mit der Aufschrift SYMMACHORVM zeigt ebenfalls eine weibliche Gestalt beim Opfern am Altar, welche nun aber sehr viel sittsamer gewandet eine streng nach oben geflochtene Haartracht trägt. Sie gibt Rauchwerk in das Feuer und wird dabei von einer Opferdienerin mit Kantharos und einem Tablett voller Früchte begleitet. Das Haupt der Opfernden ist mit Efeu bekränzt, der auf Liber Pater hindeutet. ${ }^{76}$ Die Szene spielt dabei unter einer Eiche, deren Laub ebenfalls den Altar ziert und damit deutlich auf Jupiter verweist.

Trotz allem spätantiken Synkretismus kann die Darstellung nicht ein Abbild einer realen Kultpraxis sein. ${ }^{77}$ So schließen sich Eiche und Efeu prinzipiell aus - letzterer war dem Jupiter sogar ein Gräuel. ${ }^{78}$ Genauso wenig dürften Kybele und Attis zusammen mit Ceres und Kore kultisch verehrt worden sein. Was in der Kultpraxis nicht denkbar war

RIC 3, 1358 ff.: Pietas n. l. begleitet von Opferdienern); ferner ist auch die sog. Drusilla im Museo Gregoriano Profano im Vatikan (Inv.-Nr. 9952) anzuführen.

73 BUDESHEIM (2007) 76.

74 Die Verbindung zum Mysterienkult von Eleusis stellte schon DELBRUECK (1929) 212 her; ebenso VOLBACH ${ }^{2}(1952) 39$.

75 Vgl. SIMON (1998) 243.

76 So bereits GRAEVEN (1913) 198-304, bes. 198-211 (unter Parallelisierung mit der spätantiken Ikonographie und Literatur), deutet jedoch mehr in Richtung der Ikonographie der Mysterienkulte und verweist daher hinsichtlich des Dargestellten auf einen nicht näher zu bestimmenden „Initiationsritus"; dies würde aber dem öffentlichen Charakter des Bildmediums widersprechen; vgl. CAMERON (2013) $185 \mathrm{f}$.

77 So bereits SIMON (1998).

78 Den flamines Dialis, welche überdies männlichen Geschlechts waren, war es strikt untersagt, Efeu zu berühren oder auch nur das Wort hedera auszusprechen (Gell. Noct. At. 10,15,12). 
und sicherlich so auch nicht vorkam, fand seine Entsprechung in der Gedankenwelt des neuplatonischen Synkretismus, wie sie bei Macrobius dargelegt wird. Hiernach waren Liber, Venus/Adonis, Attis/Kybele und Jupiter ${ }^{79}$ genauso Sol, wie dies im Grunde alle göttlichen Wesen waren. Insofern wird es vorstellbar, auch in der Ikonographie die göttlichen Attribute und Eigenschaften zu vermischen. Wie beliebig letztlich mit Gottheiten und ihren Attributen umgegangen werden konnte und wie auswechselbar diese waren, verdeutlicht die Ennobertus-Elfenbeintafel. Die Tafel gibt hier nicht die Attribute des Liber und Jupiter zu erkennen, sondern steht in den Zeichen des Apollon und Mercurius. Die ikonographische Variation ist denkbar simpel, aber dennoch wirkungsvoll. An die Stelle der Eiche tritt hier nun der Lorbeer, die Pflanze des Apollon. Den Sakralbau im Hintergrund identifiziert Lasko mit dem Tempel des Merkur in Rom, wie dies bereits schon Montfaucon vorschlug. ${ }^{80}$ Auch diese beiden Gottheiten werden in den Saturnalien mit Sol gleichgesetzt. ${ }^{81}$ Darüber hinaus erhält diese Diptychontafel durch die direkte Abbildung des Heiligtums eine zusätzliche Brisanz, da die Verankerung in der Realität durch die Angabe eines realen Baues deutlicher hervortritt.

Damit ist gleichzeitig das gedankliche Milieu umrissen, in welchem die Bildkomposition seinen Ursprung genommen hat. Zum einen verweist diese auf den hoch intellektuellen, theologisch-philosophischen Diskurs, der in senatsaristokratischen Kreisen geführt wurde und in der Gedankenwelt des neuplatonischen Synkretismus verwurzelt war. Zum anderen geben sich insbesondere auf der Ennobertus-Elfenbeintafel unverhüllt konkrete politische Forderungen der heidnischen Senatsaristokratie zu erkennen. Die Restauration der paganen Kulte und ihrer Heiligtümer, eben das, was seit 382 bzw. 391/392 kontrovers diskutiert wurde, scheint hiermit angesprochen zu sein. Eine wie auch immer geartete Rücksichtnahme auf die christlichen Kaiser und ihre antipagane Gesetzgebung, wie sie Delbrueck hier zu erkennen glaubte, lässt sich angesichts dessen wohl kaum vertreten.

Am Ende könnte gerade, weil sich Quintus Aurelius Symmachus in der Usurpation des Eugenius so zurücknahm und nicht an der Seite des Flavianus stand, ${ }^{82}$ die Auf-

79 Vgl. Macr. Sat. 1,17-23; bes. 1,18 (Liber ist Sol); 1,21 (Adonis, Attis, Osiris und Horus sind Sol; die Argumentation kann so auch auf Kore/Demeter angewendet werden) und Macr. Sat. 1,23 (Jupiter ist Sol).

80 Vgl. LASKO (1994) 133f. Der Tempel lag vermutlich am Hang des Aventin, nahe des Circus Maximus und wurde nach Livius 495 v.Chr. gegründet (Liv. 2,21,7 u. 2,27,5f.; ferner Val. Max. 9,3,6 und Ov. Fast. 5,669f.); eine Sesterz-Prägung aus der Zeit des Marc Aurel (Rev.: RELIG. AVG. IMP. VI COS. III, also zwischen 171 und 173) zeigt den Tempel mit Hermen-Galerie und Kultbild; diese sind vermutlich auf eine Restaurierung des Tempels zu beziehen (BMC 4 Marcus 1441-1448; RIC 3, 1074ff.); vgl. SCHEITHAUER (2000) 178f.; KOLB (1995) 119 u. 124.

81 Vgl. Macr. Sat. 1,17 (Apollon) und Macr. Sat. 1,19 (Mars und Mercur).

82 Zur Rolle des Symmachus in der Usurpation des Eugenius vgl. z. B. CAMERON (2011) $74-83$ u. $370-$ 381; SONGO (2006) 77 f. u. 79-82; WYTZES (1977) 104. Symmachus erschien zumindest im Nachgang nicht als Unterstützer des Eugenius. So tritt er nach 394 als Fürsprecher und Verteidiger der EugeniusAnhänger auf; vgl. Symm. ep. 3,33 (für Marcianus); Symm. ep. 4,4 (an Stilicho über die Rehabilitierung des Flavianus d. Ä.); Symm. ep. 4,19 und 4,51 (über die Vermögensrückerstattung des Flavianus) und 
schrift SYMMACHORVM hinzugenommen worden sein. Hierbei würde Flavianus dem Freund für dessen bereits 391 bekleidetes Konsulat die Ehre erweisen und dies zugleich mit der Aufforderung verknüpfen, sich erneut aktiv politisch für die gemeinsame Sache einzusetzen. ${ }^{83}$ Die vormals gemeinsam vertretenen religionspolitischen Forderungen wurden hier nicht nur auf einen Nenner gebracht, sondern darüber hinaus auch als erfüllt präsentiert. In den Jahren zwischen 392 und 394 gab es hierfür gewiss Gründe zu hoffen. Falls dies zutreffen sollte, wurde dieses Diptychon, welches Flavianus dann wohl anlässlich seines Konsulats 394 herausgab, als politisches ,Propagandamittel verwendet. Offensichtlich sollten mit solchen Bildern neue senatorische Unterstützer für Eugenius angeworben werden.

Es ist am Ende bezeichnend, dass sich Symmachus nicht überzeugen ließ, hier eine politisch aktivere Rolle zu spielen. Im Unterschied zu Flavianus war Symmachus offensichtlich nicht mehr bereit, sich für die heidnischen Kulte offen politisch zu positionieren und sich vor allem demonstrativ gegen das streng christliche theodosianische Kaiserhaus aufzulehnen. Dennoch ist ihm hier nicht unbedingt ein inkonsequentes Verhalten vorzuwerfen. Symmachus bleibt sich selbst treu. Als Denker und Rhetor gibt er dem intellektuellen Diskurs den Vorzug vor dem offen ausgetragenen politischen Kampf. Diese Haltung ist nach 394 für die Mehrheit des sog. Symmachus-Kreises prägend. Das verbindende Element ist die Bildung und die senatorische Pflichterfüllung gegenüber der res publica, nicht die Teilhabe am paganen cultus. Dies ist auch die Voraussetzung dafür, dass sich im sog. Symmachus-Kreis sowohl ,altgläubige‘ als auch moderat-christliche Vertreter der Senatsaristokratie wiederfinden konnten. Ein entscheidender Punkt war hierbei die Verteidigung und Immunisierung der stadtrömischen Senatsaristokratie, insbesondere des senatorischen Nachwuchs, gegenüber der religiösen Radikalisierung.

\subsection{Der vir Christianissimus und das christliche Repräsentationsbild}

Das Problem, welches die Senatsaristokratie mit dem Christentum hatte, lag nicht so sehr im Widerspruch des Christentums zu den klassischen Bildungsidealen begründet, die, wie bereits aufgezeigt, zusehends auch von christlicher Seite als verbindlich anerkannt wurden. Das Christentum, welches in seinem Ursprung eine Religion der sozialen Außenseiter bzw. der „sozialen Niedrigkeit“"84 war, schien ungeeignet zu sein,

Symm. ep. 5,47 (für einige Nachbarn); vgl. auch CROKE (1976) 535-549 und allgemein zur Usurpation SALZMAN (2010) 191-223 und SZIDAT (1979) 487-508.

83 Zur politischen Positionierung des Flavianus im Unterschied zu Symmachus, vgl. auch KLEIN 2(1986) 52-56.

84 Vgl. hierzu allgemein LEPPIN (2018) 402-414; BARCELÓ (2013) 13ff.; PIETZNER (2013) 41ff. u. 341382; MACMULLEN (2009); ZIEGLER (2007); GEMEINHARDT (2007) 81-100; ferner THEISSEN ${ }^{3}(1989)$. 


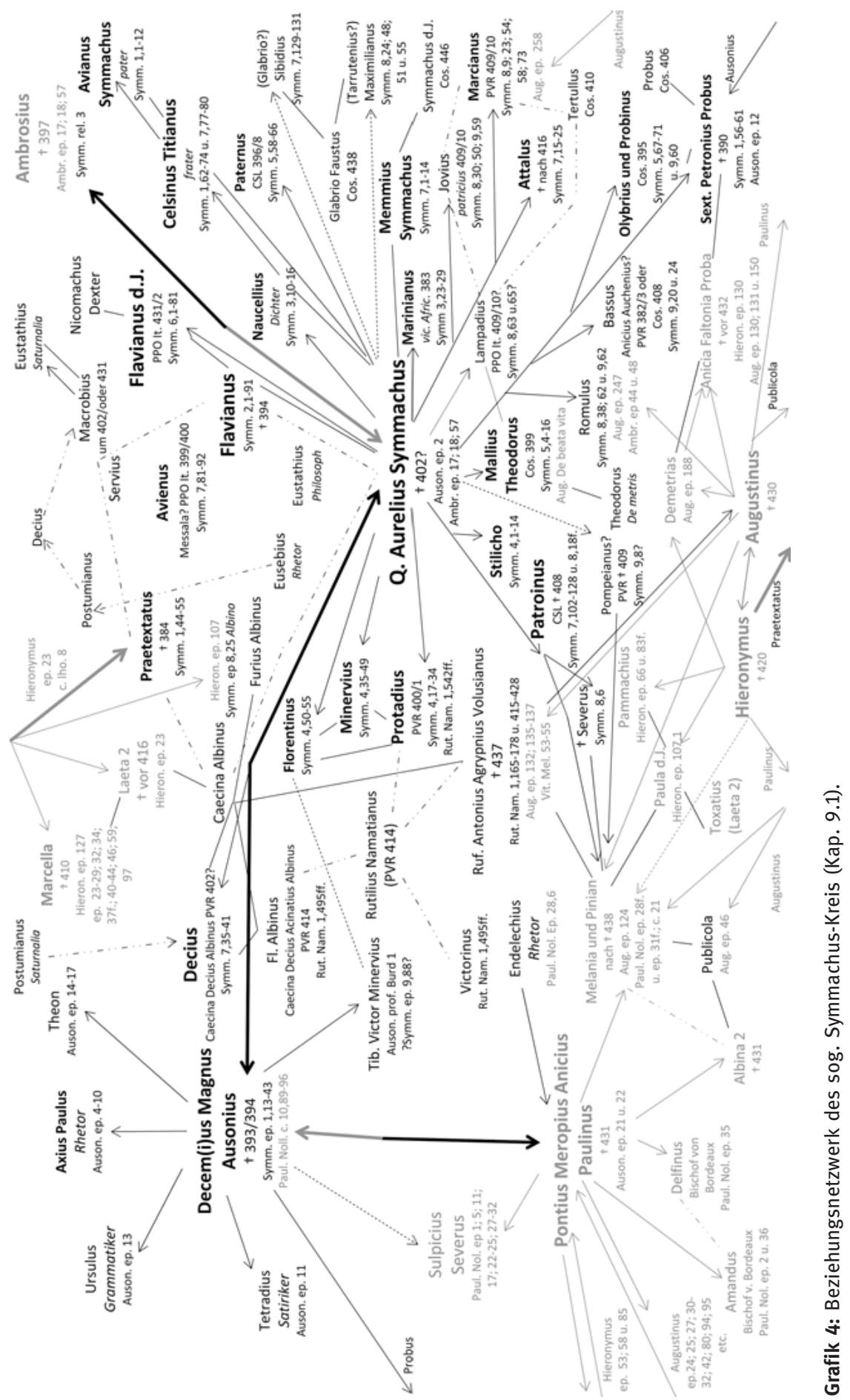


die Stellung der Senatsaristokratie zu stützen. Zugleich musste hingenommen werden, dass die religiöse Führung von Männern ausging, die oftmals einem niedrigeren Stand als dem Clarissimat ${ }^{85}$ angehörten. Die große Herausforderung, die sich mit der zunehmenden Dominanz des Christentums und dem Ende des religiösen und kultischen Pluralismus für die Senatsaristokratie stellte, lag in der Zurückgewinnung der senatsaristokratischen Führungsrolle im religiösen Leben. Damit aufs Engste verbunden war die Genese einer christlichen Aristokratie, die sich deutlich von der breiten Masse der Gläubigen abheben musste.

Die Untersuchung konzentriert sich hierbei auf zwei sehr unterschiedliche Gattungen der frühchristlichen Kunst: zum einen auf die Reliefs der christlichen Sarkophage und zum anderen auf die bildliche Ausstattung der Kirchen. Ein Zusammenhang besteht im Besonderen im benutzten Bildrepertoire, wobei die christlichen Sarkophage sich offenbar am Dekor der christlichen Großbauten orientierten. Insofern ergänzen die Sarkophage sehr gut das lückenhafte Bild, welches wir von den Bildwelten der stadtrömischen Kirchen des 4. und 5. Jhs. haben. ${ }^{86}$ Überdies gilt sowohl für den Bildschmuck der Kirchen Roms als auch für die stadtrömische Sarkophagproduktion, dass diese, wie die gesamte stadtrömische Kunstproduktion, stark unter dem patronalen Einfluss und der finanziellen Förderung der senatorischen Häuser stand. So war im Grunde die überwiegende Zahl aller Kunstäußerungen nicht etwa kaiserlich oder gar klerikal, sondern senatorisch geprägt. ${ }^{87}$ Auch der Bischof von Rom und zahlreiche Kleriker bewegten sich in senatorischen Kreisen und fanden hier neben finanzieller Unterstützung wohl auch Empfehlungen für Werkstätten und Künstler. Insofern kann davon ausgegangen werden, dass die Senatsaristokratie einen beträchtlichen Einfluss auf das Entstehen der christlichen Bildwelten hatte.

Dass dies so hinsichtlich der christlichen Kunst zutraf, lässt sich an den bedeutenden senatorischen Auftragswerken des 4. Jhs. erkennen, von welchen im Besonderen auf den Sarkophag des Iunius Bassus hinzuweisen ist. Wie eine ganze Reihe an christlichen Sarkophagen ${ }^{88}$ vom Ende des 4. Jhs. belegen, fokussierte sich das christ-

Grundlegend die Beiträge VOGT ${ }^{2}$ (1983a) 54-62 und ders. ${ }^{2}$ (1983b) 63-71; ferner SCHÖLLGEN (2002) 159-171. Speziell mit Blick auf die biblische Tradition vgl. MARKSCHIES (2012).

85 Die These, wonach die Bischöfe in eine bestimmte Rangklasse aufgenommen wurden (viri illustres?), ließ sich nicht halten; vgl. MARTIN 2(1990) 206f.; vgl. ausführlich KLEIN (2008) 1-42, bes. 8 f.; die These stammt von KLAUSER ${ }^{2}$ (1953) [1949]; dagegen fast gleichzeitig CHRYSOS (1969) 119-128 und JERG (1970). Die Feststellung, dass sich in Gallien die Bischöfe verstärkt aus dem Clarissimat rekrutierten, lässt sich, wie zu Recht ECK festhielt, nicht auf das Gesamtreich übertragen; vgl. zu Gallien STROHEKER (ND 1970) und HEINZELMANN (1976); hierzu ECK (1978) 561-585.

86 Diese Feststellung und Herangehensweise geht i. B. auf KAISER-MINN (1983) 318-338 zurück. Für die Rekonstruktion des fastigium im Lateran (Lib. Pont. 1,172-174 (v. Silvestri)) wird i. B. auf die christlichen Sarkophage verwiesen; vgl. SMITH (1970) 149-165 und DE BLAAUW (2001) 137-146; ders. (1996) 53-65.

87 Hierauf wies u. a. noch einmal WREDE (2001) 109-116 hin. Vgl. auch vgl. DRESKEN-WEILAND (1997) $19-27$.

88 Grundlegend DEICHMANN/BOVINI/BRANDENBURG (1967) [Rep. I]; ferner STUTZINGER (1982). 
liche Repräsentationsbild zunächst vor allem auf den sepulkralen Kontext. Der Säulensarkophag des Probus und der ,Mailänder Stadttorsarkophag ${ }^{69}$ sind zwei weitere bedeutende Stücke der christlichen Sarkophagproduktion aus den Werkstätten Roms. Mit den beiden erstgenannten Sarkophagen, dem des Iunius Bassus und des Probus, befinden wir uns im Zentrum der stadtrömischen Senatsaristokratie. Iunius Bassus signo Theotecnius ${ }^{90}$ und Sextus Petronius Probus ${ }^{91}$ gehörten wohl beide der gens Anicia an, die sich Mitte des 4. Jhs. an Alt-St. Peter ein eigenes Familienmausoleum ${ }^{92}$ errichtet hatte. Die stadtrömischen Anicier gehören damit nicht nur zu den ersten aus der Aristokratie Roms, die die Bedeutung von Alt-St. Peter für die eigene sakrale und sepulkrale Repräsentation erkannten, auch dürften sie zu den ersten gehört haben, die als senatorische Auftraggeber die christliche Repräsentationskunst in den senatorischen Kreisen Roms einführten.

Von einem christlichen Repräsentationsbild lässt sich im Fall des Iunius-BassusSarkophags (Abb. 27) ${ }^{93}$ im engeren Sinne bezüglich des im oberen Register zentral angeordneten Bilds sprechen. Hier zeigt sich Christus thronend. Der Gottessohn ist hierbei als Lehrer mit jugendlich-schönen Zügen dargestellt, die an die Ikonographie des Gottes Apollon ${ }^{94}$ erinnern. Die rechte Hand, die heute fehlt, war zum Redegestus erhoben. Die linke hält eine entfaltete Schriftrolle. Unter dem suppedaneum ist eine männliche Personifikation zu erkennen, die, wie aus dem kaiserlichen Repräsentationsbild oder der

89 Rep. II 150; Mailand, Basilica di Sant’Ambrogio (Atrium, Mausoleum neben der Kirche); vgl. Rep. II 56ff., Kat-Nr. 150, Taf. 59,3-8, 60,1-2; 61,1-2.

90 PLRE 1, 155 (PVR +359); vgl. mit der Inschrift CIL 6, 43141 u. a. MACHADO (2010b) 313f.; vermutlich verwandt mit dem gleichnamigen Konsul von 331, dem Stifter der Basilica Iunii Bassi (Esquilin); hier noch mit heidnischen Bildthemen (Hylas-Panel mit ägyptischen Gottheiten). Wie am Namen des Anicius Auchenius Bassus 11 und 7 (PLRE 1, 640-642: PVR 382/3 und PLRE 2, 219f.: Cos. 408) zu erkennen ist, besteht eine verwandtschaftliche Beziehung zu den Aniciern. Diese bestand vermutlich seit dem frühen 4. Jh. durch die Ehe zwischen Amnius Anicius Julianus (PLRE 1, 679f.: Cos. 325) und Caesonia Manila, der Tochter des L. Caesonius Ovinius Rufinus Manilius Bassus (PLRE 1, 156f.); vgl. SETTIPANI (2000) $374 \mathrm{f} ., 432$ u. 597. Ganz gesichert ist dies allerdings nicht.

91 PLRE 1, 736 -740 (Cos. 371; †390). Die Zuweisung erfolgt über ICVR 2,1 p. 348, wobei auch ein weiterer Sarkophag aus diesem Fundkontext infrage kommt (Rep. I 690: ,Stadttorsarkophag Borghese'); vgl. hierzu DRESKEN-WEILAND (2003) 96 u. 118f. und NIQUET (2000) 42-44.

92 Hierzu vgl. Kap. 9.4.

93 Abbildung Verfasser 2017; Rep. I 680; Rom, Musei Vaticani, S. Pietro in Vaticano. Museo del Tesoro (ursprünglich in der Confessio von Alt.-St. Peter; bis 1559); vgl. Rep. I 279ff., Kat.-Nr. 680, Taf. 104-105 und ASR I 4 (1991) Kat.-Nr. 300, Taf. 13,1-2. Daneben stehen für den „Höhepunkt“ der christlichen Sarkophagkunst in der Mitte des 4. Jhs. auch der sog. Brüder-Sarkophag im Vatican (DEICHMANN, Rep. I 45) und der Lot-Sarkophag von S. Sebastiano (Rep. I 118); vgl. knapp KAISER-MINN (1983) 318-338, hier $325 \mathrm{f}$.

94 Hierzu vgl. WESTERKAMP (2015) 144; ferner GERKE ${ }^{3}(1948) 40$ [1940]: „Es ist der Typus mit dem halblangen, nach rückwärts hochgenommenen Haar, der auch für theodosianische Passions- und Wunderszenen und für Christus victor mit dem Kreuze Vorbild wird. “ FITTSCHEN verwies darüber hinaus auch auf eine Anzahl von Büsten junger Männer und Knaben (i. B. aus Griechenland), die offensichtlich die klassischen jungen Helden zitieren; vgl. FITTSCHEN (1989) 108-113; ferner DANGUILLIER (2001) 212f. und ZANKER (1995) 234-237. 


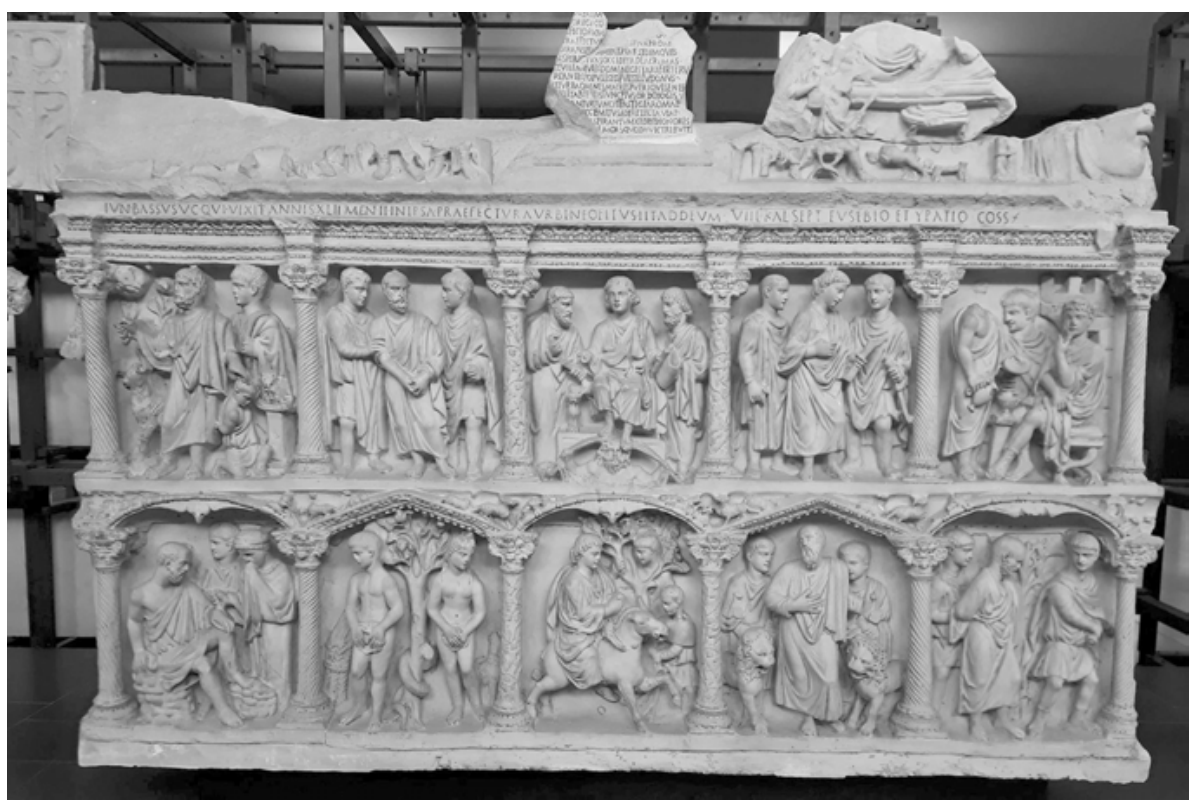

Abb. 27: lunius-Bassus-Sarkophag.

Jupiter-Ikonographie bekannt, Caelus ${ }^{95}$ meint und damit Christus als Herrscher des Himmelreichs ausweist. Zur Rechten und Linken des himmlischen Königs stehen Petrus und Paulus, ${ }^{96}$ die das Gesetz proklamiert ${ }^{97}$ bekommen. In diesem Repräsentationsbild, welches demnach als Darstellung der traditio legis ${ }^{98}$ anzusprechen ist, verbinden sich der Christus doctor veritatis ${ }^{99}$ und der Christus rex Pantokrator zu einer Einheit. In dieser Figurengruppe zeigt sich das christlich-senatorische Repräsentationsbild bereits in voller Ausprägung. Christus bildet als Herrscher des Himmelreichs das Zentrum. Deutlich niedriger sind die beiden Apostelfürsten dargestellt, womit der hierarchischen

95 Vgl. PIPER (ND 1972) 47-64 [1851].

96 Der Ehrenplatz zur Rechten Christi wird üblicherweise Petrus zugestanden; ikonographisch wird dieser oft mit Halbglatze und krausem Haarkranz dargestellt (so auch 02: Gefangensetzung des Petrus und U5: Abführung zur Hinrichtung). Da Christus oftmals im Redegestus dargestellt wird, ergibt sich, dass nur die linke Hand die Übergabe der Schrift (traditio legis) ausführen kann, folglich diese Übergabe zur Linken an Paulus erfolgt.

97 So KAISER-MINN (1983) $330 \mathrm{f}$.

98 Apg 5,1f.; hierzu vgl. HERRMANN/VAN DEN HOEK (2009) 33-80, hier 38-44 und SPERA (2000) 288-293; ferner u. a. BERGER (1973) 104-122 und SOTOMAYOR (1961) 215-320. Speziell zum IuniusBassus-Sarkophag vgl. jetzt auch LEAL LOBÓN (2011) 521-554, hier $541 \mathrm{f}$.

99 Hierzu vgl. z. B. ZANKER (1995) 272-288 und SCHUMACHER (1959) 1-39 u. 137-202; ferner KOLLWITZ (1939) 45-66 mit weiteren ikonographischen Beispielen. Zur Christologie vgl. jetzt aktuell FEULNER (2016) 25-125. Zur Verbindung mit den senatorischen Bildungsidealen vgl. ZANKER (1995) $230-233$ u. $253-272$. 
Abstufung entsprochen wurde, die so wichtig und folglich auch charakteristisch für das herrschaftliche Repräsentationsbild ist. Damit besteht auch eine Nähe zum Repräsentationsbild des senatorischen Amts- und Würdenträgers. ${ }^{100}$ Die erhobene Rechte adaptiert den senatorischen und kaiserlichen Redegestus, der gerade auch die gesetzgebende und richterliche Gewalt zum Ausdruck bringt. Selbiges gilt für den entrollten rotulus, auf welchem in anderen Fällen noch das DOMINVS LEGEM DAT ${ }^{101} \mathrm{zu}$ lesen ist. Christus thront hierbei sogar auf der sella curulis, dem Amtsstuhl der Konsuln.

In den narrativen Einzelbildern des Iunius-Bassus-Sarkophags ${ }^{102}$ entfaltete sich aufs Eindrücklichste die christliche Geisteswelt. Hier wurden aber nicht nur Bilder für eine christliche ,Mythologie“ kreiert, die als Äquivalent zu den heidnisch-mythologischen Bilderwelten ${ }^{103}$ die Gelehrsamkeit des Verstorbenen betonten. Darüber hinaus wurden in diesen Bildern zentrale Glaubensinhalte kommuniziert und die Hoffnung des Verstorbenen auf Gnade und Erlösung ${ }^{104}$ vor dem Richtstuhl Christi zum Ausdruck gebracht. Mit dem thronenden Christus im Zentrum offenbart sich die Ordnung der christlichen Welt und damit auch die ,gottgewollte' Grundlage der sozialen und politischen Ordnung, in welcher die christliche Senatsaristokratie ihren privilegierten Platz finden konnte.

Das Christus-Repräsentationsbild war hierfür prädestiniert, da es unmittelbar ein Abbild der weltlichen Ordnung darstellte, in welchem der Kaiser den höchsten Platz einnahm und die Senatoren diesen umringten. Die Monumentalkompositionen, die am Ende des 4. Jhs. die Sarkophaggestaltung prägten, entfalten das Christus-Repräsenta-

100 Zur Ableitung vom Repräsentationsbild des magistratus patricii vgl. auch SÖRRIES (1986) 139159.

101 Vgl. hierzu DRESKEN-WEILAND (2010) 59 und DEICHMANN/KLAUSER (1966) 74-77; vgl. bes. CONGAR (1962) 915-933 und SCHUMACHER (1959) 1-39.

102 In der Abfolge von links nach rechts im oberen Register: Isaak-,Opfer‘ (O1; nach Gen 22,1-14), Gefangennahme Petri (02; Apg 12,1-18), Christus auf dem Thron (03) und Gefangennahme Christi (04; Mt 26,47-56; Mk 14,43-52; Lk 22,47-53); unteres Register: Hiob (U1; Hiob 1,21), Adam und Eva (U2; Gen 3,1-24), Einzug Jesu in Jerusalem (U3; Mt 21,1-11; Mk 11,1-11; Lk 19,28 - 40; Joh 12,13-15), Daniel in der Löwengrube (U4; Dan 6,1-29) und Wegführung des Petrus zur Hinrichtung (U5; Apg 28,16-31 erwähnt nur die Ankunft in Rom); zu einzelnen Bildthemen vgl. auch DRESKEN-WEILAND (2010) 136-141 (Petrus), 233-247 (zu Daniel), 276-287 (Adam) und 294-301 (Isaak) etc.

103 So kann auf heidnische Säulensarkophage verwiesen werden, welche ebenfalls in narrativen Einzelbildern (im Unterschied zum fortlaufenden Fries) mythologische Inhalte wiedergeben. Noch für das 2./3. Jh. n. Chr. lassen sich Beispiele nennen; so adaptiert ein Säulensarkophag mit der Darstellung der Herakles-Taten im Britischen Museum (ASR III 1 (1897) 150 f., Kat.-Nr. 131, Taf. 39) die Metopen des Zeustempels von Olympia; ferner auch ein Säulensarkophag aus der Galleria Borghese (Inv.-Nr. 95) und ein Säulensarkophag aus dem Museo Torlonia (Inv.-Nr. 420); vgl. KLEIN (2002) 145-152; ferner STUTZINGER (1983) 223-240.

104 Für das Motiv der Gnade und Erlösung stehen hier Abraham, der Isaak nicht opfern muss und mit reicher Nachkommenschaft beschenkt wird (Gen 22,16-19); Petrus, den Gott aus der Gefangenschaft befreit (in Jerusalem; Apg 12,6-18), Hiob, den Gott am Ende vom Leid erlöst und das Verlorene in höherer Zahl zurückgibt (Hiob 42,10-17) und Daniel, der aus der Löwengrube errettet wird (Dan 6,1-29). 
tionsbild nun über die gesamte Bildfläche. ${ }^{105}$ Die narrativen Einzelbilder treten in den Hintergrund. Der Probus-Sarkophag ${ }^{106}$ aus Alt-St. Peter und zwei fragmentarisch erhaltene Säulensarkophage aus S. Sebastiano ${ }^{107}$ lassen sich anführen. Sie zeigen das Bild einer „Lehrversammlung“, in dessen Zentrum Christus erhöht steht ${ }^{108}$ bzw. thront. Christus hält eine Proklamation, der die Apostel ${ }^{109}$ aufmerksam folgen. Anhand der Exemplare aus S. Sebastiano wird die Nähe zu den kaiserlichen Repräsentationsbildern besonders deutlich, denn hier scheinen die Apostel dem thronenden Christus sogar Kränze $^{110}$ darzubieten, und auch das Verhüllen der Hände (manus velatae), wie es im Hofzeremoniell üblich war, kann hier beobachtet werden. Dem himmlischen König auf seinem Thron wird somit die „Kranzspende“111 dargebracht. Die philosophische Lehrversammlung wandelt sich damit zu einem höfischen Zeremonienbild.

Formvollendet findet sich dieses christliche Repräsentationsbild sodann auf den sog. Stadttorsarkophagen, von welchen hier das Exemplar aus S. Ambrogio in Mailand (Abb. 28-30) $)^{112}$ angeführt wird. Es handelt sich hierbei um das wohl qualitätsvollste Erzeugnis der ,Stadttorsarkophaggruppe', die heute einer stadtrömischen Werkstatt ${ }^{113}$ zugerechnet wird. Die Langseiten präsentieren den himmlischen Hofstaat, Christus rex und die Apostel. Auf der einen Seite ist der proklamierende Christus mit entrollter Schrift (traditio legis) stehend auf dem paradiesischen „Vierstromberg“ dargestellt, während die Apostel ihm stehend akklamieren. Auf der Gegenseite (Abb. 28) zeigt sich dann Christus thronend, die Hand zur Rede erhoben, umgeben von den sitzenden Aposteln. Neu hinzukommt, dass sich der Verstorbene in dieses himmlische Herrschaftsbild selbst hineinsetzen lässt. Abgesehen von dem Clipeus im oberen Bildfries, welches einen militärischen Amtsträger ${ }^{114}$ zusammen mit seiner Gemahlin zeigt, finden wir das Paar noch einmal zu Füßen des himmlischen Königs. ${ }^{115}$ Um die Distanz zum Göttlichen zu

$105 \mathrm{Zu}$ diesem Typus vgl. KAISER-MINN (1983) 318-328 und STUTZINGER (1982) $133 \mathrm{ff}$.

106 Rom, Musei Vaticani, Museo Pio Cristiano; vgl. Rep. I 277, Kat.-Nr. 678, Taf. 107 und ASR I 3 (2006) 239, Kat.-Nr. 159.

107 Rep. I 200 und Rep. I 193; vgl. KAISER-MINN (1983) Abb. 146 u. 149; diese Sarkophage konnten 2017 begutachtet werden; zu vergleichen ist auch der Traditio-legis-Sarkophag aus Arles (Rep. III Kat.-Nr. 53) mit Darstellungen der Fußwaschung Petri (links außen) und des Pilatus (rechts außen).

108 Hier auf dem „Vierstromberg“ (Offb 14,1 u. 22,1).

109 Einige Apostel sind hier bereits miteinander im Gespräch über das, was Christus verlautbaren lässt; zu den ikonographischen Vorbildern, i. B. auf den Staatsreliefs vgl. ENGEMANN (1983b) 260 - 266 und KAISER-MINN (1983) 322f. Vgl. i. B. die Reliefs des Konstantinsbogens.

110 Das Objekt, welches der Apostel rechts neben Christus in der rechten Hand offerierend hält, gibt eine Oberflächenstruktur zu erkennen, die als floral zu bezeichnen ist (eigene Begutachtung 2017).

111 Hierzu vgl. WESSEL (1950/1951) 103-114 und KLAUSER (1944) 129-153.

112 Abbildung nach Rep. II, Taf. 60, Abb. 2 und Taf. 61, Abb. 1 u. 2.

113 Vgl. KOLLWITZ (1963) 191-233, bes. $229 \mathrm{ff}$.

114 Der Verstorbene trägt hier das paludamentum, zusammengehalten von einer Scheibenfibel. Über der tunica zeigt sich ein Schuppenpanzer. In Händen hält der militärische Amtsträger ein Diptychon, welches wohl seine Amtsernennung beinhaltete.

115 Vgl. WARLAND (2002b) 247-253, hier 250-252 und KAISER-MINN (1983) 331. Zu diesem Darstellungstypus, der bis ins Mittelalter hinein gebräuchlich blieb, vgl. VON SCHOENEBECK (1935) $18 \mathrm{f}$. 


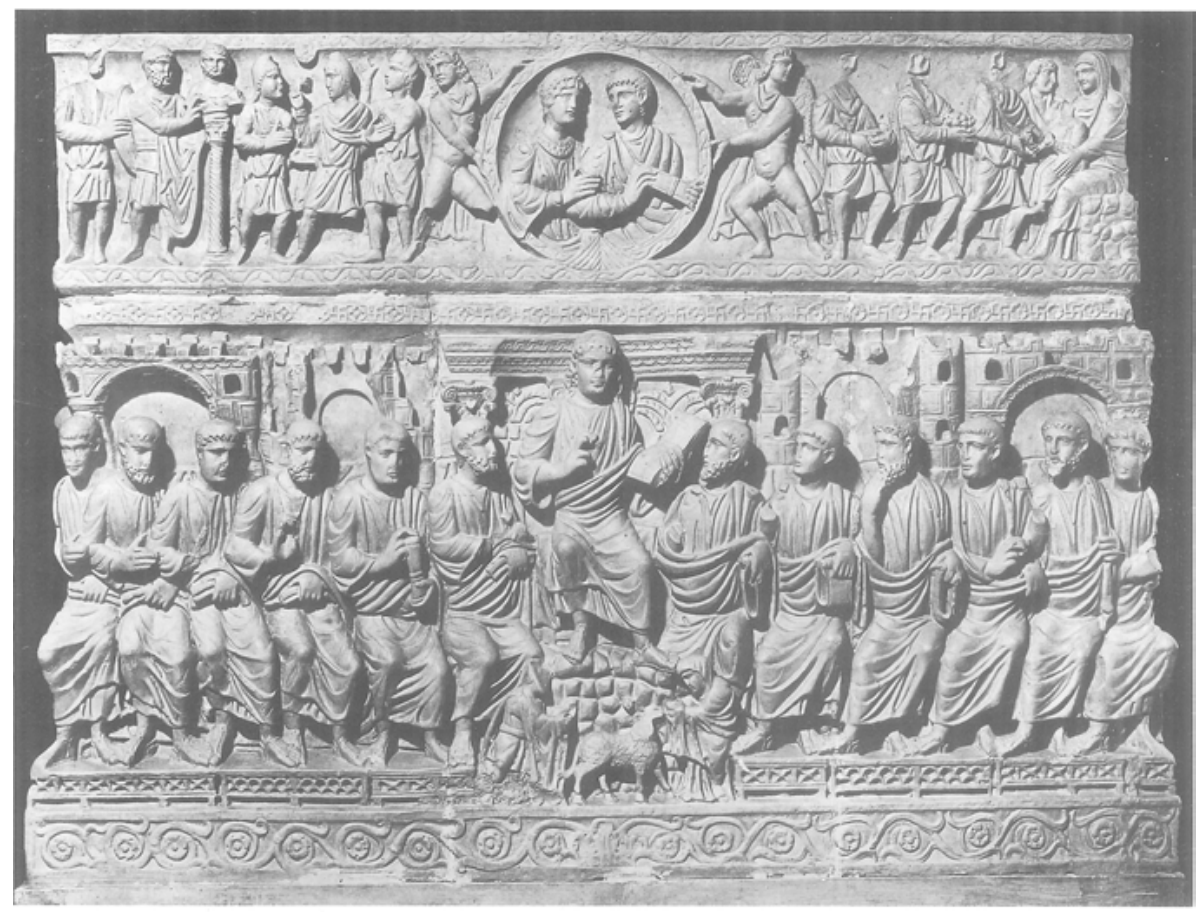

Abb. 28: Längsseiten (Hauptseite) des ,Stadttorsakophags‘ S. Ambrogio.

wahren, sind die beiden nur en miniature dargestellt. Der Mann links trägt campagi und entsprechend dazu das Dienstkostüm, eine mit cingulum gegürtete ärmellange tunica, über welche eine stoffreiche chlamys drapiert ist, in die auch seine Hände eingehüllt sind. ${ }^{116}$ Seine Gemahlin tritt in der palla ${ }^{117}$ auf. Die Adorationsszene entspricht hierbei ganz dem kaiserlich-höfischen Zeremoniell der salutatio mit manus velatae ${ }^{118}$ und Proskynese bzw. adoratio purpurae. ${ }^{119}$

Damit korrespondieren auch die beiden im oberen Bildfries dargestellten Szenen, die das Thema der Adoration erneut, nunmehr im biblischen Kontext verortet, aufgreifen. Links neben dem Clipeus zeigt sich dem Betrachter die Verweigerung der Anbetung des Standbildes des Nebukadnezar durch die drei Jünglinge und rechts davon

116 Vgl. WREDE (2001) 88f.

117 Die palla galbeata war als Hochzeitsbekleidung in Gebrauch; knapp hierzu KÖNIG (2004) 36. 118 Gebräuchlich im kaiserlichen und sakralen Zeremoniell; vgl. KESSLER-DIMIN (2008) 255-281, bes. 270 -278; DECKERS (1996) 137-184, hier 154ff.; KOLB (2001) 41, 180, 185f. und ALFÖLDI (1970) $33-35$.

119 Vgl. z. B. CTh. 8,7,4 (a. 354); hierzu vgl. KOLB (2001) 38 ff., 117 ff., 173ff.; VIELBERG (1996) bes. 12f.; LÖHKEN (1982) 48-53, 70 ff., $99 \mathrm{ff}$. und ALFÖLDI (1970) 3ff., 58f.; ausführlich SCHLINKERT (1996a) 454-482; STERN (1954) 184-189 und AVERY (1940) 66-80. 

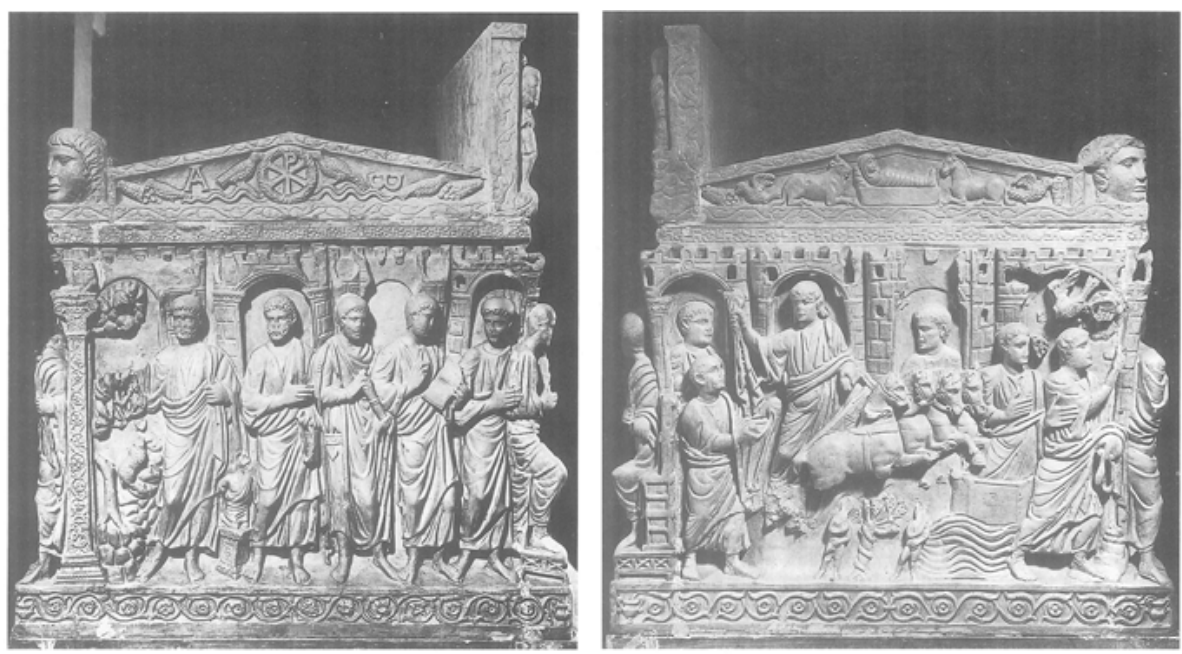

Abb. 29+30: Schmalseiten des ,Stadttorsarkophags‘.

die Anbetung des Christuskindes durch die drei Magier. ${ }^{120}$ Die besondere Spannung zwischen beiden Szenen ist in der Gegensätzlichkeit der heidnischen Idolatrie, die hier verweigert wird, und der Verehrung Christi zu sehen. Beide Szenen zusammen werden dabei auf die conversio des im Clipeus dargestellten Paares zu deuten sein. ${ }^{121}$ Seinen Höhepunkt findet das Bestreben, sich im Kreis der Apostel einzufügen und der besonderen Nähe Christi teilhaftig zu werden, auf der linken Schmalseite des Sarkophags (Abb. 29). Hier präsentiert sich der Verstorbene ein letztes Mal im reich verzierten Chlamyskostüm mit einer Schriftrolle in Händen, und zwar inmitten der Apostel. Die ehrfurchtvolle Distanz, wie sie noch auf der Vorder- und Rückseite durch Haltung und Miniaturisierung erfolgte, ist hier aufgehoben. In gleicher Größe dargestellt wird der Amtsträger von den Aposteln, als wären sie seine Amtsdiener, ${ }^{122}$ in die Mitte genommen. Der Verstorbene wurde hier wohl im Katechumenat stehend, also in der Unterweisung durch die Apostel, vielleicht auf dem Weg zur eigenen Taufe, dargestellt. Die Darstellung des Isaak-,Opfers', die sich anschließt, verweist auf den Gehorsam gegenüber Gott.

Die Bilder der gegenüberliegenden Seite (Abb. 30) greifen sodann Szenen der Verheißung auf, die deutlich auf die Auferstehung und das Gottesgericht hinweisen. Neben Adam und Eva, Noah und der Arche und Moses am Sinai ist vor allem die Himmelfahrt

120 Dan 3,1 (die drei Jünglinge im Feuerofen) und Mt 2,10.

121 Z. B. Epit. rei milit. 2,5,6. Zur Fortsetzung der Bildnisverehrung über den Kaiserkult hinaus vgl. MATTHEIS (2013) 58-72, 132-149; BARCELÓ (2003) 336-339 und BARNARD (1973) 13-29; allgemein GROSS-ALBENHAUSEN (1999).

122 Vgl. VON SCHÖENEBECK (1935) 23ff.; WARLAND (1994) 175-202, hier 186 sprach hier fälschlich von notarii, für die aber die chlamys, nicht das pallium Dienstkleidung war (vgl. den Knaben auf dem Diptychon von Monza). 
des Elias ${ }^{123}$ besonders eindrucksvoll in Szene gesetzt. Diese relativ neue Darstellung in das Bildprogramm aufzunehmen, entsprach möglicherweise sogar dem besonderen Wunsch des Auftraggebers. Jedenfalls zählt die Darstellung nicht zu dem älteren christlichen Bildrepertoire. ${ }^{124}$ Als pagane Vorlage für die Darstellung sind vermutlich die kaiserlichen Apotheose-Bilder ${ }^{125}$ bzw. auch das Bild des in seinem Viergespann über den Himmel ziehenden Helios ${ }^{126}$ anzusehen. Erst im 5. Jh. wird das Motiv sehr beliebt. So finden wir es, abgesehen von weiteren Sarkophagen, ${ }^{127}$ auch auf einer der beiden Holztüren von S. Sabina ${ }^{128}$ und im Mosaikdekor der Capella S. Aquilino in Mailand ${ }^{129}$. Sich mit dieser Szene und seinem Protagonisten zu identifizieren, barg gerade aus senatorischer Sicht einen besonderen Reiz. Zum einen dürften der Verstorbene und seine Hinterbliebenen gehofft haben, ebenso eine triumphale Himmelfahrt zu erfahren. Zum anderen wird auch die Gewandübergabe an Elisa ${ }^{130}$ sehr gut zum dynastischen Denken der Aristokratie gepasst haben, insofern sich dies als Versinnbildlichung der erblichen Übergabe von Status, Amt und Würden auffassen lässt. Überdies finden sich bei der Berufung des Elisa, der von Elia vom Feld geholt wird und, ohne zu widersprechen, Abschied von seiner Familie nimmt, entfernt Anknüpfungspunkte an das senatorische Selbstverständnis, welches das bonum exemplum des Lucius Quinctius Cincinnatus ${ }^{131}$ vorgab.

Es handelte sich hierbei nicht um das Standardprogramm. So wird unter dem Wagen des Elia statt der Personifikation des Jordan oder einer Flusslandschaft, wie sich diese auf anderen Sarkophagen findet, ${ }^{132}$ die Paradiesszene eingefügt. Auch darauf

123 2. Kön 2,1-18; hier bes. $11 \mathrm{f}$.

124 Die ältesten bekannten Beispiele finden sich in der Katakombe an der Via Latina und der Domitilla-Katakombe; wahrscheinlich aus der zweiten Hälfte des 4. Jhs. Zur bildlichen Rezeption der EliaHimmelfahrt vgl. jetzt auch BÖTTRICH (2013) 129-133 und LANDESMANN (2004) 115-140. Zu den Sarkophagen vgl. GERKE ${ }^{3}$ (1948) 87-94; hervorzuheben ist besonders ein Fragment aus dem Lateranmuseum (Rep. I 115; Museo Pio Christiano Inv.-Nr. 31488; GERKE: frühtetrarchisch?); vgl. auch LANDESMANN (2004) $147 \mathrm{f}$.

125 DELBRUECK (1929) Nr. 59; vgl. auch die kaiserlichen Konsekrationsprägungen, z. B. des Konstantin (RIC 8, 447; 449, 452f.); vgl. KOLB (2001) $253 \mathrm{f}$.

126 Hierauf ist schon mehrmals hingewiesen worden; vgl. u. a. LAWRENCE (1961) 331-334; WESSEL (1959) Sp. 1159f. und DÖGLER (1940/1950) 51-56.

127 Etwa auf dem ,Stadttorsarkophag‘ Borghese (Rep. I 829; dazugehörig zum ,Stadttorsarkophag‘ im Louvre Inv.-Nr. MA 2980; ursprünglich aus dem Grab der Anicier) und dem Exemplar aus der Cappella Collona im Vatikan (Rep. I 675,2: Ende 4. Jh.); ferner auf der Schmalseite eines figürlich dekorierten Frieses (Rep. I 25c: 2. Drittel 4. Jh.) aus S. Lucina (Gräberbezirk S. Paolo f. l. m.); zu den bekannten Beispielen mit Abbildungen vgl. LANDESMANN (2004) 147-191, hier auch ausführlich zum ,Stadttorsarkophag، von S. Ambrogio (ebd. 177-191).

128 Vgl. speziell zur Himmelfahrt des Elias LANDESMANN (2004) 193ff. und JEREMIAS (1980) 40 - 44. 129 Vgl. LANDESMANN (2004) 141-144.

130 2. Kön 2,12f.; Elisa wird von Elia zur Nachfolge berufen, ist aber kein leiblicher Nachkomme des Elia (1. Kön 19,19-21). Zur Szene vgl. auch LANDESMANN (2004) 157-160.

131 Vgl. Liv. 3,26-29. Diese Verbindung ist so in der Forschung noch nicht hergestellt worden. 132 So Rep. I 25c und Rep. I 115 (Fluss); ,Stadttorsarkophag‘ Louvre MA 2980 (Fluss und Personifikation). 
wurde offenbar besonders bestanden, auch unter Inkaufnahme ästhetischer Mängel. Adam und Eva stehen etwas ,unschön‘ im freien Raum. Dahinter steht eine Theologie, die nicht einfach auszudeuten ist. Der Bezugspunkt wäre hier in der Geburt Christi zu sehen, die genau darüber auf dem Sarkophagdeckel dargestellt ist. So können beide Szenen über den Begriff der „Erbsünde“ (peccatum originale) ${ }^{133}$, wie sie von Tertullian im Traduzianismus ${ }^{134}$ und später vor allem von Ambrosius ${ }^{135}$ und Augustinus ${ }^{136}$ vertreten wurde, zusammengeführt werden. Die Elia-Himmelfahrt kann so vielleicht auch dahingehend gedeutet werden, dass die Aufnahme ins Himmelreich Gottes nur durch die Überwindung der „Erbsünde“ durch Christus möglich wurde. Ambrosius hielt dabei in seinem Lukas-Kommentar fest, dass sowohl die Apostel als auch Moses und Elia mit geistigen Auge Christus geschaut hätten, ${ }^{137}$ womit das Erkennen Christi im Logos ebenfalls für die Größen des Alten Testaments heilsverbindlich geworden wäre. So kann Elia mit Christus in der Herrlichkeit des Himmels erscheinen. ${ }^{138}$ Selbiges wurde gewiss vom Verstorbenen erhofft, der zumindest in diesen Bildern deutlich werden ließ, dass auch er, der, ebenso umringt von den Aposteln stand, in seinem Geiste Christi geschaut habe und damit errettet sei. ${ }^{139}$

Weder die Sarkophagwerkstatt noch die Auftraggeber wurden als befähigt angesehen, eine derart ausgeklügelte Theologie $\mathrm{zu}$ entwickeln, so dass immer wieder Ambrosius von Mailand ${ }^{140}$ sozusagen als theologischer Berater für den Entwurf des Bildprogramms verantwortlich gemacht wurde. Dass die senatorische Oberschicht enge Kontakte zur hohen Geistlichkeit pflegte, ist bekannt. ${ }^{141}$ Die Möglichkeit, theologischen Rat einzuholen, war daher gegeben. Wichtiger als der Name des Geistlichen, auf den das theologische Konzept zurückgeht, ist die Feststellung, dass offenbar der

133 Augustinus verwendet den Begriff erstmals in Aug. ad Simplic. 1,1 (a. 396).

134 Vgl. WÖLFT (1960) und KARPP (1950) 41-89, zum Traduzianismus 59f.; zu weiteren Positionen vgl. z. B. FÜRST (2011) 342-344, 424- 428 u. 438-440; HAUKE (1993).

135 Ambr. Luc. 7,234 in Bezug auf 1. Kor 15,22 (vgl. auch Ps 50,7): lapsus Adami. Ambr. Luc. 2,91: Einzig Christus sei frei von dieser Sünde. Ambr. Luc. 7,147 u. 209 (Bezug Lk 19,10 u. 1. Kor 15, 22); ferner Ambr. exc. Sat. 2,6 und Ambr. obit. Val. 72,4-5: In der Geburt Christi findet sodann das Heil und die Befreiung von der Erbsünde ihren Anfang. Zur pastoralen Tätigkeit des Ambrosius und dem Inhalt seiner Theologie vgl. FENGER (1981) und SCHMITZ (1975). Zur „Erbsünde“ bei Ambrosius vgl. DUDDEN (1935) 615-620. LANDESMANN (2004) 184 spekuliert über eine Einflussnahme des Ambrosius.

136 Vgl. in Auswahl FEULNER (2016) 87-89; GEERLINGS (1999) 79-86; KREUZER (1995) 39-52; HORN (1995) $34 \mathrm{ff}$. und SIMONIS (1968) 481-501; ferner MAUSSBACH (ND 2010) 148-174 [1909].

137 Ambr. Luc. 1,5 (bezogen auf Joh 1,1f. und Mt 17,1 ff.).

138 Vgl. Ambr. Luc. 1,36 (Auslegung Lk 1,17).

139 Zur ikonographisch-theologischen Ausdeutung vor allem hinsichtlich der Überwindung der Erbsünde durch Christus vgl. auch STEEN (2001) 283-294 und i. B. LANDESMANN (2004) 184-191. 140 Vgl. hierzu RAC 8 (1972) Sp. 86 und SCHILLER (1966) 145 Anm. 9; KATZENELLENBOGEN (1947) 249-259, hier 252 und GERKE ${ }^{3}$ (1948) 88 Anm. 2 und; vgl. auch LANDESMANN (2004) 184.

141 Vgl. hierzu Kap. 9.3 und 9.4. So vertraute sich z. B. Melania d. Ä. dem Mönch Rufinus von Aquileia an und Melania d. J. und Pinian dem Gerontius und Anicia Demetria wandte sich einem Presbyter Namens Tigrinus zu. 
Klerus den elitären Anspruch der Senatsaristokratie, christlicher Adel ${ }^{142}$ zu sein, der in einem besonderen Nahverhältnis zu den Aposteln und dem Thron Christi stand, stützte. Hierbei war die Funeralkunst bei Weitem nicht das Medium, welches auf eine breite, öffentlichkeitswirksame und vor allem dauerhafte Rezeption ausgelegt war. ${ }^{143}$ Wesentlich stärkeren Einfluss auf die christliche Weltvorstellung hatte die sakrale Kunst im kirchlichen Raum. Der Bildschmuck der Kirchen besaß eine wesentlich größere mediale Präsenz. Allerdings stellen die nachfolgenden Beispiele wohl keine Auftragswerke bzw. Stiftungen der stadtrömischen Senatsaristokratie dar. Jedenfalls lässt sich dies nicht nachweisen. Im Unterschied zu den Sarkophagen sind diese Bilder nicht direkt mit der senatorischen Selbstdarstellung zu verbinden. Dennoch wird gerade hier, in den Kirchen Roms, ein christliches Repräsentationsbild öffentlichkeitswirksam präsentiert, welches dem Führungsanspruch der Senatsaristokratie voll und ganz Rechnung trug.

Das um 400 entstandene Apsismosaik von S. Pudenziana al Viminale (Abb. 31) ${ }^{144}$ gibt hierfür ein vorzügliches Beispiel ab. Wie sehen Christus thronend, umgeben von zehn Aposteln. Auch hier kann nicht mehr die Rede davon sein, dass Christus als Lehrer ${ }^{145}$ im Kreis seiner als Philosophen dargestellten Apostel auftritt. Die Zeilen, die Christus hier in der linken Hand hält, lauten: DOMINVS CONSERVATOR - ECCLESIAE PVDENTIANAE, womit versichert wird, dass der Herr die pudenzianische Kirche erhalten werde. Der geradezu exzessive Gebrauch von goldenen tesserae, mit denen das Gewand, der Thronsessel sowie der nimbus ausgearbeitet sind, lässt Christus weit abrücken vom Bild des schlichten Philosophen. Christus nimmt hier auf dem Thronsessel der Kaiser Platz, der schon einige Jahre später ähnlich dem Kreuz zum Symbolbild

142 Diese Bezeichnung wird hier in Anlehnung an die von Hieronymus benutzte Anredeformen vir omnium nobilium Christianissime, Christianorum nobilissime (Hieron. ep. 57,12,1: Pammachius; vgl. auch Hieron. ep. 129,1,1: Dardanus) bzw. vir disertissimus et Christianissimus (Hieron. c. Ioh. 39: Archelaus) gewählt; vgl. REBENICH (1992) $189 \mathrm{f}$.

143 Die öffentliche Sichtbarkeit der Sarkophage wird immer wieder thematisiert und diskutiert; auszugehen ist aber davon, dass der Grabbau selbst wohl nicht der Öffentlichkeit zugänglich war; vgl. BORG (2010) 235-248, hier 244-248 und bes. DRESKEN-WEILAND (2003) 185-198.

144 Abbildung nach BRANDENBURG ${ }^{3}(2013)$ Abb. 84. Die heute nicht mehr existente Stifterinschrift, die PANVINIO noch festhielt, nennt Innozenz (402-417); vgl. BRANDENBURG ${ }^{3}$ (2013) 154. Für den Bau und die Ausstattung waren die Presbyter Ilicius, Maximus und Leopardus, verantwortlich (Bauinschriften vermauert im Seitenschiff und Mosaik). Zum Bau und seiner Geschichte vgl. MILELLA (1999) 166-168 [LTUR 4]; KRAUTHEIMER, CBCR 3 (1971) 277-302; PETRIGNANI (1934). Zum Vorgängerbau, ein Hallenbau des 2. Jhs., vgl. ADAMS (2013) 172f.; BRANDENBURG ${ }^{3}$ (2013) 145; DOIG (2008) $37 \mathrm{f}$; ZIEGLER (2007) 157; ferner LTUR 5 (1999) 62 und RICHARDSON (1992) 393: „Thermae Novati“. Zur Stiftungslegende (Act. Sanct. Maji IV, 298 und Lib. Pont. 1,132) vgl. SCHAEFER (2013) 18-20, 32 u. 260; i. B. KRÖNUNG (2008) 92-116 und KIRSCH (1918) 149-151. titulus Pudentis: MGH Auct. Ant. XII, 411 (s.a. 499); zuvor bereits ICVR 1, 688 (s. a. 489) und ICVR 1, 3200 (s. a. 384); weitere Belege unter BRANDENBURG ${ }^{3}$ (2013) 145, Anm. 28. Ferner Greg. Magn. ep. 5,57a (titulus sancti Pudentis; s. a. 595). 145 So z. B. BRANDENBURG ${ }^{3}$ (2013) 147-151; BAUER (2004) 189; HEID (2001) 176; EFFENBERGER/ SEVERIN (1992) 31 und EFFENBERGER (1986) 185; ausführlich ENGEMANN (1997) 84ff. und DASSMANN (1970) 67-81. 


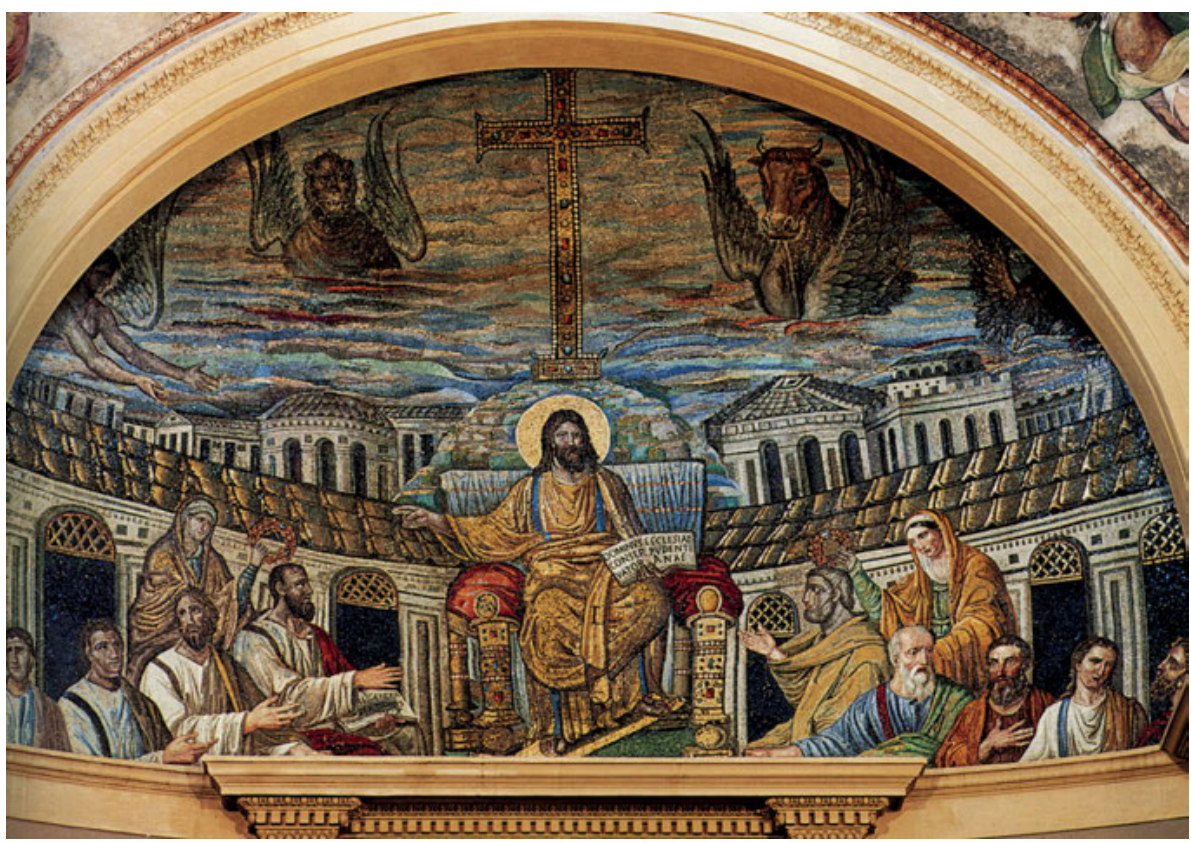

Abb. 31: Apsismosaik von S. Pudenziana.

Christi werden wird. Christus thront hier als Richter über Himmel und Erde, die rechte Hand zur Rede erhoben, womit der Moment der richterlichen Urteilsproklamation gemeint ist. Hinter dem Gemmenthron erhebt sich der Golgatha, auf welchem das goldene Gemmenkreuz in den rötlich-blau eingefärbten Himmel hineinragt. Vergleichbar mit den ,Stadttorsarkophagen' wird die Thronszene auch hier von einer Stadtarchitektur gerahmt. Hinter Arkaden bzw. sechs Toren zeigt sich mit goldenen Dächern das Himmlische Jerusalem der Johannesapokalypse. Dieses sowie die vier apokalyptischen Wesen am Firmament ${ }^{146}$ lassen die gesamte Darstellung zur endzeitlichen Gerichtsszene ${ }^{147}$ werden.

Die Anbindung an das Herrscherbild des Kaisers ${ }^{148}$ wirkte sicherlich reflexiv auf dieses zurück. So dürfte das machtvolle Christusbild auch ein machtvolles Kaiserbild

$146 \mathrm{Zu}$ sehen sind ein geflügelter Mensch, Löwe, Stierkalb und Adler; vgl. Ez 1,10 und Offb 4,7. Sie zeigen die vier Gestalten Christi und kündigen diesen an; Mensch geworden im Menschen, die Majestät im Löwen, die priesterliche Gewalt im Stier und Geist im Adler (nach Iren. Adv. haer. 3,11,8). Es handelt sich hierbei zugleich um die Symbole der vier Evangelisten: Matthäus (Mensch), Markus (Löwe), Lukas (Stier) und Johannes (Adler); vgl. Irenäus ebd., Hieron. com. Mat. 1 und Aug. cons. ev. 1,6,9.

147 Diesen Aspekt betont vor allem WISSKIRCHEN (1998) 178-192.

148 Zur Genese des christlich-imperialen Repräsentationsbilds vgl. ENGEMANN (1983b) 260 - 266. Der frühchristlichen Kunst des 1.-3. Jh. ist eine solche Christus-Darstellung nicht bekannt; hier findet sich vor allem das Bild des „Guten Hirten“, welches sich am ehesten mit Darstellungen des Orpheus ver- 
gestützt und das Vertrauen in die kaiserliche Herrschaft, in welcher sich der Kaiser als vicarius Christi ${ }^{149}$ verstand, gestärkt haben. Zugleich erhält in diesem Christusbild die senatorische Weltordnung ihre göttliche Sanktionierung, denn die Apostel, die den Thronrat Christi bilden, sind in ihrer Funktion und Tracht der Senatsaristokratie nachempfunden. Die fast schon überwältigende Farbigkeit ihrer Gewänder, die teilweise sogar den Purpurstreifen der Senatoren (latus clavus) ${ }^{150} \mathrm{zu}$ erkennen geben, ließ sich so vermutlich nur bei den Angehörigen der Senatsaristokratie beobachten. Im Grunde vollzieht sich damit zu Beginn des 5. Jhs. ein Paradigmenwechsel in der christlichen Ikonographie. Das Christusbild wurde hierbei nicht allein nur zu einem repräsentativen Herrscherbild, in dem sich die Senatoren und der Kaiser wiederfinden konnten, weiterentwickelt. Auch das Erscheinungsbild der Apostel ${ }^{151}$ wurde nun von der Lebenswirklichkeit und dem Auftreten der Senatsaristokratie her gedeutet und definiert. Im Gegenzug präsentiert sich das Christusbild, welches zuvor in der „Lehrversammlung“ noch nahbar war, nun in wachsender Distanz zu den einfachen Gläubigen.

Für die Verschmelzung von himmlischer Sphäre mit dem senatorischen Repräsentationsbild sind einmal mehr auch die Mosaiken von S. Maria Maggiore zu betrachten. ${ }^{152}$ Die Darstellung, die hier besonders Aufmerksamkeit verdient, ist die Darbringung des Christuskindes im Tempel (Abb. 32) ${ }^{153}$. Neben der oft als Simeon ${ }^{154}$ angesprochenen Person, die mit verhüllten Händen Maria und dem göttlichen Kind gebeugt entgegeneilt, empfangen mehrere weißhaarige Personen das Heilige Paar. Diese werden meistens als Priesterschaft ${ }^{155}$ des Jerusalemer Tempels verstanden. Diese tragen

gleichen lässt; hierzu vgl. ZILLING (2015) 139-166 bes. 156f. Zur Ikonographie vgl. z. B. MARKSCHIES (2016) 140f.; ders. (2005) 69-92; PROSCH (2010) 95f. und ENGEMANN (1983a) 257-259. Die Nähe Christus zu Orpheus scheint auch SHA. Sev. Alex. 29,2 zu bestätigen.

149 Zur Selbstauffassung des Kaisers als vicarius Christi seit Konstantin vgl. z. B. REBENICH (2017) 24-30; KOLB (2001) 91-139; BELLEN (1994) und LEEB (1992) 38f. u. 121ff. Zu einer politischen Interpretation der Sakralkunst (allerdings für die Zeit des Heermeisters Ricimer) kommt auch MATHISEN (2009) 308-325, hier 313-317. Zur Ikonographie vgl. auch DECKERS (2001) 3-16.

150 So auch PHILLIPS (2003) 45-52, hier 48.

151 Hier ist auch auf das Hofzeremoniell zu verweisen (hier allerdings aus mittelbyzantinischer Zeit): beim Mahl im sog. 19-Tische-Saal (Decanneacubita) nahmen zwölf Senatoren neben dem Kaiser Platz; hierzu NOETHLICHS (1998b) 44; vgl. allgemein WARLAND (2002a) 64; ausführlich KOSUCH (2011) 85-96; TREITINGER 3(1969) 124ff. [1938] spricht hier sogar von einer „Christomimese“. Seinen Niederschlag findet dies so auch noch bei der Krönung Heinrich II. (1014), der sich auf dem Weg zur Peterskirche von zwölf Senatoren das Geleit geben ließ (nach Thietmar v. Merseburg Chronicon, MGH SS NS IX 396).

152 Vgl. hierzu auch Kap. 3.3.

153 Abbildung nach STEIGERWALD (2016) Abb. 8. vgl. auch BRENK (1975) 19-23.

154 STEIGERWALD (2016) 57-59, gemäß Lk 2,25-35. Dieser Darstellungstyp, i. B. mit verhüllten Händen, findet sich auch auf einen der beiden Säulensarkophage von S. Sebastiano; Rep. I 200; hier ist allerdings Petrus gemeint. STEIGERWALD (2016) 59 gibt hier selbst zu, dass die von ihm als Simeon benannte Person „wie ein Apostel in Sandalen, weißer Tunica oder Dalmatica und weißem Pallium einherschreitet“; nachfolgend auch ebd. $64 \mathrm{f}$.

155 Zuletzt wieder STEIGERWALD (2016) 72-74. 


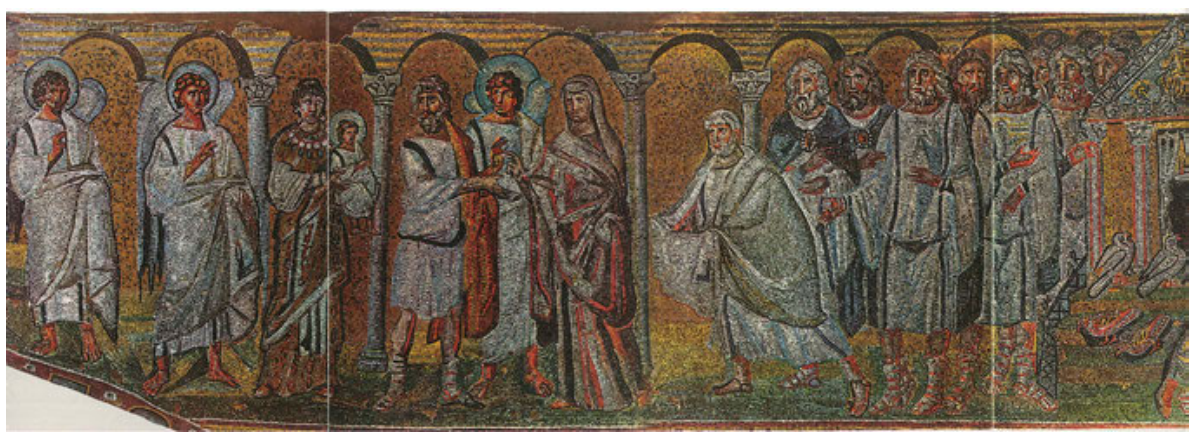

Abb. 32: S. Maria Maggiore: Darbringung des Jesuskindes im Tempel (nach Wilpert 1916).

jedoch, ganz untypisch für Priester, eine weiße dalmatica bzw. tunica, die von purpurnen clavi gesäumt wird, und mit roten Bändern hochgeschnürte Stiefel. Gegen diese Benennung hat sich Warland mit durchaus stichhaltigen Argumenten ausgesprochen. Gerade im Hinblick auf den rechts außen dargestellten Tempel, der in seinem Giebel die Stadtgöttin Roma zeigt und damit wohl den Tempel der Venus und Roma ${ }^{156}$ meint, schlug Warland ein stadtrömisches Empfangskomitee vor, wobei er die entgegeneilende Person als Simon Petrus ${ }^{157}$ benennt. Die untypisch dargestellten „Priesterschaft“ wäre so, gerade auch unter Berücksichtigung ihrer Tracht, als Ansammlung senatorischer Würdenträger ${ }^{158}$ anzusprechen. Diese stünden so in der ersten Reihe des römischen Volkes, ${ }^{159}$ das Christus hier in Empfang nimmt. Damit wurde die Führungsrolle der Senatsaristokratie im Christentum anerkannt.

Auch in den alttestamentarischen Szenen des Langhauses begegnen Figuren, die im senatorischen Habitus wiedergegeben sind. In der Darstellung der Hochzeit des Moses mit Sephora, ${ }^{160}$ die im Typus der dextrarum iunctio ${ }^{161}$ ausgeführt ist, tragen die Männer die toga, das Festgewand der Senatoren. Die Frauen sind gekleidet in die Tracht der aristokratischen bzw. kaiserlichen Damen. Damit wird die Szene in senatsaristokrati-

156 Diese Interpretation teilt auch STEIGERWALD (2016) 65-71.

157 Vgl. WARLAND (2002c) 30 f.; vgl. auch GRABAR (1936) 225 mit Anm. 9. Die Dreiergruppe davor wird dementsprechend mit Joseph, Engel und Hanna benannt; Joseph kommt für die greisenhafte männliche Gestalt rechts nicht in Frage. Die Benennung als Simon Petrus (Simeon) hat auch insofern Bedeutung, als dass hierdurch der Bischof von Rom wenigstens indirekt mit angesprochen ist.

158 Vgl. WARLAND (2002c) 30 spricht hier von einer „Vertretung der Ältesten“. Als Priester könnte die linke Person mit der dunkelblauen lacerna, die von einer ovalen Fibel zusammengehalten wird, anzusprechen sein. Vergleichbar gewandete Personen, die als „Hohepriester“ anzusprechen sind, finden sich z. B. in der Darstellung der Hochzeit des Moses und der Befragung der Magier durch Herodes. 159 Hierzu vgl. auch die Stifterinschrift XYSTVS EPISCOPVS PLEBI DEI (ILCV 976) und Ps.-Mt 15,2. 160 Ex 2,21. Abbildung in BRANDENBURG ${ }^{3}$ (2013) Abb. 127.

161 Anstelle der Concordia oder Venus Gentrix vollzieht hier offenbar ein Priester, wohl Jitro, die Ehe; vgl. DECKERS (1976) 138f. Ikonographische Zeugnisse liefern vor allem die Sarkophage; z. B. der „Annona-Sarkophag“ (ASR I 3 (2006) 216, Kat.-Nr. 82); vgl. auch WREDE (2001) $46 \mathrm{ff}$. 
sche Sphären hineinprojiziert und so zu einer Projektionsfläche senatorischer Elitendistinktion. Ähnlich verhält es sich mit der ikonographischen Umsetzung der Adoption Moses durch die Tochter des Pharaos. ${ }^{162}$ In diesem Fall ist der junge Moses ganz dem Erscheinungsbild junger Aristokraten, die in den höfischen Dienst eintreten, nachempfunden. ${ }^{163}$

Aus derselben Zeit stammen die prachtvollen Holzschnitzereien des Eingangsportals von S. Sabina ${ }^{164}$ auf dem Aventin. An dieser Stelle kann unmöglich auf das gesamte Bildprogramm eingegangen werden. Die Aufmerksamkeit ist hier insbesondere auf ein Bildpanel zu lenken, welches auf ganz exzeptionelle Weise die christliche Weltordnung als Repräsentationsbild mit einer klaren sozialen Hierarchisierung zeigt (Abb. 33) ${ }^{\mathbf{1 6 5}}$. Dieses findet sich an zweiter Stelle im unteren Register der Bildpanele. Vor zwei Türmen, die möglicherweise nur eine Stadtarchitektur angeben sollen, ${ }^{166}$ erhebt sich ein Bau, der aufgrund des Kreuzes auf seinem Dach mit einiger Sicherheit als Kirche anzusprechen ist. Zwischen den Frontsäulen des Baus steht ein Mann in Orantenhaltung, links neben ihm wohl ein Engel. In zwei Registern reihen sich darunter Dreiergruppen von akklamierenden Personen, die ihre Blicke auf den Oranten gerichtet haben. Zusammen mit zwei weiteren Bildpanelen, von welchen das eine Christus, Petrus und Paulus präsentiert und das andere die Parusie darstellt, ${ }^{167}$ gehört die hier angeführte Darstellung zu den wenigen Repräsentationsbildern der Holztür von S. Sabina, die keine biblische Textgrundlage ${ }^{168}$ besitzen.

Aus diesem Grund hat gerade diese Darstellung einige Aufmerksamkeit in der Forschung $^{169}$ gefunden. Insbesondere auf die Tracht der Figuren ist hinzuweisen. So trägt der Orant die chlamys und eine gegürtete langärmlige tunica in Kombination mit Stiefeln. Er ist somit in der Amtskleidung der hohen Zivilbeamten und Militärs wie-

162 Auch Zippora; Ex 2,1-10; Abbildung in BRANDENBURG ${ }^{3}$ (2013) Abb. 131.

163 Hier lässt sich etwa das Diptychon von Monza vergleichen.

164 Die Stifterinschrift (Mosaik ILCV 1778a (1-4) = ICVR 2, 5154) und Lib. Pont. 1,235 nennt auch hier einen Presbyter, Petrus der Illyrer, als Verantwortlichen. Zum Bau, der auf den Grundmauern einer domus aus dem 4. Jh. errichtet wurde, und seiner Gründungslegende vgl. BRANDENBURG ${ }^{3}(2013)$ 185; DIEFENBACH (2007) 354f.; BRENK (2003) 50; ferner KIRSCH (1918) 163-166.

165 Abbildung nach VOLBACH (1958) Abb. 105.

166 Ein baulicher Zusammenhang zwischen dem Gebäude mit Kreuz und den beiden Türmen scheint nicht zu bestehen; vgl. JEREMIAS (1980) 91f.; weist hier zu Recht darauf hin, dass Kirchenbauten mit Doppelturmfassade erst ab dem späten 5. Jh. im Osten (i. B. Syrien) auftreten.

167 Vgl. JEREMIAS (1980) 77-88.

168 Biblische Narrative wie die Verkündigung an Zacharias (Lk 1,5-25; vgl. BRENK (1977) 141) scheiden schon deshalb aus, da hier offenbar eine bestimmte Person porträtiert wurde; vgl. JEREMIAS (1980) 93. Auch aus eigener Begutachtung der Holztür von S. Sabina lässt sich diese Einschätzung bestätigen.

169 Grundlegend zur Holztür von S. Sabina JEREMIAS (1980); ältere Forschungsbeiträge DELBRUECK (1952a) 139-145; WIEGAND (1900); speziell zur hier besprochenen Szene SPIESER (1991) 70f.; DELBRUECK (1949) 215-217 und KANTOROWICZ (1944) 207-231. 


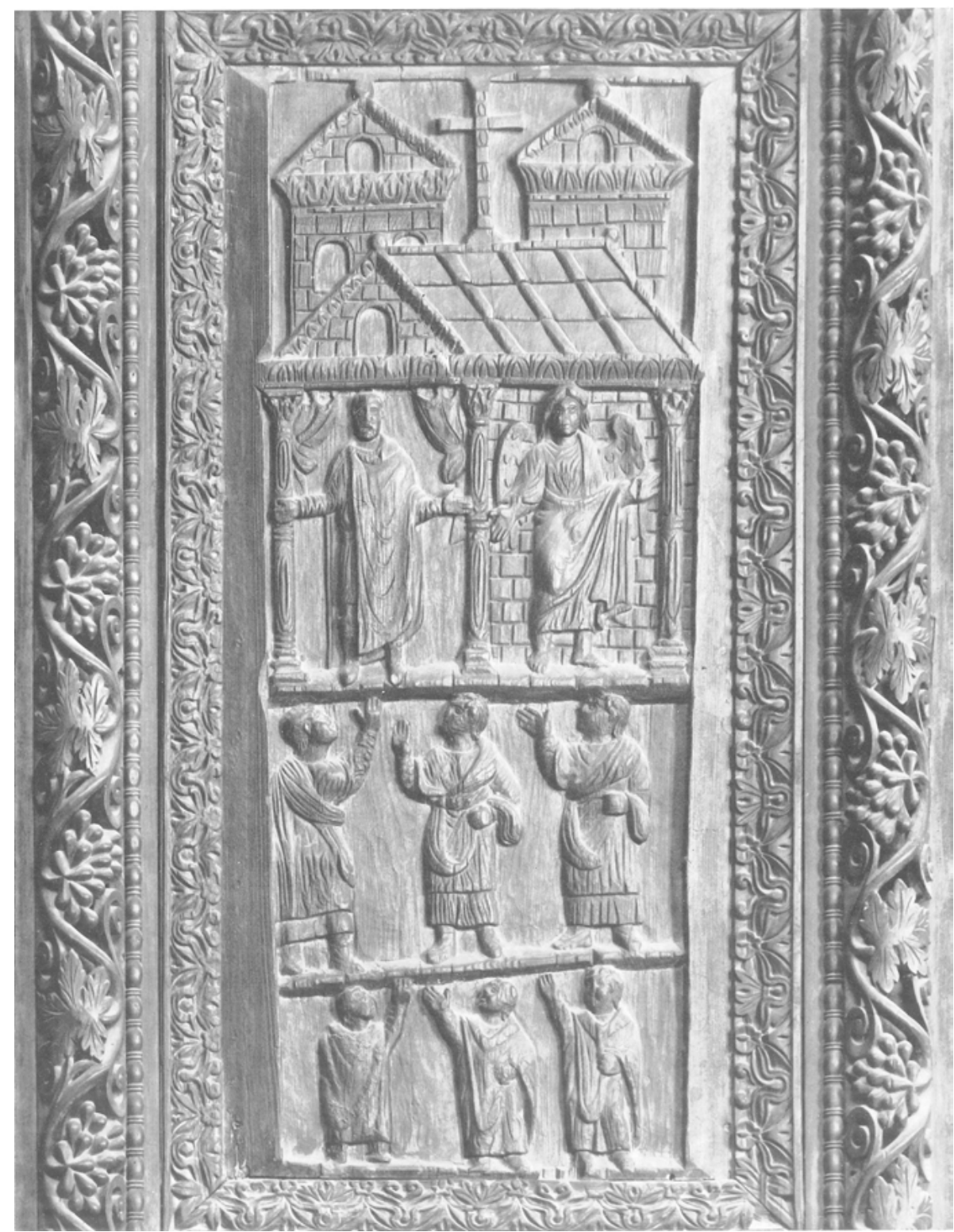

Abb. 33: Panel der Holztür von S. Sabina.

dergegeben. ${ }^{170}$ Auf der Ebene darunter tragen die drei akklamierenden Personen die toga contabulata. Dies und ihr Schuhwerk, der campagus, weisen sie als Senatoren aus.

170 Vgl. hier vor allem das Diptychon des vicarius urbis Romae Rufius Probianus (DELBRUECK Nr. 65; 
Auf der untersten Ebene sind sodann drei Männer im pallium bzw. der paenula, die hier über einer Doppeltunika getragen wird, dargestellt. An den Füßen tragen sie den geschlossenen calceus. Sowohl in der Tracht als auch in ihrer dargestellten Körpergröße und Anordnung sind sie den Senatoren nach- bzw. untergeordnet. Ungeachtet der Frage, welcher Handlungszusammenhang hier zur Darstellung gekommen ist, lässt sich festhalten, dass dieses christliche Repräsentationsbild eine klare gesellschaftliche Hierarchisierung ${ }^{171}$ vorgibt. Abermals wird die Senatsaristokratie in ihrer privilegierten gesellschaftlichen Stellung bestätigt. Sie steht dem Heiligen und Himmlischen am nächsten und ist so dem Oranten und Engel unmittelbar nachgeordnet. Dann folgen erst die palliati, die wohl für einen sozial niedrigeren Stand der Gläubigen, vielleicht sogar für die Geistlichkeit, die das pallium trug, ${ }^{172}$ stehen.

Im christlichen cultus wurde der Senatsaristokratie mit Ausnahme des Priestertums somit der Platz zugestanden, den sie vormals so auch im heidnischen cultus eingenommen hatte. Damit wurde das Christentum wie zuvor schon die paganen Kulte statusbegründend für die Senatsaristokratie, die nunmehr auch christliche Bilder für die eigene religiöse Repräsentation und elitäre Distinktion in Auftrag gab. Die kirchlichen Sakralbilder wiesen der Senatsaristokratie ebenfalls einen exponierten Platz zu. Auch im Gottesdienst ${ }^{173}$ und in christlichen Prozessionen ${ }^{174}$ zeigte sich die elitäre Stellung der Senatsaristokratie. Hier öffnet sich der kirchliche Raum, der in seinem architektonischen Aufbau ohnehin hierarchisch gegliedert war, ${ }^{175}$ für die senatsaristokratische Repräsentation und Distinktion.

VOLBACH Nr 62). Die akklamierenden Personen unter dem Oranten erinnern in ihrer Gestaltung an die Zweiergruppe von chlamydati und togati, die den vicarius Ruf. Probianus anrufen; dies ist evtl. auch für die Datierung des Diptychons ins 5. Jh. (Probianus PVR 416) relevant. Dieses Problem erkennt auch JEREMIAS (1980) 94f., spricht sich aber dennoch dafür aus, hier einen Kleriker, und zwar Petrus von Illyrien, zu sehen; so auch schon der Vorschlag von KLAUSER, Engel. RAC 5 (1962) 267 u. 309. DELBRUECK (1949) 215 ff. plädierte hier für Theodosius II. JEREMIAS (1980) 93. KANTOROWICZ (1944) 223 bezog die Darstellung auf Mal. 3,1f.

171 Hierauf kommt auch kurz JEREMIAS (1980) 92f. zu sprechen.

172 Vgl. Tert. pall. 5,7ff.; vgl. hierzu auch PIETZNER (2013) 52f. u. 87 ff.; EWALD (1999) 14-16; HYLDAHL (1966) 104-106. Noch heute existiert ein päpstliches Amtsabzeichen (getragen und verliehen) mit dem Namen pallium (griech. Omophorion), welches als eine Art Stola über dem Messgewand getragen wird; vgl. BRAUN (1907) 620 - 670.

173 In Paul. Nol. ep. 13,11 ist die Rede davon, dass anlässlich eines Gedächtnismals in St. Peter die Versammelten ihrem Rang nach Platziert wurden.

174 An dieser Stelle sei auch auf die Trierer Elfenbeintafel mit Darstellung einer Reliquientranslation hingewiesen; DELBRUECK (1929) Nr. 67 und VOLBACH 2(1952) Nr. 143. Da sich, angefangen bei der Datierung (5. Jh./9. Jh.) und der Ereignisdarstellung, zu viele offene Forschungsprobleme mit diesem Stück verbinden, wird auf eine Betrachtung und Besprechung hier verzichtet; vgl. hierzu u. a. WEBER (1979) 135-151; HOLUM/VIKAN (1979) 113-133; und aktuell NIEWÖHNER (2014) 261-288.

175 Vgl. hierzu knapp HAUG (2012) 130 f. mit Anm. 75 (allerdings in Bezug auf die Repräsentation des Klerus). 


\subsection{Die senatorischen Kirchenstiftungen - soli deo gloriam?}

Bis in die jüngste Zeit hat die Bedeutung der Kirchenstiftungen der ersten Hälfte des 5. Jhs. im Kontext der senatorischen Bautätigkeit und Repräsentation eher wenig Beachtung gefunden. Vor allem die Kaiser und die Bischöfe von Rom stehen hier stärker im Fokus. ${ }^{176}$ Pietri hatte diesbezüglich schon 1976 auf die tragende Bedeutung der Senatsaristokratie bei der Christianisierung der stadtrömischen Topographie hingewiesen. ${ }^{177}$ Hierzu lässt sich auf den Liber Pontificalis ${ }^{178}$ verweisen, der insbesondere unter den Pontifikaten von Damasus, Siricius, Innozenz, Coelestin, Sixtus III. und Leo, also in einer Zeitspanne von 366 bis 461, zahlreiche Kirchenstiftungen anführt, an welchen sich direkt oder wenigstens indirekt eine senatorische Beteiligung feststellen lässt. Hinzu kommen die epigraphischen Zeugnisse und insbesondere der archäologische Befund.

Unter Innozenz (402-417) entsteht zwischen Quirinal und Viminal, ursprünglich zur Verehrung des Gervasius und Protasius, die Kirche S. Vitale (titulus Vestinae). ${ }^{179}$ Dem Liber Pontificalis zufolge finanzierte die inlustris femina Vestina ${ }^{180}$ diesen Bau. Die Gelder hierfür wurden testamentarisch der Kirche angewiesen. Die Bauaufsicht führten der Diakon Livianus sowie die Presbyter Ursicinus und Leopardus. Letzterer war schon für die Errichtung von S. Pudenziana verantwortlich. Hier wird klar, dass zwar die Kleriker als Bauherren und auch als Vermögensverwalter und Testamentsvollstrecker fungierten, aber nicht als Finanziers und Stifter. Diese Ehre stand der verstorbenen inlustris femina $\mathrm{zu}$, die dem titulus ${ }^{181}$ auch ihren Namen gab. Die Stiftungsliste ${ }^{182}$ führt

176 Vgl. BEHRWALD (2009) 144-146; unter 134-139 (senatorische Stiftertätigkeit?) wird dies nicht angesprochen; ders. (2016) 163-176 holt dies nach, allerdings ohne den archäologischen Befund genauer zu betrachten; nur 5 von 16 Fallbeispiele betreffen den Senatorenstand. BRANDENBURG ${ }^{3}(2013)$ konzentriert sich vor allem auf die kaiserlichen und päpstlichen Kirchenbauten. MULRYAN (2014) fokussiert sehr stark auf die Rolle des Bischofs von Rom.

177 Vgl. PIETRI (1976) 461- 573; nachfolgend DUVAL/PIETRI (1997) 371-396; LIZZI TESTA (2004) 105114. Vgl. auch BEHRWALD (2016) 163 mit Anm. 3 für weitere Literatur. PIETRI (2002) 253-263 betont hingegen die Dominanz des Bischofs von Rom.

178 Eine Auflistung - wenn auch z. T. unvollständig - findet sich bei HILLNER (2006) 50 -68, hier 59 mit Anm. 1; WARD-PERKINS (1984) 239-241 und MERRIMAN (1975) 309-319.

179 Vgl. zur Kirche BRANDENBURG ${ }^{3}$ (2013) 163f. und KRAUTHEIMER, CBCR 4 (1976) 299-316. Zur Märtyrerverehrung in Rom vgl. BERGJAN/NÄF (2014) 112-119 und DIEFENBACH (2007) 215- 403.

180 Lib. Pont. 1,220: eodem temmpore dedicavit [Innocens] basilicam sanctorum Gervasi et Protasi ex devotione cuiusdam inlustris feminae Vestinae, laborantibus presbiteris Ursicino et Leopardo et diacono Liviano. Quae femina suprascripta testamenti paginam sic ordinavit ut basilica sanctorum martyrum ex ornamentis et margaritis construeretur, venditis iustis extimationibus. Zur Stiftung vgl. MACHADO (2019) 193f.; HILLNER (2007) 225 - 261, hier 227 u. 231 f. und dies. (2004) 20 f. (mit Übersetzung). Der Vorschlag von MULRYAN (2014) 17 hier einen Ankauf durch den Bischof von Rom zu sehen, lässt sich nicht zustimmen; vgl. hier auch HILLNER, Rez. BJ 215 (2016) 580f. Zur Heiligenverehrung vgl. DIEFENBACH (2007) 338-342 und zur „Privatisierung“ der Märtyrer- und Reliquienverehrung BROWN (1991) $42 \mathrm{f}$. 181 Zum Begriff des titulus im Zusammenhang mit der Besitzübertragung vgl. DIEFENBACH (2007) 331f. mit Anm. 7; grundlegend PIETRI (1976) 90-96 u. 569-573; ferner MULRYAN (2014) 8-24; 
unter anderen eine domus mit einer Empfangshalle (iuxta basilicam), eine Badeanlage (balneum) und eine Bäckerei (pistrina) im vicus Longus auf, die dem Kirchenbau angewiesen wurden. Vermutlich diente das Stadthaus der Vestina als Baugrund der Kirche, wie dies auch Diefenbach und Hillner ${ }^{183}$ annehmen. Dazu wurden dem titulus Pachteinkünfte ${ }^{184}$ aus den Zöllen der Porta Nomentana, die zuvor der Vestina zugeflossen waren, zugewiesen. Pachtrechte und Betriebe, die vormals die Dominanz des Hauses der Vestina in der Regio VI ausmachten, wurden auf den titulus übertragen. Damit übernahm dieser im Grunde die Aufgabe und Bedeutung des senatorischen Hauses.

Besonders interessant ist die Reliquienstiftung. Die Gebeine der Hll. Gervasius und Protasius sollen von Ambrosius von Mailand nach einem Traum am Ort der Basilika der Hll. Narbo und Felix aufgefunden worden sein, worauf sie nach ihrer Wiederentdeckung am 17. Juni 386 in die spätere Kirche S. Ambrogio (Basilika Ambrosiana) überführt wurden. ${ }^{185}$ An Partikeln dieser Reliquien kann Vestina nur über den Kontakt mit Ambrosius von Mailand gelangt sein. Möglicherweise war sie die Gemahlin eines hohen Amtsträgers am Mailänder Hof, vielleicht eines praefectus praetorio der 380er- /390erJahre, ${ }^{186}$ oder aber Mitglied eines stadtrömischen Aristokratenzirkels, der dem Bischof von Mailand nahestand. Reliquien verschafften der christlichen Aristokratie nicht nur persönliches Prestige, ${ }^{187}$ sie statteten ein senatorisches Haus mit einer Aura der Heiligkeit aus. Wenngleich im Liber Pontificalis nichts davon steht, was post mortem mit der Stifterin geschehen ist, lässt sich annehmen, dass auch im Tode eine besondere Nähe zum Heiligen gesucht wurde. So darf vermutet werden, dass die Kirche des titulus Vestinae auch als Memorialbau für die Stifterin gedacht war, wodurch diese auch im Tod hoffen konnte, Anteil an der Heiligkeit der Reliquien und ihrer Verehrung zu haben. ${ }^{188}$

HILLNER (2006) 60 - 62 und GUIDOBALDI (1989) 383-385. Die Zahl der Titelkirchen im 4./5. Jh. wird abweichend angegeben. Die Synodalliste von 499 nennt 29 tituli; SAXER (2001) 554f. zählt mit Verweis auf den Liber Pontificalis und die Stationsliturgie unter Hilarius (461-468) 25 tituli; GUIDOBALDI (1989) 386-391 geht von 29 tituli aus.

182 Lib. Pont. 1,220-222.

183 Vgl. DIEFENBACH (2007) 399 mit Anm. 143 und HILLNER (2004) 185-187 u. 289 (hier auch zu den übrigen Immobilien); vgl. auch MACHADO (2019) 194-196 u. 261 f. Zur Residenz der Vestina vgl. auch CHAMPLIN (1993) 51-59, hier 58f. und PALMER (1974) 113-159, hier 152f.

184 Hierzu HILLNER (2004) 185 und PALMER (1980) 217-233, hier 221.

185 Vgl. Ambr. ep. 10,77 u. 22,2; Aug. conf. 9,7,16 u. Aug. Civ. Dei 22,8 und Paul. Vit. Ambr. 32f.; hierzu u. a. GEMEINHARDT (2014) 91 u. 170; DIEFENBACH (2007) 297-299 u. 362; VOLP (2002) 116-118; KÜHNE (2000) 521f. u. 531f.; DASSMANN (1976) 49-68 und KÖTTING (1965) 19-29.

186 Über die Besitzungen eine Verbindung mit der Familie des Q. Valerius Vegetus (Cos. 112) herzustellen, bleibt rein spekulativ und kann nicht bewiesen werden; der große zeitliche Abstand macht eine familiäre Kontinuität eher unwahrscheinlich; so der Vorschlag PALMER (1974) 146-154; nachfolgend CHAMPLIN (1993) 58f.; zu Namensträgern aus dem Senatorenstand der Republik und Kaiserzeit vgl. KAJANTO (1965) 186.

187 Ein weiteres Beispiel wäre die Stiftung des Faltonius Adelfius und der Anicia Italica an die Lateranbasilika CIL 6, 41392 (a. 451); vgl. u. a. BEHRWALD (2016) 167.

188 So schon die Intention Konstantins d. Gr. bei der Errichtung der Apostelkirche (Euseb. vit. Const. 4,71). Beispiele aus dem Kreis der Senatsaristokratie überliefern Vit. Mel. 57 u. 69 und Soz. 9,2,1-15; 
Ähnlich verhält es sich mit der Stiftung des Pammachius, der Basilika von SS. Giovanni e Paolo (titulus Pammachii) ${ }^{189}$ am Clivus Scauri. Diese erfolgte vermutlich ebenfalls aus dem Nachlass eines Senators heraus, der wohl auch für die Ausstattung der Kirche mit Reliquien sorgte und sich hier für seine Person einen Erinnerungsort schuf. Die Umstände der Stiftung werden besser greifbar, da zum einen der Stifter selbst kein Unbekannter ist und zum anderen die Kirche und ihre Bauparzelle zusammen mit den Vorgängerbauten relativ gut eingesehen werden können. Pammachius ${ }^{190}$ gehörte zur gens Furia. Vermählt mit Paulina, einer Tochter der Paula und des Toxotius, war er familiär mit zwei der wichtigsten christlich-senatorischen Häuser Roms, den Valerii und Caeionii-Rufii, verbunden. Darüber hinaus pflegte Pammachius enge freundschaftliche Bande zu Hieronymus. ${ }^{191}$ Bis zum Ableben seiner Gattin Paulina im Jahr 397 kam Pammachius seinen senatorischen Verpflichtungen nach und bekleidete das Amt eines Prokonsuls (Africae?). ${ }^{192}$ Auch an den Senatssitzungen nahm er regelmäßig teil. Höhere Ambitionen entwickelte Pammachius aber nicht. Nach dem Ableben seiner Frau lag die Schwerpunktsetzung seines Lebens und Wirkens auf christlich-karitativen Werken. Aufsehen erregte er damit, dass er sein Bekenntnis ostentativ zur Schau trug und sich damit von den senatorischen Traditionen und Verhaltensmustern entfernte. So heißt es bei Hieronymus, Pammachius sei im Senat statt in der weißen purpurgesäumten toga in einer dunklen, der toga pulla, aufgetreten. ${ }^{193}$ Wo früher die Tore seines Hauses aufwartende Klienten hervorbrachten, werden diese nun von Scharen der Armen und

ferner auch Ambr. exc. Sat. 1 u. 2. Hierzu vgl. BIERMANN (1995) 24-43ff.; knapp DASSMANN (2004) 53-58; ders. (1976) 54; BROWN (1991) 36 u. 44f.; SCHMITZ (1975) 249-251 und KÖTTING (1965) 27. BROWN (1991) 42f. spricht von der „Privatisierung“ des Heiligen.

189 So noch 499 titulus Byzantis et Pammachii; nachfolgend titulus Pammachii sanctorum Iohannis et Pauli (Lib. Pont. 1,510; vgl. auch 1,236; 261 u. 265) und 595 titulus sanctorum Iohannis et Pauli (Greg. Magn. ep. 5,57a); zur Namensgeschichte vgl. BRANDENBURG ${ }^{3}(2013)$ 165f. und DIEFENBACH (2007) $355 \mathrm{f}$.

190 Zur Person PLRE 1, 663; ausführlicher FÜRST (2016) 223f.; LETSCH-BRUNNER (1997) 23ff. u. $77 \mathrm{ff}$. und REBENICH (1992) 23f., 184 u. 199-201; Angezweifelt u. a. von KRÖNUNG (2008) 31-62; BRENK (2003) 110f. und PETERSEN (1975) 443-448. MACHADO (2019) 194f.; BEHRWALD 2016, 168f.; BRANDENBURG $^{3}$ (2013) 165 und DIEFENBACH (2007) 355-357 sprechen sich für eine Gleichsetzung des Stifters mit Pammachius, dem Briefpartner des Hieronymus, aus und führen hierfür durchaus überzeigende Gründe an. Es ist hier vor allem darauf hinzuweisen, dass kein weiterer Pammachius bekannt ist. Den Vorschlag HILLNER (2006) 62f. (Presbyter, Aug. grat. Christ. 2,3,3: jedoch mit dem Briefpartner des Hieronymus identisch) weist BEHRWALD zurück.

191 Bezeichnend die Huldigungsformeln: Christianorum nobilissime (Hieron. ep. 57,12,1); zusammen wurden sie von dem Grammatiker Donat in Rom ausgebildet (Hieron. ep. 49,1); die Briefe 48, 49, 57, 66, 83, 84 u. 97 sind an ihn gerichtet; die Kommentare In Osee, In Amos, In Ioelem, In Ionam und In Abdiam ihm gewidmet.

192 Vgl. Pall. Laus. 62 und Hieron. ep. 66,7; vgl. LETSCH-BRUNNER (1997) 188 Anm. 89 und JANNACCONE (1966) 32-48, hier 43; eine besondere Verbindung zu Nordafrika hält auch Aug. ep. 58,1 fest. 193 Vgl. Hieron. ep. 66,6; allgemein zum Charakter dieses Briefes vgl. TORNAU (2006) 101-105. Das in Bezug auf diese Stelle wiedergegebene Bild des Senators im „Mönchsgewand“ ist wohl etwas zu drastisch; möglicherweise wurde hier nur ein Trauergewand getragen. 
Kranken belagert. ${ }^{194}$ Noch vor seinem Tod gründete Pammachius zusammen mit Fabiola in Portus ein xenodochium. ${ }^{195}$

SS. Giovanni e Paolo wurde ebenfalls unter Innozenz gegründet. Eine Grabinschrift dieser Zeit nennt einen titulus Vizantis, ${ }^{196}$ der mit der Kirchenstiftung des Pammachius identisch $^{197} \mathrm{zu}$ sein scheint. Demnach war an der Kirchenstiftung noch eine weitere Person, ein gewisser Byzantius, ${ }^{198}$ beteiligt. Einige Forscher ${ }^{199}$ sehen in diesem Byzantius den Vater des Pammachius, was zwar nicht abwegig ist, aber letztlich in Ermangelung von Belegen offenbleiben muss. Spätestens in der Zeit Leos d. Gr. ist es jedoch Pammachius, dem die Gründung des titulus als cultor fidei angerechnet wurde. ${ }^{200}$ Von Bedeutung ist hierbei auch der Vorgängerbau, der ein senatorisches Stadthaus war, ${ }^{201}$ welches in seinen ältesten Baustrukturen bis in das 1. Jh. n.Chr. zurückreicht. Ursprünglich handelte es sich hierbei um drei Wohnparzellen, ${ }^{202} \mathrm{zu}$ welchen auch Verkaufs und Lagerräume gehörten, die zu Beginn des 4. Jhs. zusammengelegt und zu einer luxuriösen Residenz umgestaltet wurden. ${ }^{203}$ Deutlichster Ausdruck des gesteigerten Wohn- und Repräsentationsanspruchs ${ }^{204}$ waren die qualitativ hochwertigen Mosaiken und Wandfresken, eine Badeanlage ${ }^{205}$ sowie der im 4. Jh. gestaltete Hof und Garten mit zwei Nymphäen. Die qualitätsvollen Fresken zeigen primär pagane Bildmotive. ${ }^{206}$ So findet sich am Nymphäum eine Darstellung von Göttergestalten in einer maritimen

194 Vgl. Hieron. ep. 66,5 (in Anlehnung an Verg. Georg. 2,462). Dass sich Pammachius in seiner Überzeugung und seinem religiösen Eifer vom Verhalten seiner Standesgenossen absonderte, hält so auch Aug. ep. 58,3 fest.

195 Vgl. Hieron. ep. 66,11,1. Vgl. MACHADO (2019) 188 und ders. (2011) $493 \mathrm{f}$.

196 ICVR 5, 13122.

197 Dies ergibt sich aus der Doppelbezeichnung von 499: titulus Byzantis et Pammachii (MGH AA XII 411f.) und der Verbindung mit der Stiftungslegende; doch dies ist nicht unumstritten; vgl. BRENK (2003) 111.; ferner PETERSEN (1975) 443-448.

198 Weitere Namensvariationen gibt KIRSCH (1918) 29f. an: Byzas (Bizas, Byzans, Vizantius).

199 U. a. LEYSER (2007) 140 - 162, hier $141 \mathrm{ff}$.

200 Vgl. ICVR 2, 150 Nr. 20: [...] QVIS TANTAS CHRISTO VENERANDAS CONDITIT AEDIS / SI QVAERIS: CVLTOR PAMMACHIVS FIDEI; ursprünglich über dem Eingang der Kirche. Vgl. mit der kompletten Inschrift BEHRWALD (2016) $168 \mathrm{f}$.

201 Plan in BRENK (2003) Fig. 139.

202 So die Einteilung KRAUTHEIMER, CBCR 1 (1937) 256-300: sog. residenza privata und zwei Botteghe/Apartmenthäuser (eins unter dem Mittelschiff der Kirche und eins unter dem östlichen Teil des Mittelschiffs).

203 Zur Baugeschichte vgl. BRANDENBURG 32(2013) 166-172; BRENK (2003) 82-97 und ders. (2000) 156f. mit der dort angegebenen älteren Literatur. Speziell zur Umgestaltung jetzt auch PALAZZO/ PAVOLINI (2014b) 189-194.

204 Neben den Beiträgen BRANDENBURGs und BRENKs vgl. auch CROOK (2000) $44 \mathrm{f}$. und ferner COLINI (1944) 164-175 und KRAUTHEIMER, CBCR 1 (1937) 274-281 u. 290. Aktuell vgl. ENGLEN (2014) 189-295 (Beiträge ANDREOLI u. a.).

205 Hierzu COLINI (1944) 166-168 und GASDÍA (1937) 460-474 mit Fig. 48 und 97.

206 Hierzu ausführlich BRENK (2003) 87-97; SANTOLINI (2002) 14-25 und MIELSCH (1978) 151-207, hier 158-165; mit farbigem Bildmaterial BRANDENBURG ${ }^{3}$ (2013) 166-169. Zur Datierung der Malerei vgl. BRENK (2003) 91f. und MIELSCH (1978) 158 und 163. 
Szenerie, umgeben von Eroten in kleinen Schiffchen. In einem weiteren Saal zeigen sich Girlanden tragende Genien, zwischen welchen verschiedene Vögel positioniert sind. In einem anderen Raum, der als Aula dell'Orante benannt ist, findet sich eine Orantin, die nicht unbedingt christlich ${ }^{207} \mathrm{zu}$ deuten ist.

Es lässt sich festhalten, dass zu Beginn des 4. Jhs. die Immobilie zu einem repräsentativen Stadthaus umgestaltet wurde, wobei aber dessen Ausstattungselemente und Dekor nicht gerade auf einen christlichen Besitzer oder einen christlichen Kult schließen lässt. Dies aber ändert sich noch in der zweiten Hälfte des 4. Jhs. ${ }^{208}$ Über einem Gewölbe, auf halber Höhe der Treppe wurde eine kleine „Kapelle“ (Abb. 34) ${ }^{209}$ eingerichtet, die über ihre Wanddekoration eindeutig als christlicher Gebetsraum (oratorium) $\mathrm{zu}$ identifizieren ist. Auffällig ist die bescheidene Dimensionierung des Raums (1,21 x 1,10 m), die im Grunde nur einer einzelnen Person ausreichend Platz bot, und so von Brenk als ein ,intimer Raum“210 charakterisiert wurde. Völlig zu Recht wies daran anknüpfend Diefenbach darauf hin, dass dieser Gebetsraum gerade gegenüber den großzügig bemessenen Repräsentationsräumen des Erdgeschosses in einem auffälligen Kontrast steht. Statt einer öffentlichkeitswirksamen Präsentation des Kultraumes erfolgt hier ein „programmatischer Rückzug“211 vom öffentlichen Bereich des Hauses.

Diefenbach misst dem aber etwas zu viel innovatives Gewicht zu. So ist dahingestellt, ob der Wunsch nach religiöser Zurückgezogenheit und Intimität tatsächlich eine Innovation ${ }^{212}$ darstellt, die mit der asketischen Religionsausübung zusammenhängt. Dagegen währe einzuwenden, dass die Verehrung der lares, genii und penates am Hausaltar (lararium) ${ }^{213}$ einen vergleichbaren Charakter (sacra privata) ${ }^{214}$ besaß. Der Übergang zu einer öffentlichkeitswirksamen Religionsausübung ist in beiden Fällen dennoch gegeben. Im Fall der lares, penates und genii geschah dies im Zuge von Pro-

207 So u. a. noch HOLLOWAY (2004) 62-67; TRINCI CECCHELLI (1978) 551-562, hier 560; KRAUTHEIMER, CBCR 1 (1937) 281; KIRSCH (1918) 29 und WILPERT (1916) Bd. 2, 635; vgl. auch ders. (1937). Gegen eine christliche Deutung sprachen sich i. B. DIEFENBACH (2007) 379f.; BRENK (2003) 93-97; SANTOLINI (2002) 23f. und MIELSCH (1978) 161f. aus. Ein Philosoph und zahlreiche Theatermasken nebst bukolischen Motiven sind hier ebenfalls zu sehen.

208 Hierzu vgl. aktuell auch PALAZZO/PAVOLINI (2014a) 280 - 284 und der nachfolgende Beitrag von RANUCCI ebd. 315 - 327; knapp CROOK (2000) 45- 47.

209 Abbildung nach CROOK (2000) Fig. 8; überarbeitet mit eigener Beschriftung; vgl. aber auch die detailreichere Darstellung bei BRENK (2003) Fig. 142 (BRENK nach GASDÍA).

210 BRENK (2003) $102 \mathrm{f}$.

211 DIEFENBACH (2007) $381 \mathrm{f}$.

212 So DIEFENBACH (2007) 383f. u. 389.

213 Diese Verbindung sieht bereits BRENK (2003) 98. DIEFENBACH (2007) 388f. widerspricht dem aber und betont den öffentlicheren Charakter der Lararien, sacela und aediculae, die bevorzugt auf Peristyl und Gartenanlage ausgerichtet waren (FOSS 1997, 207-216). Dem archäologischen Befund kann hier nicht widersprochen werden, allerdings ist zu berücksichtigen, dass Häuser mit Peristyl und Garten keinesfalls die Regel waren; vgl. HILLNER (2004) 3f.; NIQUET (2000) 31 und GUIDOBALDI (1999a) 56. Vgl. zu den Lararien jetzt auch MIELSCH (2016) 73-81.

214 Von einer privaten Verehrung geht so offensichtlich auch SHA. Sev. Alex. 29,2 aus; hier zur Charakterisierung des Severus Alexander. 


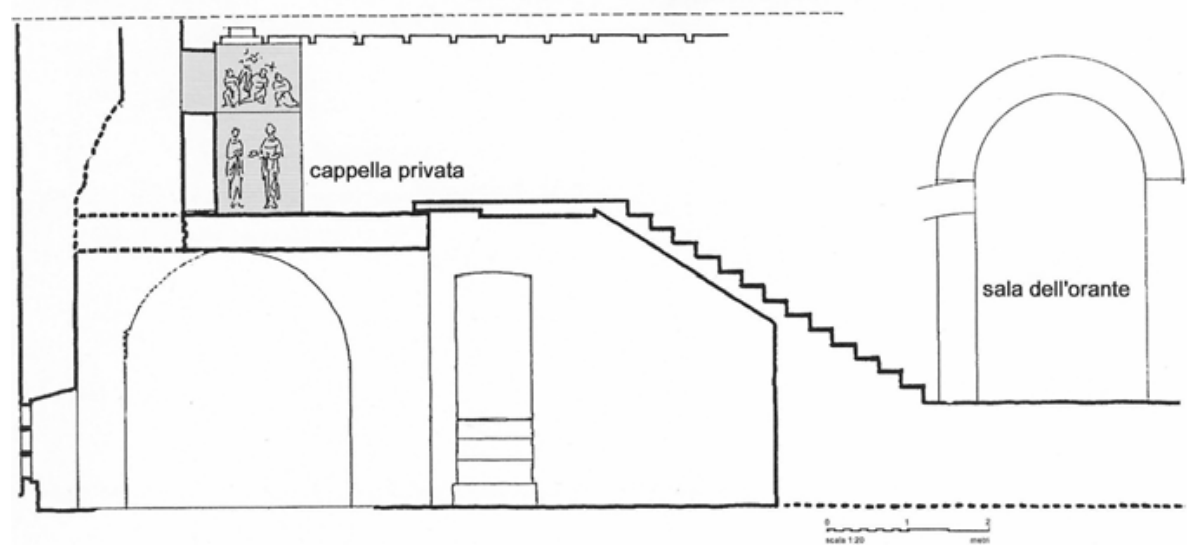

Abb. 34: Aufriss mit räumlicher Disposition der „Kapelle“ unter SS. Giovanni e Paolo (nach Brenk 2003).

zessionen anlässlich von Geburten, Adoptionen, Eheschließungen, Bestattungen und Gedächtnisfeiern. ${ }^{215}$ Die Bilder und Reliquien von Heiligen dürften an eben diese Stelle getreten sein. Dass eben dieses öffentliche zur Schau stellen den kirchlichen Autoritäten nicht recht war, scheint der wiederholte Appell des Hieronymus zu belegen: „Gehe nur selten in die Öffentlichkeit, suche die Märtyrer in deiner Kammer“216.

Aufsehen erregte vor allem ein Durchbruch (fenestella?) an der Rückwand der Kammer, weswegen der Raum lange Zeit als confessio ${ }^{217}$ gedeutet wurde. Brenk konnte zwar glaubhaft aufzeigen, dass es sich hier ursprünglich nicht um eine Öffnung, sondern um eine zugemauerte Nische handelte. ${ }^{218}$ An dem Umstand, dass in diesem oratorium höchstwahrscheinlich Reliquien verehrt wurden, ${ }^{219}$ ändert diese Feststellung

215 Hiergegen richtet sich noch Prud. C. Symm. 1,201ff. u. 2,444f.; vgl. auch Macr. Sat. 1,7,34f. u. 1,10,10. Nach CTh. 16,10,12 (a. 392) ist auch diese Kultpraxis verboten und wird mit Enteignung des Hauses belegt.

216 Der Aufruf richtet sich allerdings primär an Frauen: Hieron ep. 22,17: rarus sit egressus in publicum: martyres tibi quaerantur in cubiculo tuo (hier an Eustochium gerichtet); vgl. auch Hieron. ep. 22,25; Hieron. ep. 54,14 (an Furia), Hieron. ep. 107,7 (an Laeta) und Hieron. ep. 128,4 (an Pacatula). Hierzu vgl. mit weiteren Beispielen jetzt auch LANGE (2016) 139-141; SESSA (2012) 263- 271 und dies. (2007) 171204, hier 182f. Allgemein zur Kritik vgl. BROWN (1991) 36-40.

217 So seit der ersten Publikation DI STANISLAO (1894) 313-340; nachfolgend; KRAUTHEIMER, CBCR 1 (1937) 282 u. 293; COLINI (1944) 180f.; GASDÍA (1937) 485-535 und WILPERT (1916) 643; ausführlicher ders. (1937).

218 Vgl. BRENK (2003) 98f.; folgend BRANDENBURG ${ }^{3}(2013) 168$.

219 Auch BRENK (2003) 99f. u. 102; DIEFENBACH (2007) 356f. und BRANDENBURG ${ }^{3}$ (2013) 168 halten daran fest. Der entscheidende Unterschied besteht lediglich darin, dass es sich hierbei nicht um eine Grablege mit fenestella handelt. Solche Reliquien konnten auch materielle Hinterlassenschaften sein (wie z. B. die Ketten Petri), womit sich das Problem einer innerstädtischen bzw. häuslichen Bestattung erübrigte. 

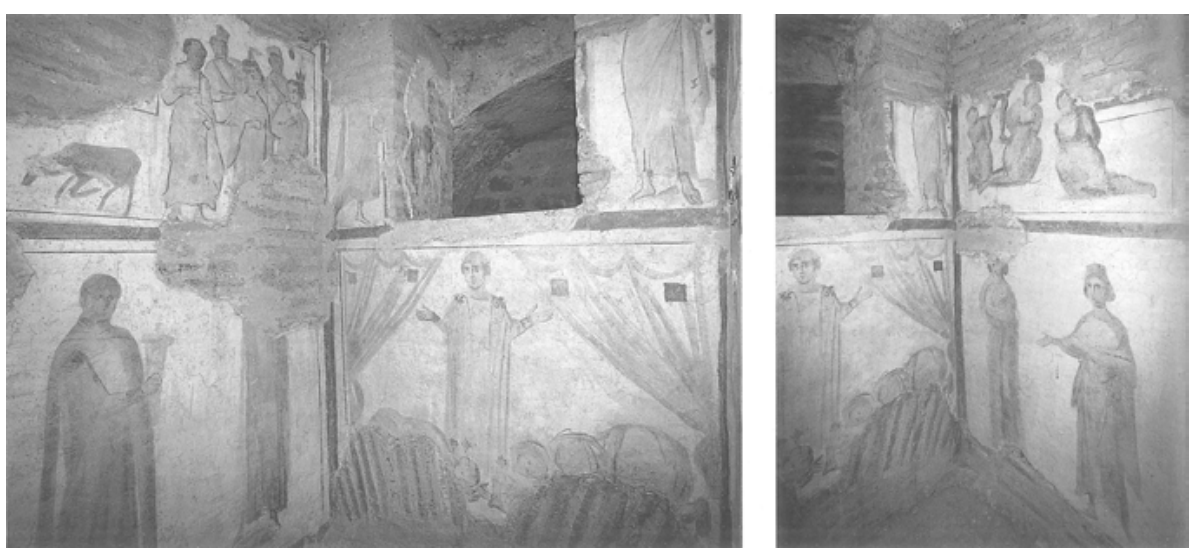

Abb. 35: Oratorium unter SS. Giovanni e Paolo, Rom (Brandenburg 2013).

aber nichts. Erhebliche Probleme bereitet jedoch die Frage, welche Reliquien und Heiligen bzw. Märtyrer hier verehrt wurden.

Direkt unter der Nische befindet sich die Darstellung eines Oranten zwischen einem zurückgezogenen Vorhang (Abb. 35) 220 , zu dessen Füßen links eine männliche und rechts eine weibliche Gestalt ${ }^{221}$ in Proskynese zu sehen sind. Diese sind sicherlich als das Stifterpaar ${ }^{222}$ anzusprechen. Der untere Bildfries der rechten Raumseite ist sodann der femina gewidmet und zeigt zwei vornehme Damen. Die gegenüberliegende Seite zeigt entsprechend zwei chlamydati, von welchen einer als Votivgabe einen Kelch mitführt. Vermutlich sind hier Angehörige des Hauses dargestellt, die in einer Prozession die familiäre Kultgemeinschaft versinnbildlichen. Gerade in dieser Darstellung wird deutlich, dass der Kultus selbst nicht ganz so intim zu denken ist, wie dies die räumlicharchitektonischen Spezifika des oratorium nahelegen. Der Orant müsste aufgrund seiner Tracht ein Heiliger bzw. Märtyrer sein. Christus wird für gewöhnlich im Pallium, nicht aber in langärmliger tunica und ärmellosem colobium ${ }^{223}$ dargestellt. Noch mehr Rätsel geben die Bildszenen in der Oberzone des Raums auf. Die linke Wandseite (Nordwand) zeigt die Gefangennahme ${ }^{224}$ zweier Männer und einer Frau. Hinter ihnen stehen zwei

220 Abbildung nach BRANDENBURG ${ }^{3}$ (2013a) Abb. 102 u. 103.

221 BRANDENBURG ${ }^{3}$ (2013a) spricht seltsamerweise von zwei Frauen; wobei - soweit sich dies noch erkennen lässt - nur die rechte Person mit verhülltem Haupt dargestellt ist; in Analogie zur linken und rechten Wand, wo in der unteren Bildebene beide Geschlechter getrennt sind (links Männer, rechts Frauen; hier spricht BRANDENBURG erneut irrtümlich von männlichen Gestalten auf beiden Seiten). 222 Vgl. BRENK (2003) 99f.; die Darstellung ist auch von den zeitgenössischen Sarkophagen bekannt (vgl. Kap. 8.2).

223 In der Darstellung der Kreuzigung kann Christus das colobium tragen; doch dies erst im 6./7. Jh.; vgl. auch BRAUN (1907) 301; KRAUTHEIMER, CBCR 1 (1937) 282 will hier dennoch Christus sehen; WILPERT (1916) 638 Johannes oder Paulus (Märtyrer); vgl. auch NEUSS (1926) 130-149.

224 Es bleibt fraglich, wie BRANDENBURG ${ }^{3}$ (2013a) 168 hier eine „paradiesische Szene“ erkennen will: Das vor der Personengruppe abgebildete Tier (WILPERT: Hund; BRENK: Miniaturhirsch, mit 
Soldaten bzw. apparatores. ${ }^{225}$ Auf der gegenüberliegenden Seite finden sich die drei Personen wieder, und zwar unmittelbar im letzten Akt ihres Martyriums, dem Moment der Hinrichtung. ${ }^{226}$ Sie sind knieend mit nach hinten gebundenen Armen vor ihren Henkern dargestellt. Die Fresken in der Kapelle lassen sich so nicht mit der Legende der stadtrömischen Märtyrer Johannes und Paulus ${ }^{227}$ in Einklang bringen, die später namensgebend für die Kirche wurden.

Mit seinen Kontakten zu Hieronymus, Augustinus und Paulinus von Nola sowie seiner Verwandtschaft im Heiligen Land verfügte Pammachius zweifelsohne über gute Kanäle für die Beschaffung von Reliquien. ${ }^{228}$ Unter Berücksichtigung des sich später etablierenden Heiligenpatroziniums des titulus kämen am ehesten Reliquien des Paulus und des Johannes ${ }^{22}$, entweder des Apostels oder des Täufers, in Frage, die über die Mailänder Distribution, allen voran durch Ambrosius, weite Verbreitung fanden. ${ }^{230}$ Mit Verweis auf den titulus Vestinae nimmt Diefenbach Vergleichbares für den titulus Pammachii an. ${ }^{231}$ Abwegig ist dies in der Tat nicht, doch lassen sich zwischen Ambrosius und Pammachius keine Kontakte feststellen. Als Mittler käme aber vielleicht Paulinus von Nola in Frage, dem ebenfalls für seine Kirchen in Cimitile bei Nola und Fundi ein ganzes Sammelsurium an Mailänder Reliquien, darunter auch des Täufers Johannes, überstellt wurden. ${ }^{232}$

Verweis auf Ps. 41,2f.), welches an einer Quelle trinkt, kann dies sicher nicht stützen; vgl. BRENK (2003) $100 \mathrm{f}$.

$225 \mathrm{Zu}$ erkennen an der „illyrischen Kappe“, dem sog. pileus Pannonicus, bekannt u. a. von der bekannten Tetrarchengruppen in Venedig und dem Ambulatio-Mosaik von Piazza Armerina. Auch auf den Sarkophagen tragen die Soldaten, die Petrus oder Paulus in Haft nehmen, diese Kopfbedeckung (z. B. Iunius-Bassus-Sarkophag).

226 Hierzu vgl. auch BISCONTI (1995) 278-280. Allgemein zur Sinnstiftung und Interpretation der Märtyrerverehrung vgl. jetzt auch BERGJAN/NÄF (2014) 133-176.

227 Diese sollen als kaiserliche Beamten an einem 26. Juni zwischen 361 und 363 das Martyrium unter Kaiser Julian Apostata erlitten haben, und zwar am Ort der späteren Kirche (Passio SS. Iohannis et Pauli zusammen mit der Vita Gallicani; ActaSS, Iuni V, 37-39); zur Legende vgl. KRÖNUNG (2008) 32-37; KIRSCH (1918) 31f. und ausführlich FRANCHI DE’CAVALIERI (1915) 41-62.

228 Die christlichen amicitia-Beziehungen waren die Basis, auf welcher die Verbreitung von Heiligenkulten und ihre Reliquien erfolgte; vgl. DIEFENBACH (2007) 365; allgemein EPP (1999) 234-298 und BROWN (1991) 36-40.

229 Zum Kult und seiner Verbreitung vgl. DIEFENBACH (2007) 361 f. Anm. 131 u. 132 und die Auflistung bei DELEHAYE (1930) 5-64, bes. 13; zur Verbreitung im gallischen und italischen Raum vgl. PICARD (1988) 272-284 und VILLA (1957) 245-264, hier 249-253.

230 DIEFENBACH (2007) 365 nahm als Herkunftsort des cultus den oberitalischen Raum (Mailand) an; vgl. auch HUMPHRIES (1999) 148 u. 201 und MCLYNN (1994) $231 \mathrm{f}$.

231 Vgl. DIEFENBACH (2007) 362.

232 Vgl. Paul. Nol. carm. 27,408-439: u. a. auch Agricola, Nazarius, Vitalis, Thomas, Lukas, Andreas und Euphemia; ferner Paul. Nol. ep. 32,17: in Fundi Gervasius, Protasius, Nazarius, Andreas und Lukas. Seinerseits verteilte Paulinus auch Reliquien (ep. 31,1: u. a. Partikel des Heiligen Kreuzes an Sulpicius Severus); hierzu vgl. DIEFENBACH (2007) 364f.; allgemein zur Verteilung und Schenkung von Reliquien unter der christlichen Aristokratie vgl. MRATSCHEK-HALFMANN (2002) 427-443 und BROWN (1991) 88-95. 
Der Kirchenbau, der von Brenk als äußerst ambitioniert charakterisiert wird, ${ }^{233}$ scheint recht gut zur Person des Pammachius und seinem Wirken zu passen. Mit dieser Stiftung war Pammachius dann doch wohl mehr Aristokrat als Mönch. Dass Hieronymus das xenodochium in Portus erwähnt, ${ }^{234}$ aber nicht den aufwändigen Kirchenbau, könnte eben damit zusammenhängen. Trotz seiner karitativen Werke und Stiftungen scheint Pammachius nicht ganz konsequent seine Lebensführung verändert zu haben. In zahlreichen Stellen bei Hieronymus klingt Kritik an, ${ }^{235}$ dass Pammachius zwar sein Vermögen, aber nicht seine Person einsetze. ${ }^{236}$ Eustochium und Paula erhalten hier den höheren Rang. ${ }^{237}$ Noch die Beisetzungsfeierlichkeiten Paulinas erfolgten im Grunde ganz nach aristokratischer Manier. Die pompa funebris wird zwar um eine Armenspeisung und Almosengabe im Atrium der Petersbasilika ergänzt. ${ }^{238}$ Doch auch dies diente in erster Linie der eigenen Repräsentation und aristokratischen Distinktion. ${ }^{239}$

Die Basilika am Clivus Scauri sollte das neue soziale und religiöse Zentrum für dieses Stadtquartier sein und besaß so auch einen missionarischen Impetus, der im Besonderen auf die senatorischen Anwesen auf dem Caelius ${ }^{240}$ abzielte. Entsprechend aufwendig und wirkungsvoll wurde hier gebaut. Die Entscheidung, den Bau über der domus zu errichten, und diese dabei als Substruktion zu benutzen, war die denkbar beste Lösung, um der Kirche in diesem sonst dicht bebauten Stadtgebiet eine - im wahrsten Sinne des Wortes - überragende Position zu sichern. Dies lässt einen ambitionierten und finanzkräftigen Stifter erkennen. Der Bischof von Rom beanspruchte diese Stellung nicht. Für die stadtrömischen Gläubigen war Pammachius hier Gründer der Kirche und cultor fidei.

Hinsichtlich persönlichen Prestiges, der Heiligkeit und der sakralisierten Erinnerungskultur übertreffen die Kirchenstiftungen um ein Vielfaches die Profanstiftungen. Den Namen und das Andenken des Stifters konnten sie über Jahrhunderte hinweg in Erinnerung halten, wobei dieser mehr und mehr mit einer Aura des Legendenhaften und Heiligen umgeben wurde. Am Ende konnte so der Senator Pammachius in der kirchli-

233 Vgl. BRENK (2003) $110 \mathrm{f}$.

234 Hieron. ep. 66,11,1. Pall. Laus. 62 (nur eine kurze Notiz) nennt keine Baustiftungen, sondern nur das Verschenken des Reichtums an die Armen. Die karitativen Werke sind hier entscheidend.

235 Vgl. Hieron. ep. 66,5-13 dient so vor allem der Belehrung des Pammachius; vgl. u. a. TORNAU (2006) 101-103 und KRUMEICH (1993) 155.

236 Vgl. explizit Hieron. ep. 66,12.

237 Vgl. Hieron. ep. 66,13. Zu Paula vgl. WITTERN (1994) 22-27 passim und REBENICH (1992) 187-196. 238 Vgl. Paul. Nol. ep.13,3;13,11 u. 13,13; hierzu vgl. LIENHARD (1977) 51, 110 ff., 124 u. 189. Eben diese Art der öffentlichkeitswirksamen und nach Prestige strebenden Form der caritas kritisiert Hieronymus; neben Hieron. ep. 66,5-13 bes. in Hieron. ep. 22,23; vgl. auch JENAL (1995) Bd. 1, 66 mit Anm. 334.

239 Hierzu vgl. MACHADO (2019) 150 und ders. (2011) 508f.; BAUER (2004) 160; KRUMEICH (2002) 53; dies. (1993) 315 und REBENICH (1992) 191; hier allerdings zur pompa funebris Paulae (Hieron. ep. 108,29,1f.); allgemein BROWN (1991) 35f.

240 Erst mit dem Bau der Kirche S. Stefano Rotondo wird Mitte des 5. Jh. ein christliches Kultzentrum auf dem Caelius geschaffen; welches dieses Standquartier dann auch baulich dominiert; zu dieser Kirche und ihrer Bedeutung für die Christianisierung dieses Stadtareals vgl. BRANDENBURG (1998) 8f. Zu den Spezifika der Lage vgl. auch MULRYAN (2014) $61 \mathrm{f}$. 
chen Tradition Roms sogar zu einem Heiligen werden. Jedoch war es nicht immer sicher, dass der Name des Stifters in Erinnerung blieb. Nach seinem Ableben hatte dieser keine Einflussmöglichkeiten mehr. Und so lässt sich beobachten, dass mitunter auch die mit dem Bau beauftragten Kleriker die Kirchenstiftung für die eigene Repräsentation nutzten.

Für S. Sabina (titulus Sabinae) (Abb. 36) und S. Balbina (titulus sanctae Balbinae) $)^{241}$ lässt sich dies aufzeigen. Bis auf den Namen des titulus ${ }^{242}$ haben sich alle Spuren, die eine senatorische Beteiligung festhalten könnten, verloren. In der Erinnerung wurden der Bischof von Rom und die mit der Bauausführung beauftragten Kleriker festgehalten. So nennt das Stiftungsmosaik über dem Haupteingang von S. Sabina Coelestin I. (422432) sowie einen Presbyter namens Petrus von Illyrien. ${ }^{243}$ Allerdings erhebt sich die Basilika wohl auf einstmals senatorischen Grundbesitz. So ist in der südlichen Seitenschiffwand der nach Nordosten ausgerichteten Kirche die Fassade einer aus dem 4. Jh. stammenden domus einbezogen worden. Ferner ist die unregelmäßige Ausrichtung des östlichen Teils des nördlichen Seitenschiffs durch ältere Vorgängerbauten bestimmt. Im Bereich des Narthex ließen sich des Weiteren Raumstrukturen fassen, welche auf ein luxuriöses spätantikes Privathaus ${ }^{244}$ schließen lassen.

Ein nicht zu übersehender Beleg für die finanzielle Potenz des Stifters sind insbesondere die kostbaren Ausstattungselemente der Basilika. ${ }^{245}$ Neben Mosaiken zierten Marmorinkrustationen, farbige Glassteine und Malereien die Wände der Basilika. Hervorzuheben ist hier auch der vierundzwanzigteilige Satz hochkaiserzeitlicher Säulen samt passender korinthischer Kapitelle, der sowohl hinsichtlich der Kosten als auch ihrer Beschaffung einen außerordentlichen Aufwand darstellte. Es ist daher wenig wahrscheinlich, dass ein Presbyter allein aus seinem Privatvermögen für die Kosten des Baugrunds, des Baus und seiner prachtvollen Ausstattung aufkommen konnte. Eine

241 Für einen Überblick vgl. BRANDENBURG ${ }^{3}$ (2013) 184-195 u. 234-236.

242 Zur Diskussion bezüglich S. Sabina vgl. BRANDENBURG ${ }^{3}$ (2013) 185; DIEFENBACH (2007) 354f.; BRENK (2003) 50 und SAXER (2001) Bd. 2, 493 - 637, hier 559. Zur Titelheiligen, der Märtyrerin Sabina, vgl. MASKARINEC (2018) 105-109; ferner BBKL 8 (1994) 1146-1148. Strittig bleibt, ob es sich auch hier um eine sanktifizierte Stifterin handelt, oder der Name der Heiligen und Märtyrerin in keiner Beziehung zur senatorischen Stifterin steht; der passio Sabinae et Serapiae diesbezüglich nichts Verlässliches zu entnehmen; vgl. KIRSCH (1918) 163-166.

243 ILCV 1778a (1-4) = ICVR 2, 5154: CVLMEN APOSTOLICVM CVM CAELESTINVS HABERET / PRIMVS ET IN TOTO FVLGERET EPISCOPVS ORBE / HAEC QVAE MIRARIS FVNDAVIT PRESBYTER VRBIS / ILLYRICA DE GENTE PETRVS [...]; eigene Lesung vor Ort 2017; vgl. Abbildung BRANDENBURG 3(2013) 327, XXVII. 4 oder EFFENBERGER (1986) Abb. 96; der Bau wird aber erst unter Sixtus III. fertiggestellt (vgl. Lib. Pont. 1,235). Zum Einfluss des Bischofs von Rom vgl. MULRYAN (2014) 66f.

244 Vgl. BRANDENBURG ${ }^{3}$ (2013) 185: Die Fassade mit einer mehrteiligen Arkadenöffnung ist in der Außenwand des Narthex verbaut; hierzu gehört ein großes Rundbogenfenster und ein bunter Marmorfußboden aus grob behauenen Steinen, welcher im 4. Jh. den darunter belassenen Mosaikboden ersetzte; ferner die Strukturen eines Badehauses; vgl. PIETRI (1976) 504-506 und KRAUTHEIMER, CBCR 4 (1970) 81-87 u. 90f.: ein repräsentativer Profanbau; ebenso DIEFENBACH (2007) 354 mit Anm. 101.

245 Hierzu BRANDENBURG ${ }^{3}(2013)$ 188-191. 


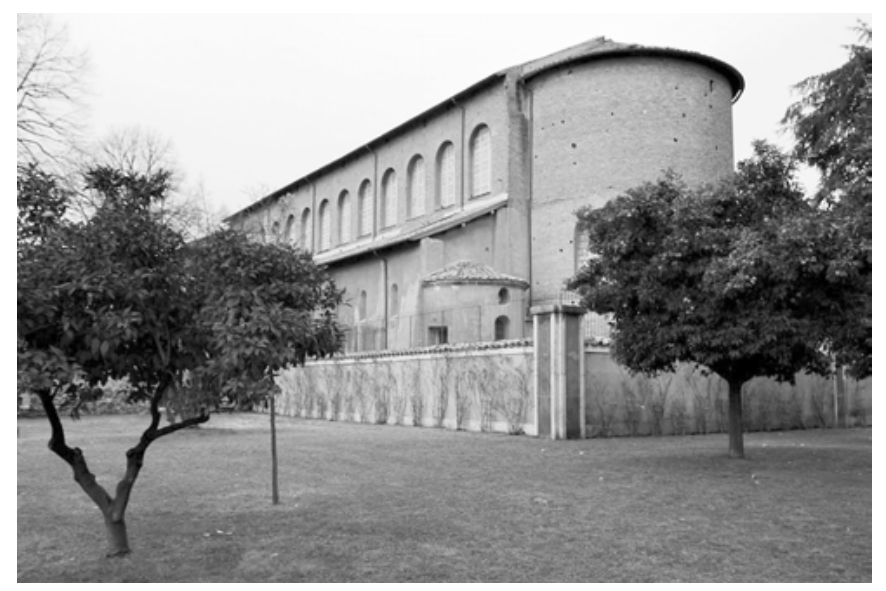

Abb. 36: S. Sabina auf dem Aventin.

senatorische Unterstützung, die die Kosten mittrug oder den Baugrund bereitstellte, wäre hier zu vermuten. ${ }^{246}$ Jedoch war dies dann offenbar nicht mit einem dauerhaften Anspruch auf eine Stiftermemoria verbunden.

Für die Kirche des titulus sanctae Balbinae, die gleichfalls auf dem Aventin (Aventinus minor) gelegen ist und über einer senatorischen domus errichtet wurde, dürfte dies ebenfalls zutreffen. Die Kirche ist hier unmittelbar in der aula absidata einer senatorischen Residenz aus der Mitte des 4. Jhs. eingerichtet worden. ${ }^{247}$ Auf die Bedeutung dieses Befundes, der sich noch an anderen Kirchen Roms feststellen lässt, ${ }^{248}$ soll hier genauer eingegangen werden. Die für den Kirchenbau genutzte Halle misst 20 x 11 m und verfügt über weit geöffnete Rundfenster im Obergaden. Die Raumabmessung bewegt sich damit im oberen Segment der aus Rom bekannten Empfangshallen senatorischer Residenzen. ${ }^{249}$ Reiche Marmorfunde zeugen von der luxuriösen Ausstattung und dem hohen repräsentativen Anspruch der domus und seiner Eigentümer. ${ }^{250}$

Als repräsentativer Kernbereich der spätantiken domus diente die aula absidata als Kommunikationsraum und wichtiger sozialer und politischer Treffpunkt. Die Überstellung in kirchlichen Besitz und die damit vermutlich einhergehende Aufgabe der

246 Hinzuweisen ist hier auch auf den jüngsten Vorschlag MASKARINEC (2018) 102f.: Caeionii (Marcella und Albina), wobei eine solche Zuweisung aufgrund der Quellenlage nicht nachzuweisen ist. 247 Hierzu ausführlich BRANDENBURG ${ }^{3}$ (2013) 234f.; CECCHELLI (2000) 421-438, hier 433 und GUIDOBALDI (2000) 134-136; ders. (1986) 165- 237 u. 446-460, hier 181f. und KRAUTHEIMER, CBCR 1 (1937) $82 \mathrm{ff}$.

248 So u. a. S. Andrea cata Barbara, SS. Quattro Coronati, SS. Quirico e Giulitta und S. Pietro in Vincoli. 249 Vgl. hierzu Kap. 8.3. Als Reverenz lassen sich die deutlich größer dimensionierte Domus Symmachorum oder Domus Valeriorum anführen; vgl. ferner GUIDOBALDI (2000) 134-136.

250 Den Namen eines früheren Eigentümers überliefert die Inschrift eines Bleirohrs (CIL 15, 7447), die den Stadtpräfekten und Konsul von 204 Lucius Fabio Cilo (PIR² (F 27)) nennt. Zur Person und seinen Nachkommen vgl. DIETZ, Chiron 13 (1983) 397-403. Vgl. hierzu jetzt auch MACHADO (2019) 209 - 211. 
domus bedeutet zum einen die Abkehr vom Luxus und Prunk und dürfte als klares Zeichen, dem weltlichen Besitz abzuschwören, auch gewertet worden sein, ${ }^{251}$ doch zum anderen wurden damit auch den politischen, sozialen und ökonomischen Pflichten, denen das senatorische Haus über Jahrhunderte nachgekommen war, entsagt. Oft dürfte es sich hierbei aber um eine testamentarische Verfügung gehandelt haben, die vor allem dann vorgenommen wurde, wenn kein Erbe oder Verwandter den Besitz übernehmen konnte. ${ }^{252}$ Zusammen mit der Übereignung der domus ging zumeist auch ein Großteil der städtischen und suburbanen Liegenschaften in den Besitz des titulus über. Damit wurden die zum senatorischen Haus gehörenden Landgüter, Betriebe und städtischen Einrichtungen $^{253}$ vor einer Parzellierung bewahrt und den hier Beschäftigten eine ökonomische und soziale Sicherheit verschafft, die anders nicht mehr zu gewährleisten war. Die Presbyter eines titulus konnten die Funktion einer Appellationsinstanz und Interessenvertretung ${ }^{254}$ übernehmen und waren damit in der Lage, ein senatorisches Patronat zu ersetzen. Die Stiftung von senatorischem Grundbesitz an die Kirche muss folglich nicht unbedingt allein von asketischen Idealen oder einem religiösen Repräsentationsstreben motiviert gewesen sein, sondern kann sich auch aus der senatorischpatronalen Fürsorgepflicht erklären. ${ }^{255}$ Auch im folgenden Beispiel kann dies ein Grund für die Stiftung gewesen sein.

Am dritten Meilenstein der Via Latina erhob sich auf dem Areal einer großzügigen und luxuriösen Villenanlage des 4. Jhs. eine dreischiffige Basilika, die in die Raumstrukturen des Anwesens eingefügt wurde und zum Teil dessen Mauern als Fundament nutzte. ${ }^{256}$ Hiervon wurde auch die Ausrichtung der Kirche bestimmt, die mit ihrer Apsis nicht nach Osten, sondern Westen lag. Die seit 1857 unter Federführung der Pontificia Commissione di Archeologia Sacra ${ }^{257}$ wiederentdeckten und ergrabenen Ruinen des Kirchenschiffs (Abb. 37) ${ }^{258}$ messen $36 \mathrm{~m}$ in der Länge und $21 \mathrm{~m}$ in der Breite. Ihrer Größe

251 U. a. fordert Salvian in der Schrift Ad ecclesiam auf, den verderblichen Reichtum abzulegen und der Kirche zu vermachen; vergleichbar Vit. Mel. 9 mit Bezug auf Mt 16,24 u. 19,21.

252 Vgl. auch Pall. Laus. 54 und CTh. 16,2,27 u. 28. Entsprechend lässt sich nur in seltenen Fällen ein stemma sicher über drei Generationen hinaus erstellen. Bekannt ist der Fall der gens Anicia, die zur Mitte des 4. Jhs. in männlicher Linie ausgestorben war und durch Sextus Claudius Petronius Probus (ILS 1267: Anicianae domus culmen; ferner Auson. ep. 16,2,32-34 [In Petronium Probum 31]) erneuert wurde. Vgl. NOVAK (1980) 473-493; knapp BRANDT (2014a) 99; zur Herkunft CAMERON (2012) 136-140.

253 Gut dokumentiert z. B. für S. Vitale (titulus Vestinae; Lib. Pont. 1,220 - 222). Eine Zusammenstellung der Stiftungen bietet VIELLIARD (1928) 89-103.

254 Grundlegend zum Presbyter vgl. PREDEL (2005); vorwiegend wurde in der Forschung Gallien betrachtet, wohingegen für Rom vergleichbare Studien fehlen.

255 Die Hypothese KIRSCHs, wonach hier vor allem eine Kulttradition in Gestalt einer domus ecclesiae die Platzwahl bestimmte, wird damit hinfällig; zu weiteren Gegenargumenten vgl. PIETRI (1978) 3-21. Daran halten in jüngerer Zeit noch fest: CECCHELLI (2000) 179f.; JOST (2000) Bd. 1, 121-126 und LAMPE (1987).

256 Zum Bau vgl. BRANDENBURG ${ }^{3}$ (2013) 257f.; MACHADO (2011) 500 - 505; BRENK (2003) 50 f. und KRAUTHEIMER, CBCR 4 (1970) 241-253.

257 Erstmals Publiziert FORTUNATI (1859); aktueller SORRENTI (1996) 253-267.

258 Abbildung nach BRENK (2003) Fig. 88. 


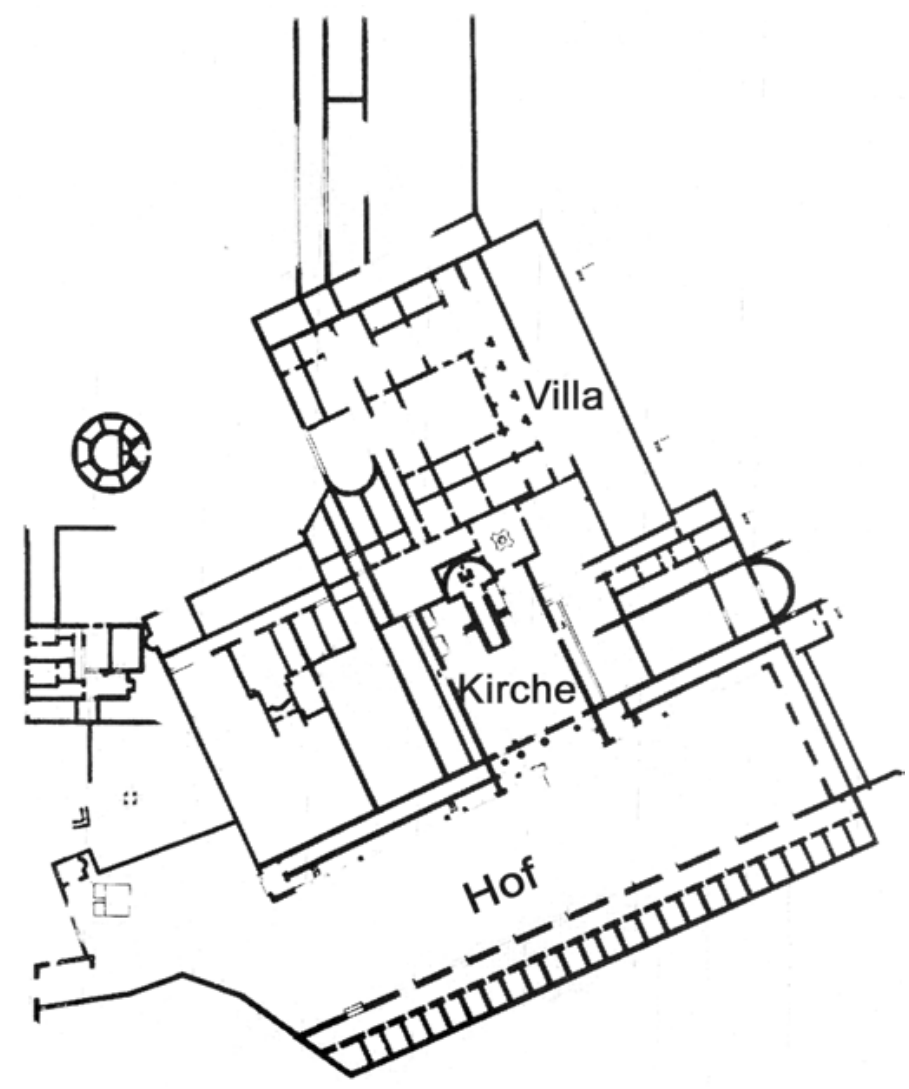

Abb. 37: Plan S. Stefano in Via Latina mit villa (nach Brenk).

nach bewegt sich die Basilika damit im gehobenen Mittelfeld der stadtrömischen Kirchenbauten. An das rechte Seitenschiff lehnt sich im Westen ein rechteckiger Raum mit einem in den Boden eingelassenen Becken an, welches von den damaligen Ausgräbern sicherlich zutreffend als baptisterium identifiziert wurde.

Dem Liber Pontificalis ${ }^{259}$ ist zu entnehmen, dass die ancilla Dei Demetria(s) ${ }^{260}$ hier eine Basilika für den Protomärtyrer Stephanus errichten ließ. Seine Bestätigung findet

259 Vgl. Lib. Pont. 1,238: Huius [Leonis] temporibus fecit Demetria ancilla dei basilicam sancto Stephano via Latina, miliario III, in praedio suo.

260 PLRE 2, 351f.; vgl. auch DISSELKAMP (1997) 62. Zur conversio (nach 410 in Africa) vgl. Hieron. ep. 130. Im Zusammenhang mit der Plünderung Roms, wohl aber im Vorfeld, siedelte Anicia Faltonia Proba zusammen mit ihren Schwiegertochter Anicia Iuliana 2 (PLRE 1,468) und Enkelin Demetria nach Nordafrika um. Zum Reichtum vgl. Hieron. ep. 130,1 und Aug. ep. 188,1. Zum Kontakt mit Pelagius vgl. Pelag. ep. ad Demetr. Hierzu vgl. u. a. GEORGIEVA (2016) 329-340; JENAL (2011) 43-77, bes. 46-49 und THIER (1999) 52-55 u. $190 \mathrm{f}$. 
diese Angabe in einer Stiftungsinschrift ${ }^{261}$. Die Stiftung ist durch ein Gelübde (extrema vota) motiviert. Sie nennt zwar auch in diesem Fall einen Presbyter, und zwar mit dem Namen Tigrinus, der „hervorragend im Geiste und tüchtig in der Tat“ auf Weisung Leos die Ausschmückung der Basilika besorgte. Doch im Liber Pontificalis ist es nur noch der Name der Demetria, der erinnerungswürdig ist. Der Presbyter nimmt hier wohl neben seiner Funktion als Nachlassverwalter und Baubeauftragter auch die Aufgabe eines Vermittlers ${ }^{262}$ zwischen dem Bischof von Rom und Demetria wahr. Die Bedeutung und Nachhaltigkeit der Stiftung sowie das Andenken an die Stifterin hing stark davon ab, ob die Kirche den Bau, der im Grunde zunächst als Privatkirche auf den eigenen Domänen errichtet wurde, als römische Gemeindekirche anerkennen würde. ${ }^{263}$ Zur Verhandlung stand hier sicherlich auch, in welchem Maße die Kirche für die Stifterin zum Memorialbau werden durfte. Bereits Sex. Anicius Paulinus (Cos. 325) wurde hier bestattet. ${ }^{264}$ So befand sich unter dem westlichen Mittelschiff eine Krypta. ${ }^{265}$ Dort hätte sich Demetria möglicherweise zusammen mit Reliquien des Stephanus bestatten lassen können. ${ }^{266}$

Allem Anschein nach wollte sich Demetria überdies mit der Christianisierung der ländlichen Bevölkerung ${ }^{267}$ einen Namen machen. Ein baptisterium gehörte offenbar zur Kirche. Dies dürfte sodann auch ganz im Interesse Leos gewesen sein. Dieser Anspruch wird auch an der Größe der Gesamtanlage deutlich, zu welcher neben der Basilika ein monumentaler Vorhof von 100 x 24 m Grundfläche zählte. Der von Brenk treffend als „megalomane[r] Aufmarschraum“ 268 bezeichnete Platz, der vermutlich schon zur Villenanlage gehörte, war sicherlich bereits vor der Kirchengründung ein überaus wichtiger sozialer und politischer Treffpunkt. Die Vita Melaniae nennt die Zahl von 62 Gehöften mit je 400 Seelen, also ca. 24.800 Menschen, die ihr Leben im Umfeld eines senatori-

261 Vgl. ICVR 6, 15764 (ILCV 1765 u. ILS 8988): CVM MVNDVM L[inqu]ENS DEM[etri]AS AMN[ia virgo] / CLA[ud]ERET EXTREMVM NON MORIT[ura diem,] / [hae]C TIBI PAP[a L]EO, VOTORVM EXTREM[ $a$ suorum $]$ / [trad]IDIT, VT S[a]CRAE SVRGERET AVLA D[omus]. / M[a]NDATI COMPLE[t]A FIDES, SED GLOR[ia maior] / al]TERIVS VOTVM [s]OLVERE QVAM PROPR[ium.] / IN[lus]TRAT CVLMEN STEPH[a]NVS QVI PRIMVS IN OR[be] / [r]APTVS MORT[e t]RVCI REGN[a]T IN ARC[e poli]. / [Pr]AESVLIS HA[ec nut]V TIGRINVS PR[esbyter instans] / EXCOLIT INS[ig]NIS MENTE LABOR[e fide]. Zum Text vgl. auch BEHRWALD (2016) 169; MACHADO (2011) 503f. und KURDOCK (2007) 223.

262 Vgl. auch BRENK (2003) 51.

263 Hierzu vgl. auch BORGOLTE (2012) 152-169 zum Begriff der „Eigenkirche“. Zur „Pfarrkirche“ im ländlichen Raum vgl. BRANDENBURG (1999) 43-81, speziell zu S. Stefano in Via Latina ebd. 49-51. 264 CIL 6, 1680 (PLRE 1, 679f.); vgl. MACHADO (2011) 502f.; ausführlich KRAUTHEIMER, CBCR 4 (1970) 249-251. Daneben gab es auch noch die Grablege der Anicier in Alt.-St. Peter; hierzu noch Kap. 9.4.

265 Hierzu vgl. BAUER (2002) 135-178, hier 158f. und KRAUTHEIMER (1987) 66.

266 Vgl. MACHADO (2011) 504f. Zu dieser Praxis vgl. Soz. 9,2,1-15 und Vit. Mel. 57 u. 65. Hierzu auch und BROWN (1991) 39-42.

267 Auch Johannes Chrysostomus ruft die senatorischen Landbesitzer zum Kirchenbau auf; vgl. Chrys. In Act. 18,4 (PG 60, 147); hierzu vgl. KRAUSE (1987) 119-126. Für Italien vgl. Zos. 5,41 (vgl. auch Soz. 9,7 und Oros. 7,37,7).

268 BRENK (2003) 51. 
schen Landguts bestritten. ${ }^{269}$ Somit wird das Gesamtensemble mit diesem ausgesprochen großzügigen Platz neben seinem pastoralen und missionarischen Auftrag, ebenso politische, sozialstrukturelle und ökonomische Funktionen übernommen haben.

Das Einlösen des Gelübdes beinhaltete somit verschiedene Punkte, die nicht alle als dezidiert christlich oder asketisch anzusehen sind. ${ }^{270}$ Primär bleibt es eine Kirchenstiftung, die der Christianisierung des suburbium Vorschub leisten sollte. Daneben aber lässt sich hier auch deutlich die Sorge um das eigene Nachleben erkennen, welches die Kirche zum Memorialbau, vielleicht auch zum Grab, der Stifterin werden ließ und ihr den Eingang in das Himmelreich durch missionierte Seelen und Gebete erleichtern sollte. Hierin spiegelt sich sowohl ein christlich-frommes als auch ein aristokratischelitäres Denken wider. Diese Ambivalenz zeigt sich nicht anders im Fall der Patronatsübertragung an die Kirche. Als ancilla Dei, die die Jungfräulichkeit gelobt hatte, hinterließ Demetria keine Nachkommen. So lässt sich annehmen, dass hier auch die senatorische Führsorgepflicht gegenüber den Menschen, die vom fortbestand des senatorischen Besitzes abhängig waren, eine Rolle spielte. Senatorische und christliche Interessen und Verhaltensmuster stehen dabei nicht gegensätzlich zueinander, sondern ergänzen sich.

Während sich in der christlichen Kunst durchaus ein senatorisches Repräsentations- und Distinktionsstreben erkennen lässt, wird dies im Fall der Kirchenstiftungen nicht so deutlich. Die Stiftermemoria setzte sich nicht immer durch. Allerdings lassen sich begünstigende Faktoren erkennen. So scheinen Reliquienstiftungen, die amicitia zu geistlicher ,Prominenz' und auch eine einflussreiche Familie, die über die memoria wachen konnte, diese begünstigt zu haben. Die Motive für eine Kirchenstiftung konnten hier ebenfalls sehr unterschiedlich ausfallen. So stehen hinter den Stiftungen sicherlich nicht nur asketische Ideale, die auf die Besitzlosigkeit oder Zurückgezogenheit ausgerichtet waren. Auch das soziale und ökonomische Pflichtbewusstsein der Senatsaristokratie wird hier eine Rolle gespielt haben; ebenso ein gesellschaftliches und religiöses Führungs- und Sendungsbewusstsein.

Abschließend sei auch darauf hingewiesen, dass in den meisten Fällen, die überliefert oder angenommen werden, die Stifter weiblich waren, was gewiss Einfluss auf das Repräsentationsverhalten hatte. Das Jenseits hatte hierbei wohl einen höheren Stellenwert als das Diesseits, immerhin bestand für Frauen keine Möglichkeit, die kirchlichen Stiftungen mit einer Amtsrepräsentation zu koppeln und einen politischen

269 Vgl. Vit. Mel. 18; Vit. Mel. Lat. XVIII, 3f.: Habebat enim ipsa possessio sexaginta villas circa se habentes quadrigentenos servos agricultores. (F); zur Zahl, die vermutlich zu hoch angesetzt ist und in anderer Überlieferung mit 40 (CDE: quadragintenos) angegeben wird, vgl. GARNSEY/WHITTAKER (1998) 277-311, hier 294f. und VERA (1986) 417; zu den Zahlen vgl. aktuell auch HARPER (2011) $194 \mathrm{f}$. mit Anm. 253. Hinzu kommen nach Vit. Mel. 10 und Pall. Laus. 61. noch 8.000 Sklaven.

270 Dies betont z. B. BEHRWALD (2016) 169 stark, wobei er den archäologischen Befund unberücksichtigt lässt. 
Machtanspruch zum Ausdruck zu bringen. Nur männlichen Vertretern stand diese Möglichkeit offen, ${ }^{271}$ auf die aber auch demonstrativ verzichtet werden konnte.

\subsection{Ein Nachtrag zur Rolle und Bedeutung der christlichen gens Anicia}

Zum Abschluss den Blick auf die gens Anicia zu richten, hat den Vorteil, dass sich hierdurch ein konziseres Bild von der Repräsentationsstrategie und den Repräsentationsmöglichkeiten einer christlich-senatorischen gens aufzeigen lässt. Überdies kann hier sehr gut nachvollzogen werden, wie sich ein christlich-senatorischer ,Adel ${ }^{\text {* }}$ erfolgreich und vor allem nachhaltig etablieren konnte. Die stadtrömischen Anicier ${ }^{272}$ waren zwar nicht die Ersten, die Kirchenstifter, christliche Jungfrauen, Witwen und Senatoren im ,Mönchsgewand“ hervorbrachten. Melania d. Ä, ihre Enkelin Melania d. J., Asella und Marcella, Paula, Eustochium, Paulina und Pammachius sowie weitere mehr ${ }^{273}$ gingen Proba und Demetria voraus. Gerade die Valerii, Caeionii-Rufii und Furii brachten, zumindest nach den Briefen des Hieronymus und Augustinus oder dem Werk des Palladius zu urteilen, eine zahlenmäßig starke christlich-asketische Prominenz hervor. Dennoch nahmen die Anicier, die in vielerlei Hinsicht, insbesondere aber bezüglich christlich-asketischer Ideale zurückhaltender agierten, unter der christlichen Aristokratie Roms den ersten Platz ein. ${ }^{274}$

Seine bauliche Manifestation fand dies schon zum Ende des 4. Jhs. mit der Errichtung eines eigenen Familienmausoleums an der vatikanischen Petersbasilika. Das sog. Templum Probi, welches nur noch durch den Plan Tiberano Alfaranos'275 in seiner Gestalt erfassbar ist, lehnte sich an den Scheitelpunkt der Apsis von Alt-St. Peter an. Für das Grabmal der Anicier wurde somit eine ganz außergewöhnliche Position ausgewählt. Als erweiterter Annexbau zur Apsis schloss das Aniciermausoleum unmittelbar an das ,Allerheiligste، der Petersbasilika an und befand sich somit in nächster Nähe zur Petrusmemoria. ${ }^{276}$ Damit ist das Aniciergrab in einem Ausmaß als sakrosankt zu bezeichnen, wie dies keine andere Grablege Roms, einschließlich der kaiserlichen Mau-

271 Vgl. u. a. CIL 6, 41379: Longinianus PVR (S. Anastasia? 400-402; wohl aber in kaiserlichem Auftrag); ILS 1293: Felix MVM etc. (Lateran 425-430); CIL 6, 1726: Paulus PVR (S. Paul 438) CIL 6, 41392: Faltonius Adelfius PVR (Lateran 451). Vgl. BEHRWALD (2016).

272 Hier speziell die Nachkommenschaft des Sex. Cl. Petronius Probus. Ferner vgl. MOMMAERTS/ KELLEY (ND 2002).

273 Eine Übersicht findet sich bei DISSELKAMP (1997) 48-101.

274 Vgl. Prud. C. Symm. 1,550-560.

275 Abbildung in BAUER (2004) Abb. 35 (hier mit Zuschnitt); vgl. hierzu KRAUTHEIMER (1964) 173175.

276 Vgl. BRANDENBURG ${ }^{3}$ (2013) 96 f. und MACHADO (2019) 155-161 und ders. (2011) 510 - 512. 
soleen, ${ }^{277}$ für sich beanspruchen konnte. Aus diesem Bau stammen der Stadttorsarkophag Borghese und der sog. Probus-Sarkophag. ${ }^{278}$ Bereits vor der Errichtung des Mausoleums hatten die Anicier die Bedeutung Alt-St. Peters für sich erkannt. So belegt für die Mitte des 4. Jhs. der Iunius-Bassus-Sarkophag ${ }^{279}$, der in der confessio gefunden wurde, die Grablege.

Über zwei Grabepigramme, die jedoch nicht mehr erhalten sind, ist die Besitzerschaft der Anicier eindeutig belegt. ${ }^{280}$ Das Mausoleum wurde mitsamt den Inschriften im Zuge des Neubaus zwar dem Erdboden gleichgemacht, jedoch hielt Maffeo Vegio, der noch 1452 das Mausoleum und seine Inschriften beschrieb, wesentliche Impressionen fest. ${ }^{281}$ Wie dem Plan Alfaranos' zu entnehmen ist, handelt es sich um eine apsidiale Halle mit einer umlaufenden Säulenreihe innen. Für die Abhaltung des Totenmahls waren im Inneren wohl auch Klinen und Tische aufgestellt. Vegio erwähnt die prachtvolle Marmorausstattung, die bereits unter Papst Nikolaus V. (1447-1455) dem Bau entnommen wurde. Auf dem Epistyl der inneren Säulenkolonnade soll sich das erste Grabepigramm befunden haben, das zweite auf dem Epistyl im Inneren eines Vorbaus. ${ }^{282}$ Beide Grabepigramme, die für Sextus Claudius Petronius Probus angefertigt wurden, besitzen einen sehr unterschiedlichen Charakter, den schon Schmidt umfassend herausgearbeitet hat. Während das erste, wohl ältere Epigramm $(\mathrm{A})^{283}$ vor allem die honestas des Probus in den Vordergrund rückt und entsprechend pagan-traditioneller Konventionen auf seine weltlichen Ämter, Würden und besonderen Qualitäten abhebt, stellt das zweite Epigramm (B) ${ }^{284}$ das Bekenntnis zu Christus, insbesondere in der Taufe, in den Vordergrund. Die beiden Inschriften stehen somit antithetisch zueinander. ${ }^{285}$ Die zweite Inschrift ist hierbei nicht nur eine Ergänzung der ersten, sie ist ihr Korrektiv, in welchem die memoria des traditionsbewussten Senators vom Bild des getauften christlichen Aristokraten quasi überschrieben wurde.

277 Diese befanden sich auf der Südseite der Basilika und damit weiter vom Petrusgrab entfernt. Vgl. u. a. LÖX (2017) 165-168; MCEVOY (2013b) 119-136; dies. (2010) 178-185; JOHNSON (2009) 168-202 und PAOLUCCI (2008) 225-252.

278 Hierzu vgl. DRESKEN-WEILAND (2003) 377f. und Rep. I 678.

279 Rep. I 279. Zu den Sarkophagen vgl. Kap. 9.2.

280 ICVR 2, 4219a-b (ICVR 2,1 p. 347-349) = ILCV 63 = CIL 6, 1756; hierzu SCHMIDT (1999) 99-116, hier $103 \mathrm{f}$.

281 Festgehalten von DE ROSSI, ICVR 2,1 p. 348; in Auszügen bei NIQUET (2000) 42 und SCHMIDT 1999, 102f.; VEGIUS (1452): Templum extra prorrectum magis prae magnitudine eius quam oratorium; besprochen von WITSCHEL (2012) 397-399.

282 Vgl. SCHMIDT (1999) 105; nach DE ROSSI ICVR 2,1 p. $348 \mathrm{f}$.

283 Vgl. z. B. ICVR 2, 4219a, v. 3-6: [...] CONSVLIBVS PROAVIS SOCERISQVE ET CONSVLE MAIOR, / QVOD GEMINAS CONSVL REDDIDIT IPSE DOMOS. / PRAEFECTVS QVARTO, TOTVM DILECTVS IN ORBEM, / SED FAMA EMENSVS QVICQVID IN ORBE HOMINVM EST. [...] und v. 17 f.: FELIX, HEV, NIMIVM FELIX, DVM VITA MANERET, / DIGNO IVNCTA VIRO, DIGNA SIMVL TVMVLO; vgl. hierzu auch SALZMAN 2(2004) 202-204.

284 Vgl. ICVR 2, 4219b, v. 8-10: [...] HAS MVNDI PHALERAS, HOS PROCERVM TITVLOS / TRANSCENDIS SENIOR DONATVS MVNERE CHRISTI: / HIC EST VERVS HONOS, HAEC TVA NOBILITAS.

285 So auch die Einschätzung NIQUET (2000) 43 und SCHMIDT (1999) 105f. u. $110 \mathrm{f.}$ 
Im ersten Epigramm ist es noch Roma, die angerufen wird; ${ }^{286}$ im zweiten sodann Christus $^{287}$. Schmidt identifizierte als Verfasser des dezidiert christlichen Epigramms keinen Geringeren als Ambrosius von Mailand, ${ }^{288}$ während Proba für die erste Inschrift verantwortlich gewesen sein soll. Die memoria dürfte sich als bonum exemplum an die Nachkommen des Sextus Claudius Petronius Probus und der Proba gerichtet haben, die sich hier zwischen dem nobilis in saeculo und dem nobilior in Deo ${ }^{289}$ entscheiden sollten. Die drei Probussöhne Olybrius, Probinus und Probus beschreiten im Folgenden jedoch einen Mittelweg. Auf der einen Seite treten sie das Konsulat an und standen, zumindest was die Korrespondenz mit Symmachus ${ }^{290}$ und die Panegyrik Claudians angeht, durchaus noch im Konsens mit den traditionellen senatorischen Werten und Pflichten. Auf der anderen Seite knüpft aber keiner von ihnen an die außerordentliche machtpolitische Stellung ihres Vaters an. Zwar erhalten sie bis 406 alle das Konsulat, ${ }^{291}$ doch in einem hohen Amt der Reichsadministration oder des Hofs findet man sie nicht. Nach der Zäsur von $410^{292}$ sind es vor allem Fl. Anicius Auchenius Bassus, Anicius Acilius Glabrio Faustus und Petronius Maximus, die hier den Anschluss finden. ${ }^{293}$

Für die edlen Damen des Hauses stand Letzteres, ein Adel ausgerichtet auf Gott und Christus, im Vordergrund. Dennoch beanspruchten sie in ihrer christlichen Witwen- und Jungfrauenschaft ebenso immer auch einen weltlichen, aristokratischen Führungsanspruch. Proba distanziert sich so auch in der Folgezeit in keiner Weise von der geradezu vermessen wirkenden Grablege. Diese entsprach gewiss nicht bescheidenen asketischen Idealen, wohl aber dem elitären Denken eines senatorischen Hauses, welches als das erste, edelste und nun auch als das christlichste unter den senatorischen Häusern Roms gelten wollte. Selbst in ihrem nordafrikanischen Exil ist sie nicht eine von Vielen oder zieht sich aus der Öffentlichkeit zurück, sondern tritt als Führerin der aristokratischen Exilanten auf. ${ }^{294}$ In der Enkelgeneration steht Demetria mit ihrer Kirchenstiftung nicht weniger in dieser Tradition und beweist damit, dass sich in der Praxis der Gegensatz nobilis in saeculo - nobilior in Deo im Grunde aufhob.

286 ICVR 2, 4219a, v. 7 f.: AETERNOS, HEV, ROMA, TIBI QVI POSCERET ANNOS, / CVR NON VOTA TVI VIXIT AD VSQVE BONI? [...] v. 11 f.: SED PERIISSE PROBVM MERITIS PRO TALIBVS ABSIT / CREDAS ROMA TVVM, VIVIT ET ASTRA TENET!

287 ICVR 2, 4219b, v. 21 f.: HIS SOLARE TVOS, QVAMQVAM SOLACIA MAESTA / GRATIA NON QVERAT, GRATIA, CHRISTE, TVA! [...]; v. 27: HVNC TV, CHRISTE, CHORIS IVNGAS CAELESTIBVS ORO [...].

288 Vgl. SCHMIDT (1999) 107-115; hier erfolgt ein Abgleich mit den Grabreden des Ambrosius.

289 Hierzu vgl. NIQUET (2000) 43f.; SCHMIDT (1999) 110 und ausführlicher NÄF (1995) 101-107.

290 Vgl. Kap. 9.1.

291 Vgl. CIL 6, 1754b (= 6, 31921 = ILS 1269; a. 409): hier ist auch Anicius Probus, Sohn des Olybrius, als quaestor canidatus angeführt.

292 Hierzu vgl. die Diskussion um die Domus Pinciana; Kap. 8.4.

$293 \mathrm{Zu}$ Petronius Maximus vgl. bes. Kap. 3.3, Kap. 4.3 und Kap. 5.3. Zu Alternativen und der Diskussion vgl. HENNING (1999) 29-33; MOMMAERTS/KELLEY (ND 2002) 117-120 mit Fig. 10.1 und GILLETT (2003) 88 Anm. 11.

294 Vgl. Hieron. ep. 130,7 und Aug. beat. vit. 24; hierzu vgl. CURRAN (2000) 309; ausführlicher REBENICH (1992) 154-170 und GORDINI (1956) 220 - 260, hier 243-247. 
Auch Anicia Italica und ihr Gatte Valerius Faltonius Adelfius, der Konsul von 451, lassen sich als Stifter ${ }^{295}$ in der Lateranbasilika verewigen. Abgesehen von den bescheidenen Ausmaßen der Stiftung, die aber, wenn es sich tatsächlich um einen Altar mit Reliquiar gehandelt haben sollte, außerordentlich kostbar war, verweist vor allem die Stifterinschrift auf den gesellschaftlichen und auch politischen Führungsanspruch des Stifterpaars. Auf die Auflistung der Ämter und Rangtitel wird hier nicht verzichtet und ebenso ist Anicia Italica mit dem höchsten Rangtitel als inlustris femina benannt. Hinzu kommt möglicherweise auch noch der titulus Chrysogoni (S. Crisogono) in Trastevere, ${ }^{296}$ für welchen zuletzt Diefenbach im Hinblick auf den cultus der drei Märtyrer aus Aquileia (passio Cantianorum) eine enge Verbindung zur gens Anicia herstellte. ${ }^{297}$ Falls hier von Seiten der Anicier eine Stiftung erfolgte, könnte diese etwa von Anicius Probus und Adelfia ${ }^{298}$ ausgegangen sein. Für Rom ist uns dann noch ein xenodochium der Anicier überliefert, ${ }^{299}$ welches vermutlich schon im 5. Jh. existent war. Auch die heute als Sant'Andrea cata Barbara ${ }^{300}$ bekannte Kirche geht auf ein Stadthaus der Anicier zurück, zu welchen die sog. Junius-Bassus-Basilika mit den berühmten OpusSectile-Arbeiten, die den Konsul von 331 zeigen, gehörte. Der Stifter, der magister militum Flavius Valila Theodosius, vermachte 483 die Kirche dem Bischof von Rom. ${ }^{301}$ Der anicische Kirchenbau fand dann im 6. Jh. in Konstantinopel mit der von Anicia Iuliana gestifteten Polyeuktoskirche, ${ }^{302}$ die sogar den salomonischen Tempel übertreffen wollte

295 Vgl. CIL 6, 41392 (AE 1954,180 a-b und AE 1959,237): [Faltonius Adelfiu]S + V(ir) C(larissimus) ET INL(ustris) P(raefectus) V(rbi) PAT(ricius) CONS(ul) ORD(inarius) ET ITALICA INL(ustris) F(emina) [...]; hier die Erneuerung/Stiftung eines Reliquienaltars. Hierzu KRAUTHEIMER/CORBET (1957) 79-98, hier 95-98. Vgl. hierzu auch BEHRWALD (2016) 167, der allerdings die repräsentative Wirkung stark relativiert. Zur Person vgl. PLRE 2, 8f. (Adelfius 3).

296 Vgl. BRANDENBURG ${ }^{3}(2013) 174$.

297 Vgl. DIEFENBACH (2007) 366-372: hier eher Sextus Claudius Petronius Probus vorschlagend. 298 Die enge Verbindung der Anicier mit Aquileia bleibt auch im 5. Jh. bestehen, so wurde hier die Grabinschrift der Anicia Iuliana 2 (PLRE 2, 635), die im Jahr 459 mit 16. Jahren als V(ir)G(o) DEO (AE 1975,412 = CIL 5, 47) verstarb, aufgefunden. Diese war Tochter des Anicius Probus 7 (PLRE 2, 911) und der Adelfia 2 (PLRE 2, 8).

299 Vgl. Greg. Magn. ep. 9,8. Als Stifter dieses xenodochium kommt eventuell Anicius Acilius Glabrio Faustus in Betracht; zumindest nennt eine im Areal der Piazza Paganica aufgefundene Inschrift einen Faustus xenodokos (ICVR 1, 69); vgl. LTUR 5 (1999) 215f.; MANACORDA (1993) 31-51, bes. 32f. und ausführlich GUARDUCCI (1969/1970) 219-243.

300 Zur Kirche und dem Vorgängerbau vgl. BRANDENBURG ${ }^{3}(2013) 236 \mathrm{f}$.

301 CIL 6, 41402 (ILCV 1785) und Lib. Pont. 1,260; Vgl. hierzu MACHADO (2019) 195; BEHRWALD (2016) 165f.; ORLANDI (2004) 513-516. Wie die Besitzübertragung von den Anicern an Valila erfolgte, lässt sich nicht ermitteln. Denkbar ist allerdings, dass dieser in die gens Anicia eingeheiratet hatte. Gerade Ende des 5. Jhs. sind solche Verbindungen nicht mehr ungewöhnlich (so Ainicia Juliana 3 und Areobindus 1). Zur Person vgl. PLRE 2, 1147 und ANDERS (2010) $277 \mathrm{f}$.

302 Anicia Iuliana 3 (PLRE 2, 635f.), Tochter des Olybrius (Kaiser 472) und der Placidia (Tochter Valentinians III.); zum Bau und seiner Bedeutung vgl. aktuell u. a. BARDILL (2006) 339-370 und TOIVANEN (2005) 127-149. Zur Person und der Kirchenstiftung vgl. jetzt auch BEGASS (2018) 351-383, hier bes. 368-370 zusammen mit der dort angegeben Literatur. 
und bis zur Errichtung der justinianischen Hagia Sophia der größte und prachtvollste Kirchenbau war, ihren Zenit.

Es zeigt sich also, dass die Anicier gerade im Verlauf des 5. Jhs. aktiv die christlichsakrale Topographie in Rom, aber auch in den Provinzen und später ebenso in Konstantinopel, mitprägten. Gerade mit Blick auf die gens Anicia kann wohl kaum davon die Rede sein, dass die stadtrömische Senatsaristokratie kein Interesse an der Stiftertätigkeit in Rom hatte. Auch zeigt sich hier, dass Kirchenstiftungen durchaus zur elitären Repräsentation und Distinktion dienen und einer gens eine besondere Vorrangstellung verschaffen konnten, ${ }^{303}$ die dann auch anerkannt wurde. ${ }^{304}$ Eine wichtige Grundvoraussetzung hierfür war aber, dass nicht asketische Ideale das Übergewicht erhielten, sondern auch am weltlichen Stand und Einfluss festgehalten wurde. Nicht zuletzt dürften auch Ambrosius, Hieronymus und Augustinus sowie die Bischöfe von Rom vom weltlichen Einfluss der christlichen Aristokratie profitiert haben. In seinem Nachruf auf Marcella gibt dies Hieronymus auch indirekt zu, indem er hervorhebt, dass Jesus den Jünger Johannes ${ }^{305}$ vor allem deshalb am meisten geliebt haben soll, weil dieser von vornehmer Herkunft war. Hieronymus hebt auch in diesem Fall den Verzicht auf die Vorrechte adeliger Abstammung sowie des Reichtums lobend hervor, doch im Folgenden ist es vor allem seine vornehme Herkunft, ${ }^{306}$ sein Einfluss und die Bekanntschaft mit dem Hohepriester, mit welchem Johannes dem Herrn und Petrus zu Diensten gewesen sein soll. Trotz gegensätzlicher Äußerungen ist es am Ende die Trias aus Reichtum, Macht und Herkunft, welche den christlichen Aristokraten ausmachte und ihn überhaupt erst in die Lage versetzte, die Kirche und einzelne Geistliche tatkräftig zu unterstützen. Insofern werden diese Grundpfeiler der Aristokratie auch nicht einfach nivelliert oder gar als etwas Schlechtes stigmatisiert, sondern für Kirchenstiftungen und karitative Werke nutzbar gemacht. Auch die zweite dezidiert christliche Inschrift aus dem Grabmal der Anicier verzichtet nicht auf das Lob von Reichtum, Macht und Herkunft, ${ }^{307}$ wenngleich das Maximum hier erst durch die Taufe erreicht wird.

An das Konkurrenzdenken der Aristokratie auch in puncto Christianisierung, karitativer Werke, Stiftungen sowie eigener Frömmigkeit und Heiligkeit $\mathrm{zu}$ appellieren, dürfte das Engagement der Senatsaristokratie ungeheuer beflügelt haben. Stellen wir etwa die gens Anicia den übrigen senatorischen gentes gegenüber, die eine besondere christlich-asketische Prominenz hervorgebracht haben, so lässt sich erkennen, dass die Anicier hier zunächst eher ,Nachzügler` waren. Doch gerade dies verschaffte der gens Anicia den entscheidenden Vorteil, um ihre Vorrangstellung ausbauen zu können. Im Gegensatz zu den Furii, Valerii und Teilen der Caeionii-Rufii, die sich im wahrsten Sinne

303 Hier entgegen der Einschätzung BEHRWALD (2016) $170 \mathrm{f}$.

304 Vgl. hier auch Prud. C. Symm. 1,552; Aug. ep. 150; Hieron. ep. 130,3. Zu Prudentius vgl. BARNES (1991) 50-61 und ders. (1995) 135-147, hier 143.

305 Hieron. ep. 127,5 (bezogen auf Joh 18,15f.; hier jedoch ohne Nennung des Johannes).

306 Diese interpretiert Hieronymus in die Person des Johannes bewusst hinein, da nach biblischen Zeugnis Johannes gleich seinem Vater Zebedäus und Bruder Jakobus Fischer war (Mt 1,19f.).

307 Vgl. ICVR 2, 4219b, v. 5-7 (dazu a, v. 1-6); vgl. SCHMIDT (1999) $110 \mathrm{f.}$ 
des Wortes ganz in der Witwen- und Jungfrauenschaft bzw. im monastisch-asketischen Leben aufzehrten, so dass Jacobs nicht grundlos von einer „Lost Generation“308 sprach, verfügte das Haus der Anicier einschließlich aller seiner Verästelungen immer noch über genügend Vertreter, die den Reichtum und die Macht ihres Hauses erhielten. Soweit bekannt ist, hat nie ein männlicher Vertreter dieses Hauses einen Lebensweg gewählt, wie ihn Pammachius oder Pinian einschlugen. Hierdurch war die gens Anicia in der vorteilhaften Position, dass die notwendige Basis für ihre kirchlichen Stiftungen und karitativen Werke nicht wegbrach, sondern für mehrere Generationen erhalten blieb. ${ }^{309}$ Auch die Stiftermemoria ließ sich so über mehr als nur eine Generation bewahren. Abgesehen von der monetären Grundlage ist der weltliche Einfluss auch hier nicht ohne Bedeutung. Umso höher dieser war, desto selbstbewusster ließ sich vor den kirchlichen Autoritäten, dem Bischof von Rom und dem Klerus auftreten. Das Mausoleum in so prominenter Lage war keineswegs der Lohn für die außergewöhnliche Frömmigkeit der Anicier, sondern spiegelte in erster Linie ihre exorbitante machtpolitische und gesellschaftliche Bedeutung wider. Genauso prononciert offenbart sich der weltliche Einfluss der Anicier und die Bedeutung ihres Hauses in der Kirchenstiftung der Demetria, die sich hiermit wohl als Christianisiererin der römischen Campagna verstand und offenbar Hundertschaften in Gebet und Gesang eben auch für ihre eigene memoria und den Eintritt in das Himmelreich zu mobilisieren wünschte.

Der Aufstieg der Anicier zum führenden senatorischen Haus sowohl in Rom als auch in der Provinz begründet sich im Besonderen mit dem gut ausbalancierten Weg, den das Haus beschritt. Den Angehörigen der gens Anicia gelang es den christlichen Adel par excellence zu verkörpern. Ohne hierbei in Extreme zu verfallen, waren die Anicier imstande, sowohl bedeutende christliche Stifter und Vorbilder in Gestalt von ,heiligen Witwen und Jungfrauen hervorzubringenden als auch durch hohe Amts- und Würdenträger über Jahrzehnte hinweg beträchtlichen Einfluss auf die gesellschaftlichen und politischen Entwicklungen zu nehmen. Ermöglicht wurde dies vor allem durch die weite Verzweigung dieser gens, die kaum in der Gesamtheit ihrer Vertreter zu überblicken ist, was es eben auch so schwierig macht, von „den Aniciern“ zu sprechen. Dementsprechend vielfältig ist das Spektrum senatorischer und gesamtgesellschaftlicher Interessen, welches das Haus - oder besser, die Häuser der Anicier - abzudecken imstande waren. Gerade in Fragen der Religion und individuellen Frömmigkeit setzte sich insgesamt aber eher ein moderater Kurs durch, der nicht im Widerstreit zu den senatorischen Pflichten stand, sondern sich hiermit gut vereinbaren ließ. In der Summe ihrer weit verzweigten Glieder verband die gens Anicia somit christliche Frömmigkeit mit klassisch aristokratischen Werten. Einerseits umgaben sich die Anicier mit einer Aura des Heiligen und konnte so als christlicher Adel eine religiöse Führungsrolle für sich beanspruchen. Andererseits rückten die meisten Anicier nicht vom symmacheischen

308 JACOBS (2017) 207-221. Vgl. zu den Motiven CAMERON (1994) 151-152.

309 Eben dies scheint ein Grundproblem für die Stiftungen der Melania und der Paula zu sein, welches sowohl die Heiligenvita als auch die Briefe des Hieronymus motivierte. 
Diktum der pars melior humani generis ${ }^{310} \mathrm{ab}$, blieben auf diese Weise in der paganen Bildungstradition verwurzelt und verpflichteten sich in machtpolitischer Partizipation zum Dienst am Gemeinwesen. Hierin näherte sich die christliche gens durchaus den traditionsgesinnten moderat-paganen Kreisen der stadtrömischen Senatsaristokratie an, so dass, zumal sich die Anicier in Teilen offenbar mit dem Haus des Symmachus familiär verbunden hatten, ${ }^{311}$ auch in diese Richtung noch immer eine Konsensfähigkeit bestand. Hier konnten die Anicier eine Mittlerrolle übernehmen. Die Bevorzugung, welche die gens Anicia durch Theodosius I. und dann auch durch Honorius und Valentinian III. erfuhren, dürfte zum Teil auch hiermit zu begründen sein. Die Anicier vertraten keine radikalen christlichen Positionen. Damit waren sie in der Lage, das Leitbild $^{312}$ eines neuen christliche-senatorischen Adels zu verkörpern, welches zugleich die alten senatorischen Werte und Pflichten inkludierte.

Wo andere gentes noch Anfang des 5. Jhs. konfessionell gespalten waren, oft die männlichen Vertreter dem alten Glauben anhingen, während sich die weiblichen ${ }^{313}$ dem Christentum zuwandten, genoss die gens Anicia den Vorteil einer konsequenten, schon früh erfolgten Christianisierung. ${ }^{314}$ Möglicherweise war gerade dies der Grund dafür, dass die religiöse Radikalisierung in dieser gens weniger Nährboden fand. So dürfte die Entscheidung der Marcella, Asella, Paula und des Pammachius sowie der Melania und des Pinian für das christlich-asketisch-monastische Leben auch von dem Wunsch herrühren, sich von der noch immer in Teilen heidnischen Verwandtschaft ${ }^{315}$ und damit dem eigenen Haus und sozialen Umfeld radikal abzugrenzen. ${ }^{316}$ Im Unterschied zu den Aniciern befanden sich die Caeionii-Rufii und Valerii offenbar noch immer in einer konfessionellen und identitären ,Findungsphase‘. Ein Ausgleich erreichen die CaeioniiRufii erst nach 410 etwa in der Person des Rufius Antonius Agrypnius Volusianus oder Flavius Albinus. ${ }^{317}$ Die gens Valeria und die gens Furia gingen hingegen dem römischen Gemeinwesen und der stadtrömischen Senatsaristokratie offenbar dauerhaft verloren.

Der Erfolg der Anicier fußt somit auf zwei Faktoren, die aufeinander aufbauen. Hier ist zunächst die konsequent vollzogene Christianisierung zu nennen, die dafür sorgte, dass die gens Anicia verhältnismäßig schnell zu einer konfessionellen Geschlossenheit

310 Symm. ep. 1,52 und Symm. or. 6,1; hierzu vgl. REBENICH (2008).

$311 \mathrm{Vgl}$. Aurelius Anicius Symmachus 6.

312 Vgl. HENNING (1999) 168; NÄF (1995) 93 und TAEGERT (1988) 20.

313 Zur Bedeutung der Aristokratinnen bei der Christianisierung der senatorischen Häuser vgl. z. B. KÖNIG (2008) 266-275; SALZMAN 22(2004) 138ff.; JENAL (2002) 35-54; LETSCH-BRUNNER (1998) $1 \mathrm{ff.}$ und DISSELKAMP (1997) 217-227.

314 Vgl. SALZMAN 22(2004) 160 - 168 u. 183 f.; NÄF (1995) 93; ZECCHENI (1981) und NOVAK (1980) 491493.

315 PLRE 1, 978-980 (Volusianus 5) und PLRE 1, 511 (Lolliana); als Sacerdos der Iisis CIL 6, 512; vgl. CHASTAGNOL (1961) bes. 754-757 und ders. (1956) 241-253.

316 Vgl. KÖNIG 2008, 275-286.

$317 \mathrm{Zu}$ Fl. Albinus $(10=7$ ?), dem bedeutendsten Vertreter dieses Hauses vgl. Kap. 5.3; zur gens Decia vgl. knapp HENNING (1999) 155f.; ZECCHENI (1981) 129; MATTHEWS (1975) 360; ausführlich WEBER (1989) 472-497, hier 473-479. 
zurückfand. Infolgedessen scheinen die Anicier für die religiöse Radikalisierung, insbesondere für extreme Formen der christlichen Askese, weniger empfänglich gewesen zu sein. Die ausbleibende Radikalisierung, die hier als zweiter entscheidender Faktor anzuführen ist, verschaffte ihr, im Unterschied zu anderen senatorischen Häusern, eine größere Stabilität und Beständigkeit, die durch Heiratsverbindungen und eine verhältnismäßig große Nachkommenschaft auch weiter erhalten wurde. Die Vertreter der gens Anicia, die trotz ihres christlichen Bekenntnisses so weiterhin für Ämter und öffentliche Leistungen zur Verfügung standen, schafften den Ausgleich zwischen den neuen christlichen Glaubensidealen und den alten senatorischen Pflichten und Werten. Hier zeigen die Anicier den Weg auf, auf welchem sich nicht nur die pars melior humani generis, die Senatsaristokratie, erhalten ließ, sondern wie durch das Christentum, welches nun auch ganz neue Möglichkeiten der sakralen Überhöhung, Repräsentation und memoria bot, der „bessere Teil der Menschheit“ noch ,besser“ werden konnte.

\subsection{Zusammenfassung: Christianisierung und ,Aristokratisierung}

Der letzte Abschnitt dieser Untersuchung befasste sich mit der Christianisierung der stadtrömischen Senatsaristokratie und der ,Aristokratisierung' des Christentums. Zunächst wurde danach gefragt, wie sich der sog. Symmachus-Kreis nach 394 formierte. An erster Stelle galt es zu untersuchen, welche Rolle der Religionsfrage bei der inneren Formierung und Vernetzung der stadtrömischen Senatsaristokratie zufiel. An der Korrespondenz des Symmachus wurde deutlich, dass sich keineswegs eine starke Spaltung zwischen Christen und ,Heiden“ herausbildete. Diese Einschätzung, die bereits Matthews und nachfolgend auch Cameron vorbrachten, ${ }^{318}$ ließ sich hier bestätigen. So war der ,Symmachus-Kreis` nach 394 offensichtlich eher ein senatsaristokratisches Netzwerk, welches die Mehrheit der Senatoren Roms im Konsens mit den senatorischen Pflichten und Werten halten wollte. Besonders fiel dabei das Bemühen um die jungen christlichen Aristokraten auf. Aus diesem Netzwerk und Wertekonsens schieden lediglich die radikalen Strömungen aus. Um die heidnischen Kulte oder die Formierung einer dezidiert heidnischen Senatsaristokratie ging es hier nicht mehr.

Das sich daran anschließende Kapitel beschäftigte sich mit dem Problem der Aristokratie, ihren elitären Platz in der christlichen Weltordnung zu bewahren und zu manifestieren. Die Rückgewinnung der senatsaristokratischen Majorität im religiösen Leben erfolgte maßgeblich über die christlichen Bildwelten. So ließ sich für das 5. Jh. nun auch eine zunehmende ,Aristokratisierung، der christlichen Bildsprache feststellen, die an die ,Imperialisierung‘ des Christusbilds anknüpfte. Vor allem im Bildprogramm der christlichen Sarkophage und im Bildschmuck der Kirchen entstand ein

318 MATTHEWS (1974) 59-99 und nachfolgend CAMERON (2016b) 64-111. Zu berücksichtigen bleibt jedoch, dass die Briefsammlung eine postume Auswahl darstellt und hier sicherlich Briefe mit kritischen Inhalten nicht aufgenommen wurden. 
christlich-senatorisches Repräsentationsbild, welches imstande war, die Führungsrolle der Aristokratie christlich zu fundamentieren. Die Senatsaristokratie wurde hier in die unmittelbare Nähe biblischer Gestalten, der Apostel, Heiligen und auch Christus selbst gerückt und partizipierte damit an der Aura des Heiligen, die ihr im Christentum eine besonders exponierten Platz verschaffte. Diesen Anspruch brachten nicht nur die senatorischen Auftragswerke zum Ausdruck, sondern gerade auch die kirchlichen Bildwerke, die sich ebenfalls ,aristokratisierten' und damit der gestiegenen Bedeutung der Senatsaristokratie im Christentum Rechnung trugen.

Über Kirchenstiftungen bestand für die Senatsaristokratie überdies eine Möglichkeit, nun auch wieder eine gewisse Dominanz über die Sakrallandschaft Roms auszuüben. Die Intention des senatorischen Stifters bzw. der Stifterin erwies sich in den meisten Fällen als recht ambivalent. Auch wenn ein Frömmigkeitsmotiv nicht gänzlich von der Hand zu weisen ist, sind die Kirchenstiftungen vor allem eine Absicherung für die eigenen memoria, für das irdische und himmlischen Nachleben, und sind somit stark vom senatorisch-elitären Denken geprägt. Die Partizipation an der Heiligkeit, vor allem in Verbindung mit privaten Reliquiensammlungen, und das Empfangen von Gebeten und Gesängen stand hier offenbar im Vordergrund. Als weiterer wichtiger Motivationsgrund war die ökonomisch-soziale Fürsorgepflicht der senatorischen Häuser anzuführen, die gerade dann eine Rolle spielte, wenn es keine regulären Erben gab. In welchem Ausmaß eine Stiftung zur Selbstrepräsentation und Elitendistinktion genutzt wurde und wie dauerhaft die Stiftermemoria war, hing letztlich von zahlreichen Faktoren ab, allen voran vom Selbstverständnis des Stifters, seiner Prominenz, seinen Kontakten zu kirchlichen Autoritäten und dem Einfluss seiner gens. Ein einheitliches Bild ergibt sich hier nicht.

Insofern lag es nahe, den Blick abschließend auf die gens Anicia zu richten. Hierbei zeigte sich, dass sich die Führungsrolle dieser gens vor allem auf den moderaten Weg, den das Haus einschlug, gründete. Die frühe Christianisierung der Anicier bewahrte diese offenbar vor einer religiösen Radikalisierung und Spaltung. Hier konnte die gens Anicia schneller und leichter einen Ausgleich zwischen den senatorischen Pflichten und Werten und den neuen christlichen Glaubens- und Lebensidealen erreichen. Dementsprechend demonstrieren die anicischen Stiftungen zwar christliche Frömmigkeit, lassen aber auch deutlich das senatorische Repräsentationsund Distinktionsstreben erkennen. Die Anicier erweisen sich hier nicht nur als „Schrittmacher“319 der Christianisierung der Senatsaristokratie, sie geben auch den Weg vor, wie die Senatsaristokratie im Christentum ihre gesellschaftliche und politische Vorrang- und Führungsstellung nicht nur erhalten, sondern noch ausbauen konnte.

319 HENNING (1999) 168. Vgl. auch NÄF (1995) 93; TAEGERT (1988) 20; ZECCHINI (1981); NOVAK (1980) 491-493. 